\title{
Examination and Characterization of Brook Trout Ecology Before and After a Broad Scale Disturbance Event in Headwater Streams of West Virginia, USA
}

\author{
Ross Gilbert Andrew
}

Follow this and additional works at: https://researchrepository.wvu.edu/etd

\section{Recommended Citation}

Andrew, Ross Gilbert, "Examination and Characterization of Brook Trout Ecology Before and After a Broad Scale Disturbance Event in Headwater Streams of West Virginia, USA" (2018). Graduate Theses,

Dissertations, and Problem Reports. 7153.

https://researchrepository.wvu.edu/etd/7153

This Dissertation is protected by copyright and/or related rights. It has been brought to you by the The Research Repository @ WVU with permission from the rights-holder(s). You are free to use this Dissertation in any way that is permitted by the copyright and related rights legislation that applies to your use. For other uses you must obtain permission from the rights-holder(s) directly, unless additional rights are indicated by a Creative Commons license in the record and/ or on the work itself. This Dissertation has been accepted for inclusion in WVU Graduate Theses, Dissertations, and Problem Reports collection by an authorized administrator of The Research Repository @ WVU.

For more information, please contact researchrepository@mail.wvu.edu. 


\title{
Examination and Characterization of Brook Trout Ecology Before and After a Broad Scale Disturbance Event in Headwater Streams of West Virginia, USA
}

\author{
Ross Gilbert Andrew
}

Dissertation submitted to the

Davis College of Agriculture, Natural Resources and Design

at West Virginia University

in partial fulfillment of the requirements

for the degree of

Doctor of Philosophy

in

Forest Resources Science

Kyle J. Hartman, Ph.D., Chair

J. Steven Kite, Ph.D.

George T. Merovich, Jr., Ph.D.

J. Todd Petty, Ph.D.

Quinton E. Phelps, Ph.D.

Wildlife and Fisheries Resources Program

Morgantown, West Virginia

2018

Keywords: disturbance, large wood (LW), population growth, synchrony/asynchrony, bioelectrical impedance, fish condition, fish habitat

Copyright 2018 Ross Andrew 


\title{
ABSTRACT
Examination and Characterization of Brook Trout Ecology Before and After a Broad Scale Disturbance Event in Headwater Streams of West Virginia, USA

\author{
Ross Gilbert Andrew
}

The Appalachian Mountains have experienced comprehensive human disturbance since the colonial period. Activities such as mining, logging, and development for agriculture and residential lands have changed the landscape from the old growth state of centuries past. These disturbances have also led to changes in the forests and their drainage systems over time. Native species like the Brook Trout Salvelinus fontinalis have experienced declines in both size and abundance due to changes in their headwater stream habitats as a function of human activities. Restoration of these habitats by both state and federal agencies, as well as non-government organizations, has been occurring following the destructive logging of the late nineteenth and early twentieth centuries. In many places, a return to the conditions found in the old-growth state would take hundreds or even thousands of years, but restoration efforts have shown promise in accelerating the recovery of these native ecosystems.

Restoration efforts may focus on chemical, physical, or biological endpoints. Within these headwater streams, a lack of physical channel structure in the form of deep pools and large wood has been shown to limit Brook Trout growth and reproduction. Therefore, many times restoration teams will focus on rebuilding habitat complexity through the physical construction of pools or addition of large wood pieces that may aid in providing fish cover and sediment/organic matter retention. These artificial habitat supplements have been studied by others and have shown some successes in benefitting habitat conditions. However, less is known about natural disturbances that may represent additional stream habitat benefits.

Brook Trout populations of headwater streams in West Virginia, USA, and the effects of one such natural disturbance are the focus of the following chapters. Hurricane Sandy, otherwise known as "superstorm" or "frankenstorm" Sandy was the largest (by area) Atlantic hurricane on record in the United States. It struck the eastern continental United States in late October/early November 2012 and combined with a traditional winter nor'easter storm across the mid-Atlantic. This combination of storms produced record snowfall in much of the Appalachian Mountains, with snow accumulations over three feet ( 0.9 meters) in just a 24 hour period. The snowfall was very wet and dense, and resulted in widespread tree collapse in many forested areas. Some of those trees were deposited in headwater streams that coincided with study sites for a 15+ year study of stream habitat and Brook Trout populations conducted at West Virginia University.

The objectives of this work were numerous and were to first quantify the amount and extent of large wood deposition within the set of headwater streams used in the long-term study. The second objective was to identify and explain some Brook Trout population dynamics across 
space and time within the study streams as they relate to habitat variables. The third objective was to identify any immediate habitat changes based upon large wood additions and quantify the retention and importance of the natural wood additions as habitat features in these streams and any effect they may have on benthic invertebrate communities across time. Finally, the last objective of this work sought to identify important habitat features that correlate to Brook Trout body composition.

In the first chapter, our results showed significant increases of large wood deposition from Sandy as compared to previous years. We also illustrate a significant inverse relationship between wood deposition from Sandy and elevation among our study streams. In the second chapter, we identified variables using classification trees such as relative abundance of age-0 fish, mean fish length, and fall drought index as important for defining Brook Trout population growth rate in a given stream or year. We also identified synchrony in population growth rate among a subset of the study streams and found variables such as age- 2 fish abundance, spawning area, and distance to tributaries contributed greatly to partitioning of synchronous and asynchronous populations.

In the third chapter, results show tracked pieces of large wood moved greater distances downstream in the first year following deposition than the second. Our analyses also indicate drainage area to have a significant positive influence on large wood movement. Habitat variables such as pool quality and proportion of $16 \mathrm{~mm}$ diameter gravel increased significantly with increasing wood density but a portion of the variance explained came from stream, year, and underlying geologic unit across model sets. Also, comparisons of habitat variables grouped as pre and post-Sandy showed significant increases in mean pool depth, mean maximum pool depth, and wood density. Finally, macroinvertebrate communities showed no significant change from year one to year two of post-Sandy sampling but did show a significant difference when compared between pre and post-Sandy communities, with the dominant functional feeding groups shifting from scraper pre-Sandy to collector post-Sandy.

In the fourth chapter, body composition was measured on wild Brook Trout across space and time using bioelectrical impedance analysis. Our analyses showed the greatest weight of evidence for influential variables related to Brook Trout percent dry weight being benthic macroinvertebrate density, fish length at age, and mean summer water temperature. We also compared percent dry weight in Brook Trout that were marked and recaptured to define life history as residents or migrants. Overall, migrants and residents showed no differences in length or percent dry weight, but within two individual streams migrants had significantly longer lengths and higher percent dry weight on average.

Within the context of the natural disturbance of Hurricane Sandy and the large wood additions, the following chapters identify important factors related to native Brook Trout habitat, population dynamics, and energetics which carry meaning into a future of growing uncertainty with respect to climate, human impacts, and invasive species interactions. These chapters further demonstrate the utility of long term datasets in ecological studies as a way to clearly identify effects across time with proper perspective on prior conditions. 


\section{ACKNOWLEDGEMENTS}

I would like to extend my sincere gratitude to many people who have helped me throughout the process of this dissertation work. First, thanks to Dr. Kyle Hartman as my graduate advisor and as the chair of my academic committee during this degree. Dr. Hartman was instrumental in my development as a researcher, teacher, and communicator and I am forever grateful for his help along the way. Second, the other members of my committee, Dr. Steve Kite, Dr. George Merovich, Dr. Quinton Phelps, and Dr. Todd Petty helped tremendously in my pursuit of this degree through their expertise and guidance. I would also like to thank Mike Owen for his guidance and contribution with my committee. Next, I would like to thank all of the previous and current members of the Hartman lab who helped create and maintain the long-term project and its associated datasets which I was able to benefit from with the use of data for my research endeavors. Members I had the good fortune to work with included Jered Studinski, Daniel Hanks, Erin Thayer, Ed Olesh, and Chris Schwinghamer. Others who were valuable with help in the field include Zac Zacavish, John Howell, Cory Hartman, Melinda Hartman, Greg Shafer, Mike Migliore, Jimmy “2 Pinch” Hartley, Tyler Plum, Patrick Smith, Martin Hayden, and Blake Strumbel among others. I was lucky to have many helpful volunteers, students, and technicians that made working in sometimes difficult field conditions much easier. I would also like to thank other graduate students who helped me along the way with data collection, analysis, and all of the other day to day tasks which vary from complex to mundane. Folks like Brock Huntsman, Eric Merriam, Gabe Strain, Jonas Leveque, Darren Wood, Tom Rounsville, Reina Tyl, Sam Fino, Crissa Cooey, Ryan and Missy Braham, Andrew Watson, Brian Carlson, Eric Miller, Cory Trego, Ben Harris, Alison Anderson, Becky Long, Lacy Rucker, Kristen Wickert, Alex Storm, Brian Gordon, Iris Allen, Kevin Eliason, and Josh Ankeny among many others made this grad school experience enjoyable and embraced me as a colleague both professionally and personally. Thank you to all of the cooperators and supporters of this research including the U.S Forest Service, West Virginia Division of Natural Resources, Mead Westvaco, Penn Virginia, Southwestern Energy, the WVU Division of Forestry and Natural Resources, and the WVU Davis College. I would also like to thank the faculty and staff who I both learned and benefitting from during my time at WVU. Thanks to my Masters advisor Dr. Stuart Welsh, along with members of Leetown Science Center who gave me confidence and support to continue to pursue a PhD. A special thanks to Donna Hartman and Ida Holaskova for their advanced knowledge and support with parts of my data analysis. I would also like to thank my family and friends for their endless love and support during my pursuit of this degree and my extended "student" status through this portion of my life. A very special thanks to Caitlin Burton for the love and encouragement when things were difficult, without you I would be far less than I am today. I'm a firm believer that nobody accomplishes anything alone, and now I have my own personal case study of how all these people (and too many more to list) helped me accomplish this goal. Thank you all. 


\section{Table of Contents}

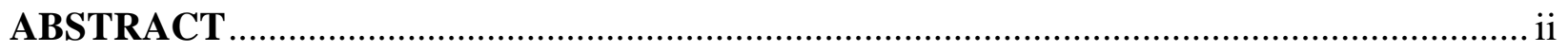

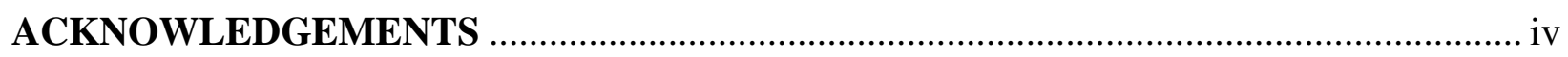

Chapter 1: Uneven inputs of woody debris to Appalachian streams from superstorm Sandy ..... 1

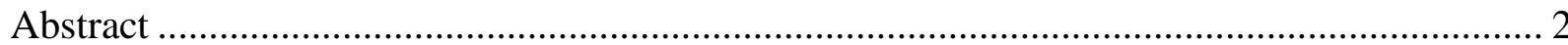

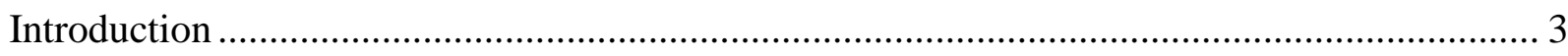

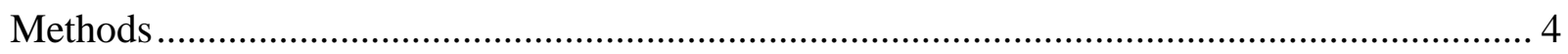

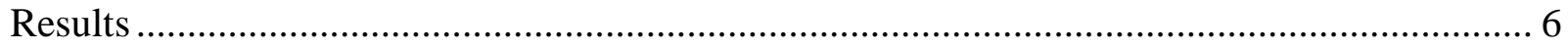

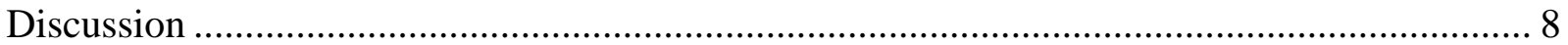

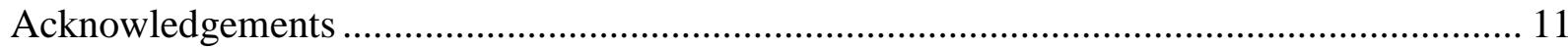

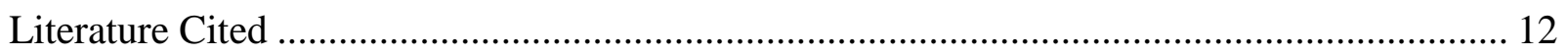

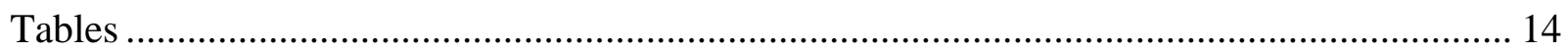

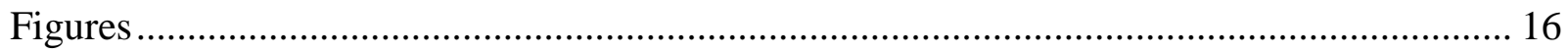

Chapter 2: Brook Trout Population Growth and Synchrony in the Central Appalachians ........ 19

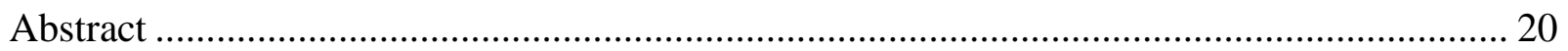

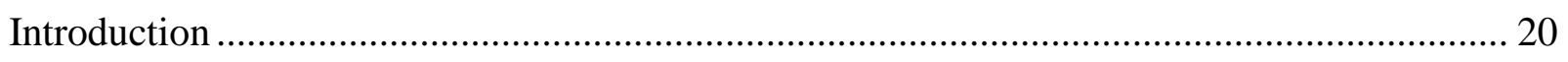

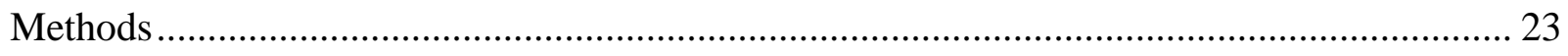

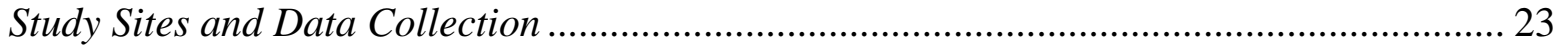

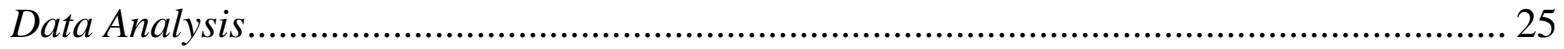

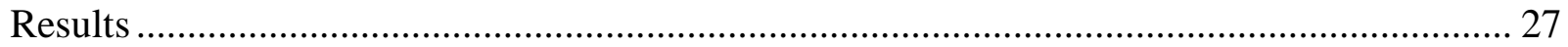

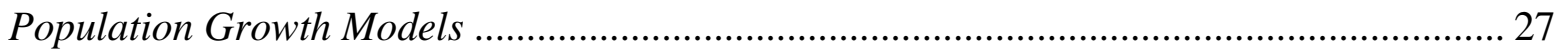

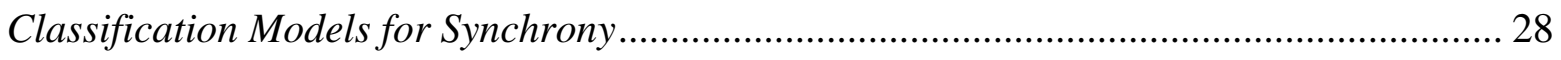

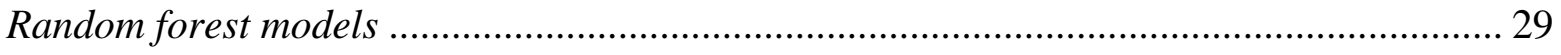

Logistic Regression Models for Synchrony ................................................................... 30

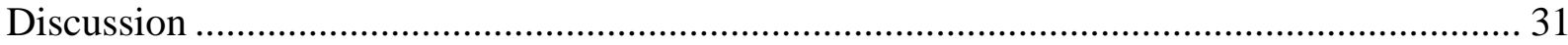

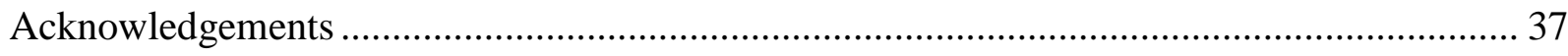

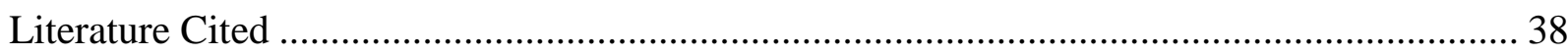

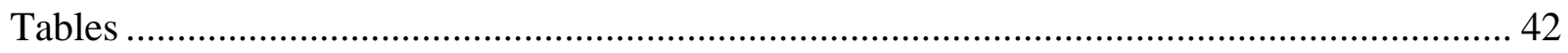

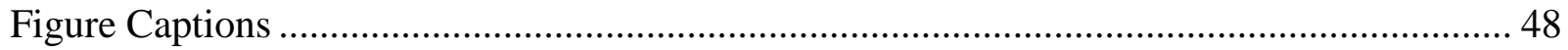

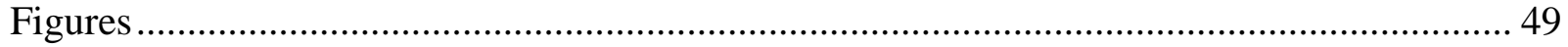


Chapter 3: Large Wood Fate, Channel Structure, and Macroinvertebrate Community Characteristics Following Superstorm Sandy in Central Appalachian Headwater Streams

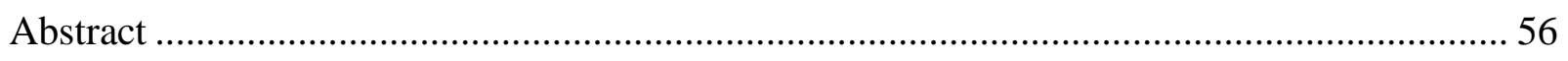

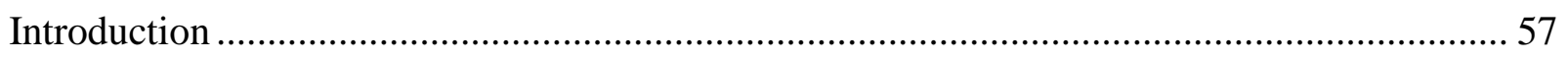

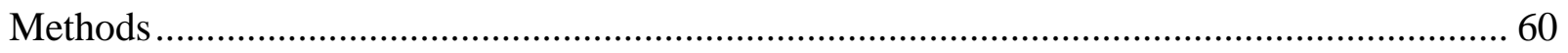

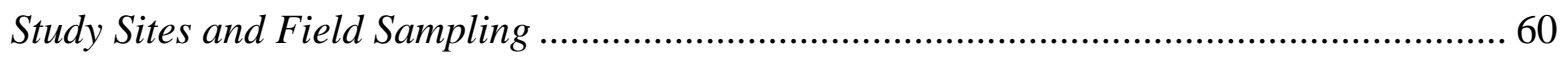

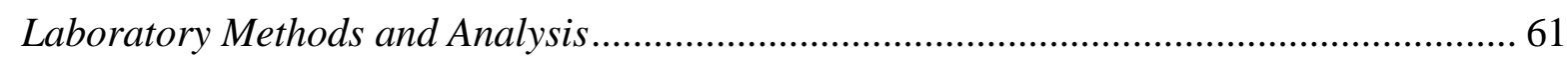

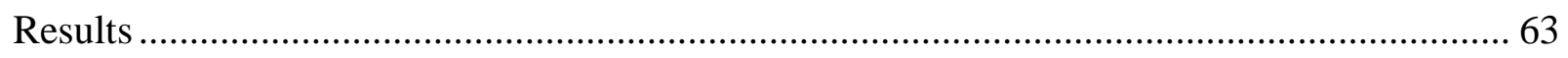

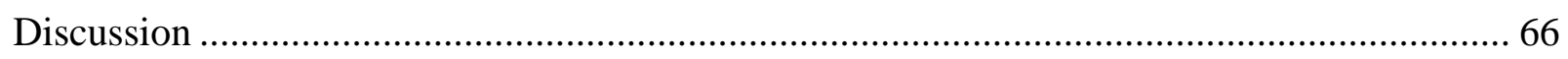

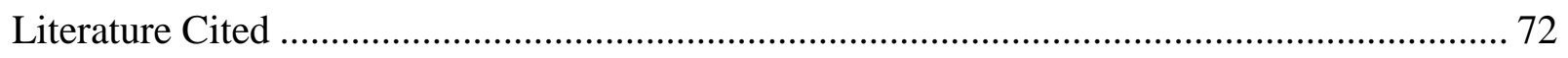

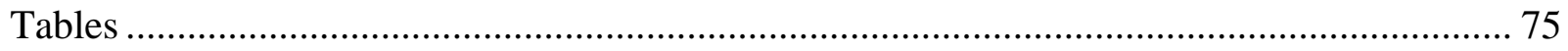

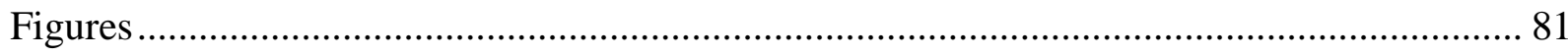

Chapter 4: Using local and catchment-level variables to explain differences in BIA-predicted body composition of Brook Trout in headwater streams of West Virginia, USA ...................... 95

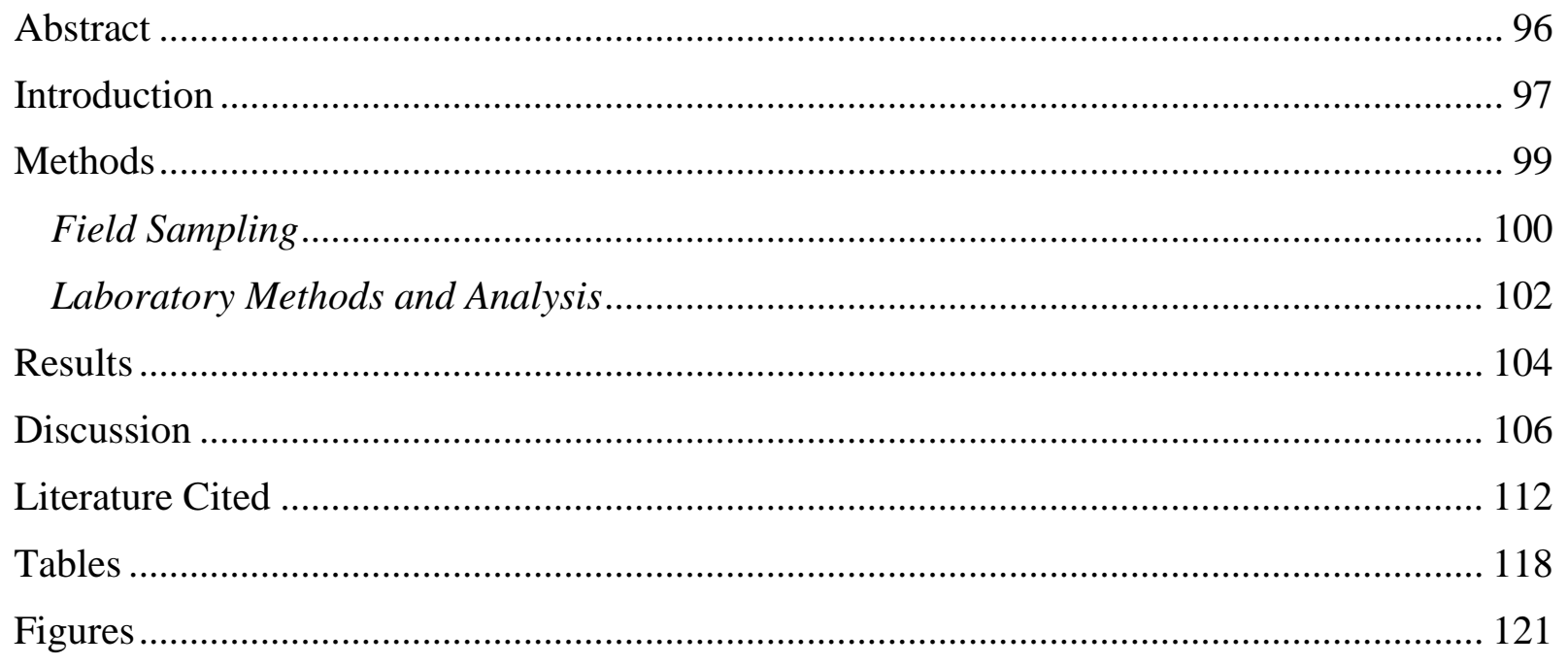




\title{
Chapter 1: Uneven inputs of woody debris to Appalachian streams from superstorm Sandy
}

\author{
Ross G. Andrew* and Kyle J. Hartman \\ Division of Forestry and Natural Resources, Davis College of Agriculture, Natural Resources, \\ and Design, West Virginia University, Morgantown, WV 26506-6125, USA \\ *Corresponding author, randrew4@ mix.wvu.edu Ph: (304)-293-0053 Fax: (304) 293-2441
}

THIS CHAPTER HAS BEEN ACCEPTED FOR PUBLICATION IN THE JOURNAL

Canadian Journal of Fisheries and Aquatic Sciences, AND THE FORMAT FOLLOWS THAT REQUIRED FOR THE JOURNAL. 
Abstract

Headwater streams are the beginnings of fluvial networks and therefore fill a critical role in the development of the Earth's drainages. Therefore, it is important that we understand the role that disturbances have on these systems and how they translate disturbance downstream. Hurricane Sandy struck the eastern seaboard of the United States in late October 2012 and produced record snowfall in the Appalachian Mountains which caused widespread destruction of trees and subsequent deposition of large wood ( $\mathrm{LW}$; pieces $\geq 1.0 \mathrm{~m} \times 0.05 \mathrm{~m}$ ) in many headwater streams throughout the region. We investigated these effects in 25 West Virginia headwater streams and found varying levels (0-195\% change from previous annual data; 0-820 LW pieces $\mathrm{km}^{-1}$ ) of new wood additions. When compared to years prior to Sandy, the rate of LW deposition was significant across all size classes and streams ( $\mathrm{p}<0.0001)$. We also found a significantly $(\mathrm{p}<0.01)$ negative pattern of LW impact based upon elevation, with higher elevations receiving lower levels of LW deposition. This research provides a unique glimpse at the initial magnitude of natural wood addition on headwater streams following a large disturbance.

Keywords: large woody debris (LW), headwater streams, disturbance, climate change, production 
Introduction

Given the ecological (Lowe and Likens 2005), economic (Constanza et al. 1997), and evolutionary value of fluvial networks and particularly headwater streams, we seek to understand the consequences of alteration to these systems. Headwater streams are typically variable environments, with dramatic differences in habitat, diversity, and productivity across temporal scales (Lowe and Likens 2005). Additionally, ecosystem resilience is affected by the frequency and intensity of disturbance and may have implications for conservation of such habitats. Therefore, the timely study of disturbed ecosystems may provide valuable information for estimates of system capacity and resilience.

Additions of large wood (LW) may have profound effects on stream habitat and biota. Fausch and Northcote (1992) found more complex, deeper stream habitat when LW was present. When LW was manually added to a channelized stream, habitat changes such as decreased mean water velocity and increased pool number and volume were observed (Zika and Peter 2002). These effects of LW on habitat subsequently influence both the biotic communities and ecosystem processes of headwater streams. Effects of LW addition on stream organisms are seen as biotic responses to changes in the amount of LW in streams. Experimental additions of LW has shown to increase density and biomass of brown trout Salmo trutta in forested streams which were previously wood-poor relative to old-growth forested streams (Lehane et al. 2002). Greater abundance and production of such biotic elements provide potential benefits to overall ecosystem function and processing in these headwater stream environments influenced by LW additions.

During late October 2012, the largest Atlantic hurricane on record struck the eastern seaboard of the United States (NOAA 2012a.) This hurricane combined with a low pressure 
system typically responsible for winter storms in the eastern United States, creating a "super storm" named Sandy by the National Oceanic and Atmospheric Administration (NOAA) National Weather Service. The storm killed 191 people and caused an estimated USD \$20 billion in property damage (NOAA 2012b). The Appalachian Mountains received record snowfalls in excess of $70 \mathrm{~cm}$ in many high elevation locations (NOAA 2012a). West Virginia was particularly impacted by snowfall, owing to its high-relief topography throughout the eastern half of the state. Heavy weight of snow buildup on branches coupled with strong winds led to the secondary effect of widespread tree collapse throughout many mountainous areas. We hypothesized that this large scale deposition of wood in mountainous areas provided extraordinary inputs of LW into headwater streams. We sought to characterize those inputs and provide initial information leading to further research of the effects these natural LW additions have on headwater stream biota and processes. We also hypothesized that the inputs of LW would not be evenly distributed in space because site-specific factors such as slope, soils, forest species composition, and storm intensity likely vary with elevation.

\section{Methods}

We have created a long-term dataset using 25 West Virginia headwater (mean drainage area $=7.39 \mathrm{~km}^{2}$ ) streams located in the mountainous eastern part of the state (Figure 1). We have surveyed both the physical habitat and brook trout Salvelinus fontinalis populations annually since 2003. Habitat was assessed using a modified basin-wide visual estimation technique (BVET, per Hankin \& Reeves, 1988). These BVET surveys were conducted during low flow conditions (June - October) and included a measure of LW within stream reaches that we used as a baseline for pre-Sandy conditions. Following the same method for LW survey as 
previous years, we then surveyed those 25 headwater streams for LW inputs in the months between November 2012 and February 2013 following the events of hurricane Sandy. The LW counts within these sections in the post-Sandy surveys were compared with the LW counts in matching sections during 2003-2012 habitat surveys. Newly added LW was easy to identify based upon its fresher appearance and relative lack of decay compared to older LW inputs. We classified LW into seven size categories commonly used in studies of LW, representing differences in length and diameter (See Flebbe and Dolloff 1995; Johnston et al. 2011 for size class descriptions). During habitat surveys all LW was counted, provided that it was within the bankfull channel and met the minimum size requirements of $\geq 1$ meter length and $\geq 5$ centimeters in diameter used in other published studies (Flebbe and Dolloff 1995; Johnston et al. 2011).

Large wood loadings were calculated using the distance sampled along with the raw counts of LW pieces in order to create a standardized loading of pieces $\mathrm{km}^{-1}$ for each stream. For the first set of statistical analyses (Nos. 1-5; Table 1), LW loadings were standardized by month and monthly rates of change before and after Sandy for each size class within each stream. In this way, we could compare the annual LW loading on a time scale more appropriate to the storm disturbance of Sandy. The second set of statistical analyses (Nos. 6-10; Table 1) used the total standing load per month from 2012 (including Sandy inputs) versus the total standing load per month for 2013. The statistical analyses were generated using [SAS/STAT] software, Version 9.3 of the SAS System. Copyright 2002-2011, SAS Institute Inc., Cary, NC, USA. Specifically, for the gain or loss of LW counts per month, Proc Freq procedures with Cochran-Mantel-Heanszel (CMH) statistics were used, with the option of scores being used as ranks. In this case, the row mean score statistic is identical to Friedmans' chi-square test. It was 
performed a) with stratification on streams and LW sizes, b) with stratification on LW sizes only and c) without stratification on streams and LW sizes. Because they are not controlling for either stream or LW size class, analyses number 3, 5, 8 and 10 are equivalent to a Wilcoxon rank sum test. Specific size class differences for both temporal scales of analysis were examined using a dependent 2-group Wilcoxon signed rank test. Simple linear regression was run using software JMP (version Pro 11) also from the SAS Institute, Copyright 2013, to identify the relationship between elevation and instantaneous LW loading $\left(\mathrm{LW} \mathrm{km}^{-1}\right)$ from Sandy.

Evaluation of site specific variables that may influence spatial patterns in storm impact to LW loadings included stream elevation, mean wetted width, and percent forest land cover. Elevation and stream wetted widths were determined from GIS layers and habitat surveys, respectively. Land cover in stream riparian zones was assessed using a 100 meter buffer zone and calculating percentage of forested land cover with the buffer capable of inputting trees to the streams. Spatial distribution of LW loadings in streams was assessed using a Moran's I test for spatial autocorrelation of the LW loading variable across all sites in ArcGIS (version 10.1; ESRI, Redlands, CA).

Results

We found significantly higher monthly rates of change of LW loading immediately after Sandy than in the years before (Analyses 1-5). We found less significant differences between the total monthly LW standing load in the year 2012 (including Sandy) versus 2013 (Analyses 6-10). The Proc Freq procedure produced significant results $(\mathrm{p}<.0001)$ for all tests of LW monthly rate of change before and immediately after Sandy (Analyses 1-5; Table 1). Adjusting for both stream and LW size classes did not change the significance of any test. The same procedure produced mostly insignificant results for the monthly LW loads in 2012 (including Sandy) versus 2013 (Analyses 6-10). For this comparison, the only two significant differences existed in 
analyses $6(\mathrm{p}=0.018)$ and $10(\mathrm{p}=0.040)$ which represent the analysis when controlling for stream and LW size classes and the overall population (i.e. Wilcoxon rank sum) test, respectively (Table 1). Land cover within watersheds was dominated by deciduous forests with coniferous and mixed forests also being common. These three cover types were combined into a "forested" land cover type which was dominant in every watershed examined, representing an average of $91 \%$ of riparian land cover (Table 2).

Impact of hurricane Sandy was not evenly distributed within the state of West Virginia, with some areas receiving little to no snow and wind effects. The Moran's I test of spatial autocorrelation showed a clustered pattern, albeit not statistically significant at the $\alpha=0.05$ level, with a Moran's Index value of 0.083 and a p-value of 0.07 . Using a linear regression model, the F test revealed a significant elevational trend $\left(p=0.002\right.$; adjusted $\left.R^{2}=0.31\right)$, where LW additions decreased with increasing elevations (Figure 2a). The data point for Elklick run (value $=820 \mathrm{LW} \mathrm{km}^{-1}$ ) was identified as a statistically significant outlier in the regression model which skewed the distribution to the right and created a non-normal distribution $(\mathrm{p}<.0001$ in ShapiroWilk $\mathrm{W}$ test). The regression was run again without this data point, following a normal distribution ( $\mathrm{p}=0.339$ in Shapiro-Wilk W test) and also achieved a statistically significant ( $\mathrm{p}$ $=0.004$, adjusted $\left.\mathrm{R}^{2}=0.28\right)$ pattern. Therefore, we chose to present all the data in Figure 2(a, b) for completeness.

Inputs of LW were not evenly distributed across the seven size classes examined (Figure 3). The addition of LW from Sandy represented significant ( $p<0.01$ for all classes) inputs across all seven size classes and the total sum of inputs when average monthly LW load rate of change was compared in the years before Sandy and the months immediately following Sandy (Table 1). When comparing the standing load of LW per month between the year 2012 
(including Sandy) and 2013, the only significant differences occurred for size class 1 and the total sum of inputs ( $\mathrm{p}=0.012$ and 0.048 , respectively). Figure 3 shows a comparison of size classes 4 and 5 (i.e., $>5 \mathrm{~m}$ long and 5-10 cm in diameter and $>5 \mathrm{~m}$ long and 10-50 $\mathrm{cm}$ in diameter, respectively) for before and after comparisons using the two different temporal time scales discussed previously (panels a and b). Significant differences $(p<.0001$ for both size classes) existed for the monthly rate of change of LW loading in the years before Sandy (20032012; "before") and immediately following Sandy ("after"), however neither size class showed a significant ( $\mathrm{p}=0.144$ and 0.696 , respectively) difference when compared with total monthly standing LW load in the second set of analyses (6-10). For these analyses, the temporal scale is represented by 2012 (including Sandy; "before”) and 2013 (“after”)). The second temporal analysis did not contain negative values because it was only concerned with monthly standing LW load, not rate of change like the first temporal analysis (Figure 3b). Using $\mathrm{F}$ tests for linear regression models, significant negative relationships between instantaneous LW loading from Sandy and elevation were found for size classes 2,4 , and 5 with p-values $=0.019,0.001$, and 0.004 respectively (Figure 3b). Variability of LW inputs from Sandy were documented as some streams received very large instantaneous inputs (e.g., Elklick and Whites Run) while others received very little or no instantaneous inputs (e.g., Block, Big, and Elleber Runs) (Table 2).

\section{Discussion}

Large wood is known to be an important habitat feature for trout in headwater streams.

Kratzer and Warren (2013) showed increased brook trout biomass in Vermont streams once LW reached a threshold density of 100 pieces $\mathrm{ha}^{-1}\left(50\right.$ pieces $\mathrm{km}^{-1}$ based on their mean wetted width of $5 \mathrm{~m}$ ) and a stronger positive relationship when total LW exceeded 200 pieces ha ${ }^{-1}$. All of our study streams exceed this threshold. Additionally, we provide some evidence for the potentially compensatory nature of LW deposition via disturbance, shown by streams which were relatively 
wood-poor prior to Sandy and received relatively high levels of LW addition, resulting in a high percent change in LW loading following Sandy (Table 2). In this way, disturbance via Sandy in headwater systems may act as a stabilizing force which redistributes wood across broad spatial scales with ecological implications. The addition of high volumes of LW through natural processes may create more readily available wood pieces for downstream transport via debris flows which may influence the structure and function of downstream habitats. Therefore, the retention and residence of LW additions to these headwater streams is important to identify the potential for habitat change or stabilization.

Variability of LW loadings may be influenced by the successional stage of the riparian forest. Hedman et al. (1996) reported LW loadings ranging from 7.1-31.2 $\mathrm{m}^{3} 100 \mathrm{~m}^{-1}$ in midsuccessional forested streams of southern Appalachian watersheds. Our streams showed new LW additions following Sandy which ranged from 0-64.5 $\mathrm{m}^{3} 100 \mathrm{~m}^{-1}$. Dolloff et al. (1994) found ranges of 69-86 and 142-224 pieces km$~^{-1}$ in three North Carolina streams before and after Hurricane Hugo respectively. Our streams varied widely with ranges between 80-1402 pieces $\mathrm{km}^{-1}$ prior to Sandy and newly added LW ranging between 0-820 pieces $\mathrm{km}^{-1}$ after Sandy. Interestingly, our analyses (1-5) found significantly higher monthly rates of LW loading immediately after Sandy than in the years before across all size classes but found mostly no significant differences when comparing the year 2012 (including Sandy) with the year 2013 (Analyses 6-10). This may be due to a delay in LW recruitment, as some trees were damaged by the storm but not deposited into the stream immediately, causing the numbers for some streams to be higher in 2013 than in 2012 immediately following the storm.

Additionally, the loading of in-stream LW may be affected by anthropogenic activities such as harvest of trees within the riparian zone or direct removal from the stream (Hedman et al. 
1996). Flebbe and Dolloff (1995) report counts ranging from 100-162 pieces km-1 for two oldgrowth forested streams in North Carolina, USA, in which the riparian forests have never been harvested for timber. Our study streams in West Virginia are surrounded by second growth stands ranging in age from ca. 50-80 years, and thus may differ substantially in the size class structure of LW available for input into streams. Therefore, the addition of larger size classes via superstorm Sandy disturbance may help compensate for a general lack of such size classes, or expedite the recovery of LW in these streams of second-growth forests. Jones and Daniels (2008) noted the dynamics of LW structurally and temporally following the 2001 Dogrib fire in the Alberta foothills and predicted a delay of ca. 70 years before new LW could be recruited as structurally functional in headwater streams. Disturbance from Sandy may differ from this finding as a powerful wind and snow storm may damage riparian trees more selectively than a wildfire.

Our results report the immediate effects of a storm disturbance on LW loading in mountainous headwater streams of the eastern U.S. These findings provide a baseline for the long-term effects of these acute impacts, since LW may have effects for decades to come (Jones and Daniels 2008). Additionally, future research in these watersheds could provide some unique evidence for the effects these powerful disturbances have on native brook trout populations in the face of climate change and increasing frequency of such formidable disturbance (Bender et al. 2010). We believe that such baseline data are needed in order to more fully comprehend the dynamics of the systems we work in and to statistically determine an extreme ecological response given an extreme climatic impact. Current ecological dynamics may be greatly altered in the coming decades, as the temporal pace of climate change may be variable across ecosystems. For these reasons, a study such as this which uses long-term data to act as a baseline 
and an extreme weather event like Sandy to elucidate the potential ecological response is critical to better develop our understanding moving forward.

Acknowledgements

We are grateful to Dr. Ida Holaskova of West Virginia University for statistical consultation and assistance on this manuscript. Also to two anonymous reviewers who provided comments on a previous draft of the manuscript which improved it greatly. 


\section{Literature Cited}

Bender, M. A., Knutson, T. R., Tuleya, R. E., Sirutis, J. J., Vecchi, G. A., Garner, S. T., and Held, I. M. 2010. Modeled impact of anthropogenic warming on the frequency of intense Atlantic hurricanes. Science 327(5964): 454-458. Doi: 10.1126/science.1180568.

Costanza, R., d'Arge,R., deGroot, R., Farber, S., Grasso, M., Hannon, B., Limburg, K., Naeem, S., O’Neill, R. V., Paruelo, J., Raskin, R. G., Sutton, P., and van den Belt, M. 1997. The value of the world's ecosystem services and natural capital. Nature 387(6630): 253260. Available from http://www.esd.ornl.gov/benefits_conference/nature_paper.pdf [accessed 19 March 2013].

Dolloff, C. A., Flebbe, P. A., and Owen, M. D. 1994. Fish habitat and fish populations in a southern Appalachian watershed before and after Hurricane Hugo. Transactions of the American Fisheries Society, 123(4): 668 -678. Doi: 10.1577/15488659(1994)123<0668:FHAFPI>2.3.CO;2.

Fausch, K. D. and Northcote, T. G. 1992. Large woody debris and salmonid habitat in a small coastal British Columbia stream. Canadian Journal of Fisheries and Aquatic Sciences 49(4): 682-693. Doi: 10.1139/f92-077.

Flebbe, P. A. and Dolloff, C. A. 1995. Trout use of woody debris and habitat in Appalachian wilderness streams of North Carolina. North American Journal of Fisheries Management 15(3): 579—590. Doi: 10.1577/1548-8675(1995)015<0579:TUOWDA>2.3.CO;2.

Hankin, D. G. and Reeves, G. H. 1988. Estimating total fish abundance and total habitat area in small streams based on visual estimation methods. Canadian Journal of Fisheries and Aquatic Sciences 45(5): 834-844. Doi: 10.1139/f88-101

Hedman, C. W., Lear, D. H. V., and Swank, W. T. 1996. In-stream large woody debris loading and riparian forest seral stage associations in the southern Appalachian Mountains. Canadian Journal of Forest Research, 26(7): 1218 - 1227. Doi: 10.1139/x26-136.

Johnston, N. T., Bird, S. A., Hogan, D. L., and MacIsaac, E. A. 2011. Mechanisms and source distances for the input of large woody debris to forested streams in British Columbia, Canada. Canadian Journal of Forest Research, 41(11): 2231-2246. Doi: 10.1139/x11110.

Jones, T. A. and Daniels, L. D. 2008. Dynamics of large woody debris in small streams disturbed by the 2001 Dogrib fire in the Alberta foothills. Forest Ecology and Management 256(10): 1751-1759. Doi: http://dx.doi.org/10.1016/j.foreco.2008.02.048.

Kratzer, J. F. and Warren, D. R. 2013. Factors limiting brook trout biomass in northeastern Vermont streams. North American Journal of Fisheries Management 33(1): 130 -139. Doi: 10.1080/02755947.2012.743934. 
Lehane, B. M., Giller, P. S., O’Halloran, J., Smith, C., and Murphy, J. 2002. Experimental provision of large woody debris in streams as a trout management technique. Aquatic Conservation 12(3): 289-311. Doi: 10.1002/aqc.516.

Lowe, W. H. and Likens, G. E. 2005. Moving headwater streams to the head of the class. BioScience 55(3): 196-197. Doi: http://dx.doi.org/10.1641/00063568(2005)055[0196:MHSTTH]2.0.CO;2.

NOAA - National Weather Service, 2012a. Superstorm Sandy event review, synopsis and highlights [online]. Available from http://www.erh.noaa.gov/rnk/events/2012/Sandy/summary.php [accessed 7 February 2013].

NOAA - National Weather Service, 2012b. October 29, 2012, Hurricane Sandy - event overview [online]. Available from http://www.erh.noaa.gov/mhx/EventReviews/20121029/20121029.php [accessed 7 February 2013].

Zika, U. and Peter, A. 2002. The introduction of woody debris into a channelized stream: effect on trout populations and habitat. River Research and Applications 18(4): 355-366. Doi: $10.1002 /$ rra.677. 
Tables

Table 1: Summary of Proc Freq procedure using Cochran-Mantel-Heanszel (CMH) statistics for comparison of monthly rate of change of LW loading (Analyses 1-5) and monthly standing load of LW (Analyses 6-10) when controlling for certain variables. Analyses 1-5 used the years prior to Sandy (2003-2012) in comparison to the months immediately following Sandy for comparison while analyses 6-10 used the year 2012 (including Sandy) to the year 2013 for comparison. Differences in sample sizes for analyses 6-10 resulted from two streams having missing LW data in the year 2013.

\begin{tabular}{ccccccc}
\hline $\begin{array}{c}\text { Analysis } \\
\text { Number }\end{array}$ & Stratified By & $\begin{array}{c}\text { Minimum } \\
\text { Value (rank) }\end{array}$ & $\begin{array}{c}\text { Maximum } \\
\text { Value (rank) }\end{array}$ & $\begin{array}{c}\text { Sample } \\
\text { Size (n) }\end{array}$ & $\begin{array}{c}\text { Critical } \\
\text { Value } \\
(\mathbf{D F})\end{array}$ & P-Value \\
\hline 1 & Stream + LW Size & -4.94 & 98.89 & 350 & $109.13(1)$ & $<.0001$ \\
2 & LW Size & -4.94 & 98.89 & 350 & $170.33(1)$ & $<.0001$ \\
3 & None & -4.94 & 98.89 & 350 & $182.25(1)$ & $<.0001$ \\
4 & Stream & -14.21 & 273.33 & 50 & $25.00(1)$ & $<.0001$ \\
5 & None & -14.21 & 273.33 & 50 & $34.45(1)$ & $<.0001$ \\
6 & Stream + LW Size & 0.00 & 125.45 & 336 & $5.56(1)$ & 0.0183 \\
7 & LW Size & 0.00 & 125.45 & 336 & $1.69(1)$ & 0.1939 \\
8 & None & 0.00 & 125.45 & 336 & $2.48(1)$ & 0.1151 \\
9 & Stream & 3.51 & 166.67 & 48 & $1.09(1)$ & 0.2971 \\
10 & None & 3.51 & 166.67 & 48 & $4.22(1)$ & 0.0400 \\
\hline
\end{tabular}


Table 2: Summary of streams sampled for LW in West Virginia prior to and following Hurricane Sandy in October 2012 . Columns 2 and 3 represent the first temporal comparison of monthly rate of change of LW loading. Columns 4 and 5 represent the second temporal comparison of monthly standing load of LW in 2012 (including Sandy) and 2013 (after Sandy). Column 6 represents the instantaneous total load of new LW immediately following Sandy. Mean wetted widths were calculated by field measurements during summer low flow conditions and averaged across a 10 year period. Percent change is calculated for standing LW load per kilometer and averaged across years before Sandy and immediately following Sandy. Mean elevation and percent forested land cover were calculated using ArcGIS.

\begin{tabular}{|c|c|c|c|c|c|c|c|c|c|}
\hline Stream & $\begin{array}{c}\text { Pre-Sandy LW } \\
\text { Rate of Change } \\
\text { per Month } \\
\text { \#LW } \mathbf{k m}^{-1} \text { month- } \\
{ }^{1}(2003-2012) \\
\end{array}$ & $\begin{array}{l}\text { Post-Sandy LW Rate } \\
\text { of Change per Month } \\
\text { \#LW } \mathrm{km}^{-1} \text { month }^{-1} \\
(2012-2013 \text { months } \\
\text { following Sandy) }\end{array}$ & $\begin{array}{c}2012 \text { Total } \\
\text { Monthly LW } \\
\text { Load } \\
\text { (including } \\
\text { Sandy inputs) } \\
\end{array}$ & $\begin{array}{l}2013 \text { Total } \\
\text { Monthly LW } \\
\text { Load }\end{array}$ & $\begin{array}{l}\text { Instantaneous } \\
\text { LW Added } \\
\text { from Sandy } \\
\# \mathbf{L W ~ k m - 1}\end{array}$ & $\begin{array}{c}\text { Percent } \\
\text { Change } \\
\text { LW } \\
\mathbf{k m}^{-1} \\
(\%) \\
\end{array}$ & $\begin{array}{l}\text { Mean } \\
\text { Wetted } \\
\text { Width } \\
\text { (m) }\end{array}$ & $\begin{array}{c}\text { Mean } \\
\text { Elevation } \\
\quad(\mathbf{m})\end{array}$ & $\begin{array}{c}\text { Percent Forested } \\
\text { Land Cover in } \\
100 \text { meter } \\
\text { Riparian Buffer } \\
\text { Zone }(\%) \\
\end{array}$ \\
\hline Big Run & 1.79 & 2.50 & 17.85 & 4.99 & 10 & 3.01 & 2.58 & 1155 & 98.6 \\
\hline Birch Fork & -7.80 & 23.33 & 18.84 & 8.94 & 140 & 36.3 & 2.84 & 865 & 99.6 \\
\hline Block Run & -5.01 & 0.00 & 3.69 & 36.50 & 0.00 & 0.00 & 3.05 & 1023 & 99.5 \\
\hline Brushy Run & -1.59 & 16.00 & 5.54 & 44.38 & 80 & 45.0 & 2.37 & 697 & 67.0 \\
\hline Clubhouse Run & -2.46 & 31.33 & 30.78 & NA & 160 & 11.2 & 3.22 & 955 & 96.7 \\
\hline Crooked Fork & -7.67 & 39.17 & 17.54 & 8.05 & 160 & 53.2 & 3.28 & 1020 & 92.1 \\
\hline Elklick Run & -7.37 & 273.33 & 55.06 & 76.53 & 820 & 194.6 & 4.04 & 613 & 79.4 \\
\hline Elleber Run & -4.70 & 0.00 & 5.35 & 31.15 & 0.00 & 0.00 & 2.65 & 1129 & 84.5 \\
\hline Lick Run & 0.71 & 8.67 & 31.96 & 18.92 & 40 & 3.45 & 2.28 & 972 & 84.7 \\
\hline Light Run & -3.17 & 26.67 & 9.35 & 164.61 & 130 & 49.0 & 3.33 & 757 & 92.6 \\
\hline Little Branch & -13.27 & 37.78 & 16.25 & 4.13 & 230 & 55.3 & 1.75 & 1075 & 100.0 \\
\hline Little Low Place & -5.92 & 6.67 & 9.19 & 166.67 & 20 & 4.66 & 1.90 & 970 & 90.8 \\
\hline Long Run (Seneca) & 0.10 & 65.00 & 43.95 & 17.42 & 260 & 22.8 & 1.74 & 759 & 86.8 \\
\hline Long Run (Middle Fork) & 0.18 & 29.44 & 15.99 & 135.54 & 180 & 41.9 & 3.73 & 695 & 81.0 \\
\hline North Fork Panther Run & 2.11 & 56.67 & 71.30 & 31.61 & 280 & 42.5 & 3.85 & 760 & 100.0 \\
\hline North Fork Red Run & -1.77 & 21.11 & 7.23 & 3.51 & 60 & 78.6 & 5.19 & 942 & 85.6 \\
\hline Panther Run & -14.21 & 24.44 & 7.72 & 15.21 & 150 & 24.2 & 3.21 & 755 & 100.0 \\
\hline Poca Run & -3.14 & 34.00 & 19.97 & 161.29 & 170 & 53.4 & 2.31 & 1055 & 79.7 \\
\hline Roaring Creek & -8.79 & 23.33 & 10.42 & 6.82 & 90 & 28.0 & 2.85 & 765 & 92.0 \\
\hline Rocky Run & -12.37 & 18.33 & 7.52 & 125.31 & 110 & 16.1 & 4.54 & 817 & 99.1 \\
\hline Sand/Red Run & -4.67 & 8.33 & 5.82 & NA & 30 & 13.5 & 3.08 & 1065 & 100.0 \\
\hline Schoolcraft Run & -2.94 & 42.00 & 14.10 & 26.87 & 210 & 39.1 & 4.11 & 736 & 94.5 \\
\hline Seneca Creek & -3.91 & 12.50 & 8.90 & 92.17 & 50 & 18.0 & 2.76 & 1144 & 85.0 \\
\hline Sugar Drain & -4.20 & 40.67 & 11.95 & 25.09 & 200 & 55.0 & 1.91 & 872 & 99.4 \\
\hline Whites Run & -3.51 & 59.33 & 27.68 & 29.92 & 300 & 141.9 & 3.57 & 728 & 85.6 \\
\hline Average & -4.54 & 36.02 & 18.96 & 53.72 & 155 & 41.2 & 3.05 & 893 & 91.0 \\
\hline
\end{tabular}


Figures

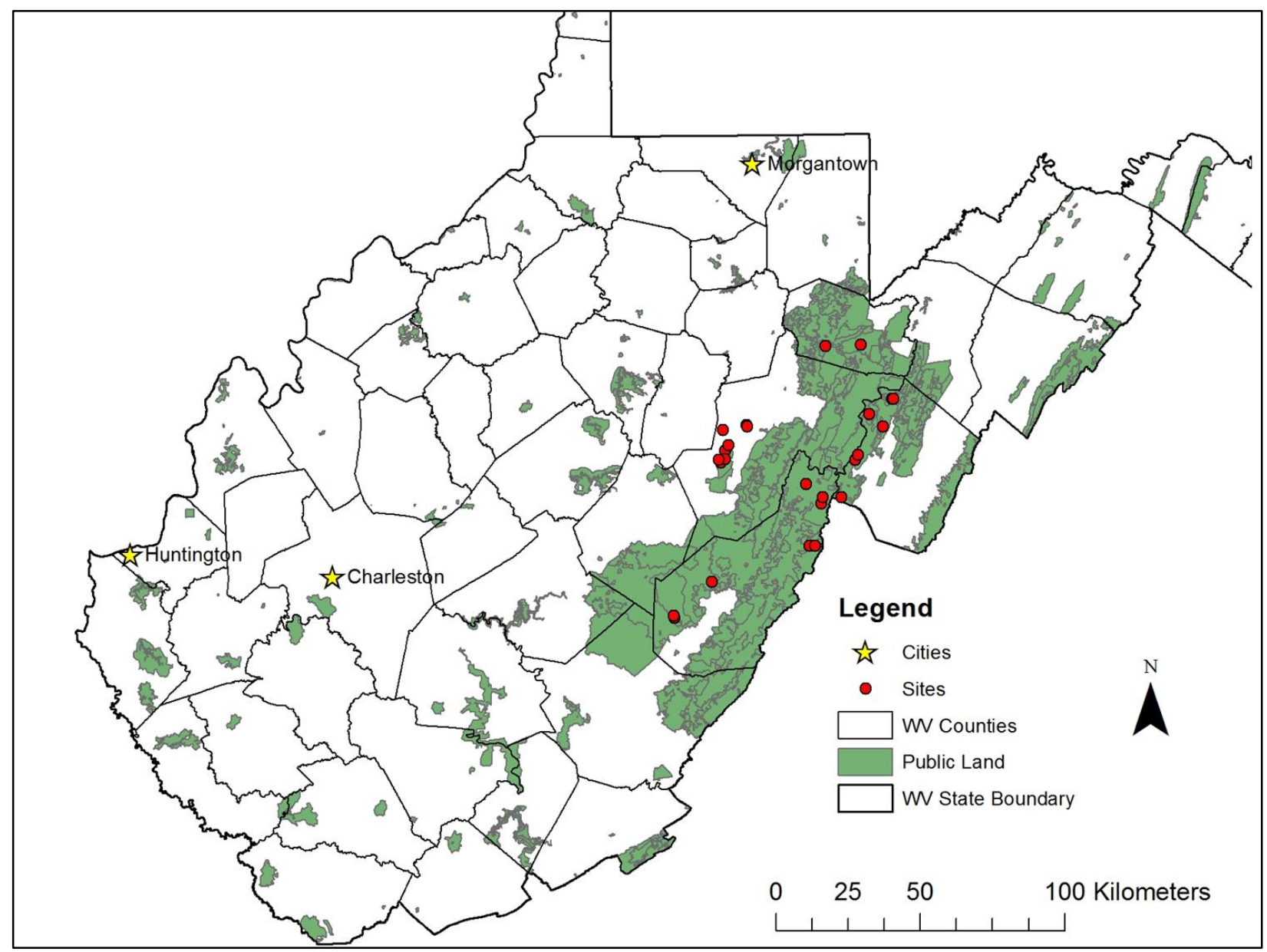

Fig 1. Map of West Virginia, USA showing headwater stream study sites across the mountainous eastern portion of the state. 


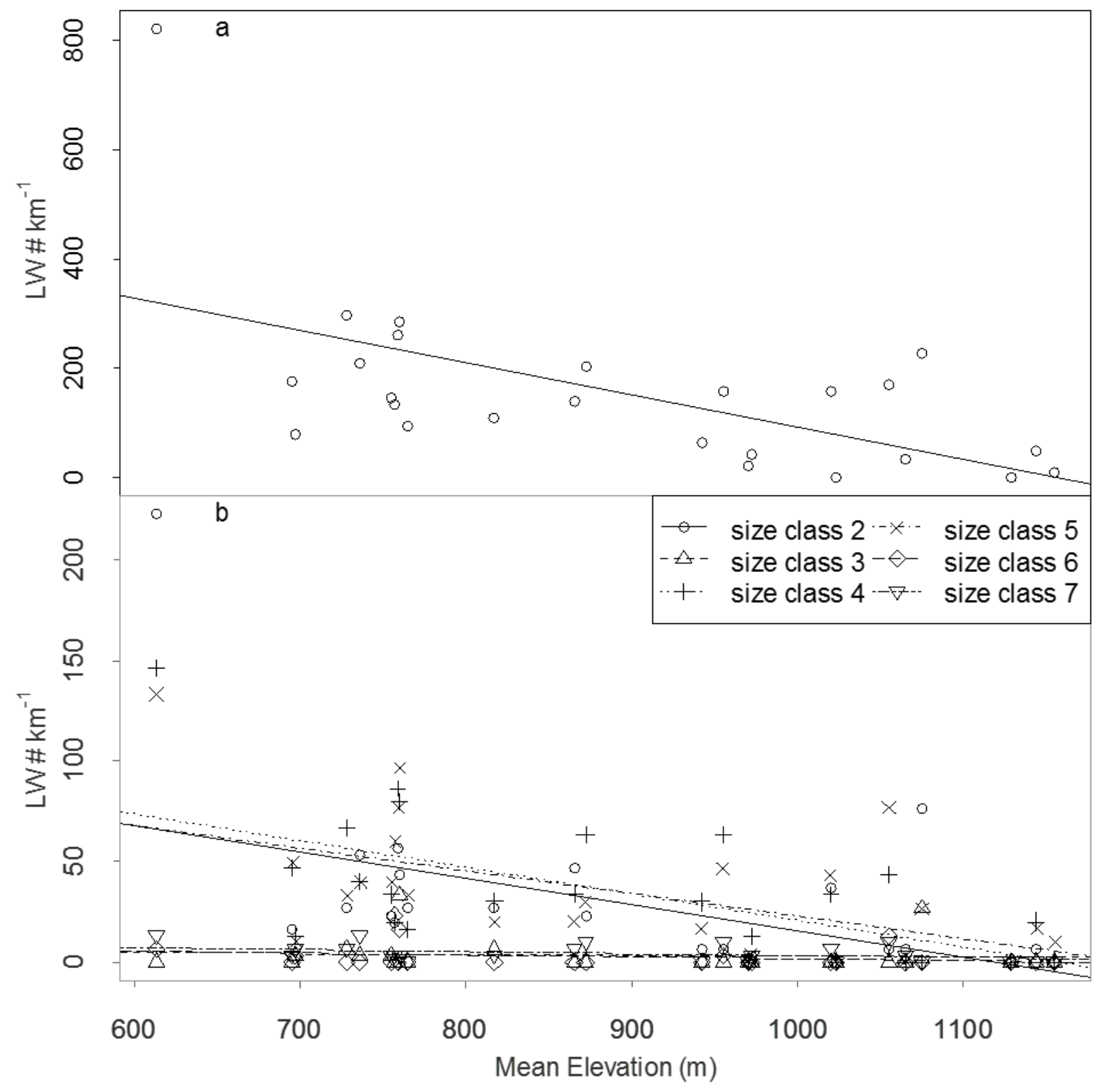

Fig 2. Negative relationship between number of newly added LW pieces per linear stream kilometer and elevation for 25 sampled streams (Panel a). Significant negative linear regression line is shown with adjusted $\mathrm{R}^{2}$ value $=0.31$ and $\mathrm{p}$-value $=0.002$. The negative relationship between the numbers of newly added LW pieces per linear stream kilometer by LW size classes (Panel b). Significant negative linear regression lines are shown for size classes 2, 4, and 5 with p-values $=0.019,0.001$, and 0.004 respectively. 


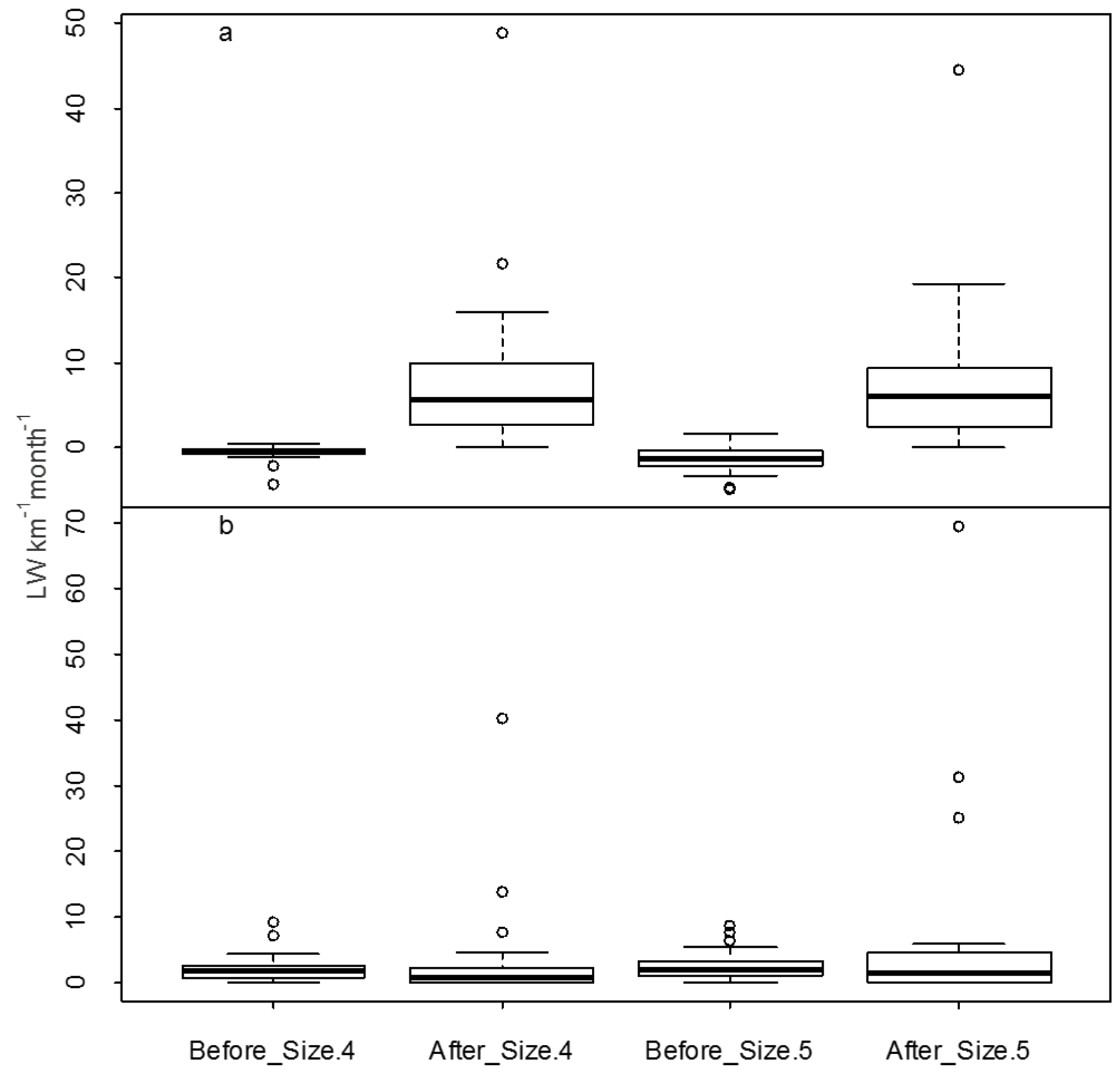

Fig 3. Comparison of LW load rate of change per month for a) the years prior to Sandy (2003-2012, i.e., "before") and the months following Sandy ("after") for LW size classes 4 and 5. Both show a significantly (p $<.0001$ for both size classes) higher rate of monthly LW loading after Sandy. In panel b) the same size classes are compared but for the entire year 2012, including Sandy ("before") and the year 2013 ("after"). These values are the standing monthly LW load and thus do not contain any negative values as the rates of monthly change do in panel (a). Neither size class showed significant difference before and after in the comparisons made in panel (b). 


\title{
Chapter 2: Brook Trout Population Growth and Synchrony in the Central Appalachians
}

\author{
Ross G. Andrew* and Kyle J. Hartman \\ Division of Forestry and Natural Resources, Davis College of Agriculture, Natural Resources, \\ and Design, 322 Percival Hall, West Virginia University, Morgantown, WV 26506-6125, USA \\ *Corresponding author, randrew4@ mix.wvu.edu Ph: (304)-293-0053 Fax: (304) 293-2441
}




\section{Abstract}

Identifying populations which act in synchrony across time and space may be valuable for understanding vulnerability and/or resilience to disturbance. We sought to identify variables which correlated highly with population growth rates and levels of synchrony for Brook Trout Salvelinus fontinalis populations. We used a long-term Brook Trout dataset within 25 streams of West Virginia, USA to analyze population growth rates across time and the correlation among demography of separate streams. We used regression to identify both local and regional variables related to population growth, and classification trees and random forest generation to identify variables which separated populations based upon their synchrony. Variables such as relative abundance of age- 0 fish, mean fish length, and fall drought index were all important for defining population growth rate in a given stream or year. Variables such as age-2 fish abundance, spawning area, and distance to tributaries contributed greatly to partitioning of synchronous and asynchronous populations. These results help identify populations which are experiencing unique demographics and variables which may help explain reasons for these scenarios. Furthermore, this research provides some insight into resilience of Brook Trout populations within Central Appalachian streams as they respond differently to both local and regional factors.

Introduction

Populations and communities of fishes may be affected by both local and regional processes which may influence their occurrence (Pont et al. 2005) and important population vital rates like survival and reproduction (Einum and Nislow 2005). The biological unit being examined, whether functional or taxonomic, may define the importance of local, regional, or 
some combination of factors, in structuring stream fish assemblages (Hoeinghaus et al. 2007). Within a biological unit, there may also be differing levels of influence across life stages. For example, salmonids that migrate as adults but are distributed in patches as eggs and juveniles show locally driven density dependence associated with higher costs of dispersal (Einum and Nislow 2005). Furthermore, local habitat structure, microhabitat diversity, and biotic interactions may help define local species diversity in given areas (Angermeier and Winston 1998).

However, depending on the spatial scale of investigation, local factors do not always provide strong prediction of local species diversity (Angermeier and Winston 1998). Increasingly, a combination of both local and regional factors are being used to understand the dynamics of fish populations and communities within stream reaches (Smith and Kraft 2005; Ferreira et al. 2007; Hoeinghaus et al. 2007). Local factors such as substrate, canopy cover, and temperature may interact with watershed variables such as confluence link and stream order to best predict fish assemblage structure (Smith and Kraft 2005). Also, the spatial structure of a stream network and longitudinal positioning along this network may greatly influence local species richness at a given site (Grenouillet et al. 2004). Regional scale factors may also better explain species distributions based on the stream size that species typically inhabit (Ferreira 2007). This study also found shared (both local and regional) effects for headwater stream fish endpoints, which may indicate some spatial structuring of effects or local attributes acting as proxies for otherwise unmeasured regional processes (Ferreira et al. 2007).

Given the nature of both local and regional factors and species mobility, populations of fishes may show similar or different responses across space and time. Similar responses may be manifested as synchronous timing of juvenile development for multiple species based upon 
stream discharges (Zorn and Nuhfer 2007). Differing responses may be shown as variability in predicted declines of salmonid populations based on changes in temperature, flow regime, and biotic interactions under climate change scenarios (Wenger et al. 2011). Differing responses may also result in spatially proximate populations showing patterns of asynchrony in their dynamics due to differences in spawning habitats (Rogers and Schindler 2008). Because such responses are variable, it is important to identify fish populations which show both similar and dissimilar responses to both local and regional factors when identifying conservation and/or management priorities.

Populations of fishes that experience similar vital rates and/or fluctuations in one or more of these vital rates may be said to be in synchrony. The underlying factors which drive this synchrony are often complex and have been the target of population studies in the past (Liebhold et al. 2004). Identifying asynchronous fish populations along an ecologically relevant spatial scale may allow investigation of factors which act alternatively to help structure each population differently. As disturbance and climate change effects do not act on consistent spatial scales, it is important to identify the ability of native populations to be resilient to changes (Dunham et al. 2007). Diversification of life history forms and suitable habitats across space may ensure less synchrony of populations and could lead to more resilience to harmful effects of stochastic disturbances (Isaak et al. 2003).

Brook Trout Salvelinus fontinalis populations in headwater streams of West Virginia, USA are wild, native populations that occur widely in the mountainous eastern part of the state. Like many native Brook Trout populations in the eastern U.S., they have been affected by human disturbances and land use since the colonial period. These disturbances have resulted in the reduction of both occurrence and abundance in many subwatersheds within their native range 
(Hudy et al. 2008). Still, natural reproduction occurs in many headwater streams and populations persist throughout a wide geographic range on both public and private lands. Adult Brook Trout spawn in these streams in the fall and fry emerge in the early spring. Evidence for both resident and migratory adult life forms exists within this area (Petty et al. 2012). Given suitable downstream conditions with respect to temperature, flow, and other variables, Brook Trout may migrate to larger mainstem habitats to forage in more productive areas (Petty et al. 2012). In this study, we sought to 1) discover variables that contribute to population growth rate across space and time, 2) identify levels of population synchrony, and 3) determine the role of both local and regional correlates in determining the level of synchrony in a given stream population. By doing this across a large spatial scale $\left(\sim 4800 \mathrm{~km}^{2}\right)$ in West Virginia among native Brook Trout populations we hope to help identify factors of utility for management and conservation of these native populations in the central Appalachians.

\section{Methods}

Study Sites and Data Collection.-The present study considers 25 headwater Brook Trout streams within the mountainous eastern portion of West Virginia which have been surveyed via backpack electrofishing every fall since 2003 (Table 1). Streams are surveyed using triple-pass electrofishing in three 100 meter segments representing the lower, middle, and upper portion of the headwater drainage. All captured Brook Trout are measured for total length in millimeters and wet weight in grams (Table 2). Condition factor on individual fish was calculated as the residual from the long-term regression relationship between the natural logarithm of total length (mm) and wet weight (g). This regression relationship contains over 20,000 data points which adds confidence to the relationship. Stream size varies as drainage area varies from 2.0-18.6 
$\mathrm{km}^{2}$ and elevations range from 613-1155 meters. All streams flow through predominantly forested land cover, with some light development and agricultural activities in the riparian areas of a few watersheds. Other fish species that commonly occur within these streams are Mottled Sculpin (Cottus bairdi) and Riffle Dace (Rhinichthys spp.). Sympatric occurrence of both Rainbow (Onchyrhnchus mykiss) and Brown Trout (Salmo trutta) with Brook Trout is rare, but does occur within a few select sample streams.

Habitat surveys have been conducted during the summer low flow period since 2003, following a modified basin-wide visual estimation technique (BVET, per Hankin and Reeves 1988). These surveys collect information about local habitat variables such as width, depth, and substrate among others (Table 2). Temperature data on these streams was also collected via temperature loggers placed in streams during 2011. Because temperature was only recorded for one year, this variable was not used in analyses over time, but rather only in site comparisons (much like a variable such as elevation). Temperatures were calculated using a moving average within a season (spring, summer, and fall) and also for a 24 hour maximum. Regional variables such as elevation, drainage area, and geology among others (Table 2) were collected using a geographic information system (GIS) and remotely sensed data. Drought index was considered a regional variable and used Palmer's Z Index (Palmer 1965) across the eastern mountain region of West Virginia from data available from the NOAA National Center for Environmental Information (NCEI; https://www.ncdc.noaa.gov). Palmer's Z Index was used because it is an indicator of short-term (monthly) drought that could easily be grouped into seasonal (spring, summer, fall) averages. Stream connectivity was calculated using stream network distance within GIS and field knowledge of barriers to Brook Trout (e.g. warm-water reaches, physical barriers, etc.). To assess the effect of stream size on tributary connections, the difference in the 
flow accumulation value (a proxy for drainage area) between a sampled stream and the nearest downstream tributary was also calculated (Table 1).

Data Analysis.-The temporal range of samples allowed the examination of synchrony over a range of environmental conditions and population sizes. Analyses were conducted on detrended population numbers. Population numbers were the combined abundances of all sizes of Brook Trout of all three sample reaches in a given stream and given year. Annual differencing was done by calculating the instantaneous population rate of change, $r$, as $\log _{e}\left(N_{t} / N_{t-1}\right)$ where $\mathrm{N}_{\mathrm{t}}$ was the sampled population size at time $t$. This differencing procedure provided an estimate of population rate of change that was independent of population size across time. In order to identify factors which influenced the value of $\mathrm{r}$ in a given stream or year, we employed exploratory forward-selecting multiple regression models to identify these variables at the $0.05 \alpha$ level. Models were developed to select significant variables across streams $(n=14$ for number of years sampled) and years ( $\mathrm{n}=25$ for number of streams sampled) separately and important variables were identified.

Population synchrony was analyzed using pair-wise Pearson correlations of all 25 sample streams with respect to individual $r$ values across all years. This yielded $n=300$ pair-wise comparisons which were then tested for significance away from zero using the Pearson productmoment correlation coefficient test. This test used a non-directional p-value with equation $t=r \sqrt{\frac{n-2}{1-r^{2}}}$ where $\mathrm{r}=$ sample correlation and $\mathrm{n}=$ sample size. We set significance at $\alpha=0.05$ and identified those streams which were included with significant correlations as synchronous and those that were not included with any significant correlations as asynchronous. We also tested 
correlation between streams that were fluvially connected and those that were not connected using a simple Student's t-test.

Within the set of 25 streams, four streams presented the opportunity to examine patterns of synchrony while controlling for the effects of regional processes at an effective distance. The four streams, two pairs of two, which included one synchronous and one asynchronous population each were examined in detail with differences between specific variables compared using t-tests. These pairs of streams were compared in detail because of their close spatial proximity (sample sites $<2 \mathrm{~km}$ apart) which effectively removed regional processes as a source of variance between sites. These two pairs of streams were unique in their spatial proximity and contrast in synchrony and afforded an opportunity to examine a subset of the streams in detail to address our research questions.

The relationships between population synchrony and both local and regional factors were examined using regression models developed a priori. Due to the multitude of potential factors that could be important, we used an assisted model development procedure which included the use of classification and regression tree (CART) models to help define important factors for populations both in and out of synchrony. We further assessed the importance of variables for determining population synchrony using random forest models. Random forests generate a large number of classification trees that use bootstrapping of random samples of variables. The final model outcome is therefore more accurate than a single classification tree and variable contribution may be calculated across many iterations (Breiman 2001). We then used these datadriven factors of importance along with expert knowledge and opinion to create all the candidate models. The models were compared using Akaike's information criterion (AIC) scores and the best models were determined. The factors within the best performing models were then assessed 
to determine their individual contribution to the synchrony of populations. Due to the binary categorical nature of response, logistic regression was used to categorize the response between synchronous and asynchronous streams. Explanatory variables within the best performing models were examined further to identify both the direction and size of the effect.

Results

Population Growth Models.-The first set of forward-selecting regression models for $\mathrm{r}$ included 14 models across all streams in a given year (2003-2016). These models were dominated by fish variables including abundance, length, and condition factor. The most commonly occurring significant variable was the abundance of age 0 fish (Table 3 ) for these yearly models across all streams. The second set of these forward-selecting models for $\mathrm{r}$ contained 25 models going across all sample years for a given stream. This set of models also contained many significant fish variables such as abundance, length, and condition, but also contained a few significant environmental variables such as fall drought index (Table 4). Significant variables across both model sets were also grouped by the direction of their effect on response variable $\mathrm{r}$ (Table 5). Average length was the variable with the most frequent positive association with $\mathrm{r}$ while overall abundance of Brook Trout and abundance of age 0 and age 1 classes had the most frequent negative association with $\mathrm{r}$ across both model sets.

Population growth rate over time shows clear patterns of synchrony in these streams (Figure 1). The Pearson correlation tests yielded 80 significantly correlated pair-wise sets of streams. Of those 80 pairs, 21 of the 25 streams appeared greater than three times, with some as many as 13 times. These 21 streams were then said to be synchronous due to their consistent pattern of significant pair-wise correlation. Four of the 25 streams appeared zero times, and were thus considered asynchronous due to their lack of significant correlation with any other 
stream. Correlation between streams that were fluvially connected was significantly higher than those streams not fluvially connected across all pairwise sites (t-test, $\mathrm{p}<0.01)$.

For the two pairs of spatially similar streams with one synchronous and one asynchronous population, the first pair included no significant differences in local habitat or fish variables with the exception of spawning area. The spawning area, measured as the area of clean, medium-large $\left(\right.$ median $=8.9 \mathrm{~mm}$ diameter per Witzel $(1980)$ gravel in $\mathrm{m}^{2}$ per $100 \mathrm{~m}^{2}$ of pool area sampled, differed between the two streams significantly $(\mathrm{p}<0.01)$ with the asynchronous stream holding a larger amount $\left(\right.$ mean $\left.=3.39 \mathrm{~m}^{2}\right)$ than the synchronous stream $\left(\right.$ mean $\left.=0.81 \mathrm{~m}^{2}\right)$. The second pair of spatially similar streams contained significant differences for the local fish variables of Brook Trout abundance ( $p<0.05$ ), age-0 Brook Trout abundance $(\mathrm{p}=0.05)$, and age-1 Brook Trout abundance $(\mathrm{p}<0.05)$ with the asynchronous stream always having a lower number for each of these variables. These local relationships contrast with the relationship between age-0 Brook Trout Abundance and a regional drought index (Palmer's Z) for the previous fall (Figure 2, panel A). As the drought index for the previous fall decreases (more dry conditions), age-0 Brook Trout Abundance in the following year also decreases. This effect may override local density dependence relationships across the entire study area and decrease population growth rates unexpectedly (Figure 2, panel B).

Classification Models for Synchrony.-The assisted model development procedure for the synchrony models began with a set of CART models to identify important factors within three strata. The three strata were fish-related variables, stream-scale habitat variables, and drainagescale habitat variables. The fish-related variables that CART partitioned the synchronous and asynchronous streams using were: average age- 2 fish length, average age- 2 fish abundance, and average age-0 fish abundance. This classification tree contained three splits with a final 
complexity parameter of 0.01 . For three of the four asynchronous streams, average age- 2 fish length and abundance were higher than all other streams (Figure 3, panel A). For one asynchronous stream, age- 2 length and both age- 2 and age- 0 abundance was low relative to other streams (Figure 3, panel A).

The stream habitat CART models produced the partitioning variables of spawning area $\left(\mathrm{m}^{2}\right.$ per $100 \mathrm{~m}^{2}$ pool area) and proportion of pool habitat overall. This classification tree contained four splits with a final complexity parameter of 0.01 . Two of the four asynchronous streams had very low spawning area and very low proportion of pools relative to other streams, while the other two asynchronous streams had very high spawning area and somewhat high proportion of pools relative to other streams (Figure 4, panel A ).

The drainage-scale variables identified by CART models were distance to downstream tributary, drainage area, and flow accumulation difference with a downstream tributary. This tree also had four splits and a final complexity parameter of 0.01 . Two of the asynchronous streams had very low distance to downstream tributary relative to other streams, one had a very large relative drainage area, and one had and intermediate drainage area and a relatively high flow accumulation difference with a downstream tributary (Figure 5, panel A ).

Random forest models.-The random forest generation for each of these three classification groups produced similar results. For the fish-related variables, the random forest models produced an out-of-bag (OOB) error estimate of $16 \%$ across 500 trees. The OOB error is an unbiased estimate of the test set error obtained by bootstrap construction of each tree and measurement of misclassification of other data pulled "out of the bag" of other data points over all possible trees (Breiman 1996; Breiman 2001) The variables with the highest average 
reduction in the Gini impurity criterion, a measure of variable importance (Archer and Kimes 2008), were average age-2 fish length (2.14), average age-2 fish abundance (1.55), and average age-0 fish abundance (0.98) (Figure 3, panel B). The Gini impurity criterion is calculated as the decrease in node impurity at each split in a given tree (Archer and Kimes 2008). This is then averaged across all trees in the random forest for a given variable to identify the variables most responsible for reductions in impurity of classification. The stream habitat models produced an OOB error estimate of $20 \%$ across 500 trees. The variable with the highest average reduction in the Gini impurity criterion was spawning area (1.90) (Figure 4, panel B). The drainage-scale models produced an OOB error estimate of $16 \%$ across 500 trees. The variables with the highest average reduction in the Gini impurity criterion were distance to downstream tributary (1.85), flow accumulation difference (1.17), percent forest cover (1.14), and drainage area (0.96) (Figure 5, panel B).

Logistic Regression Models for Synchrony.-The regression models were built using generalized linear models (GLMs) with a binomial (logit) link function for the binary response of synchrony or asynchrony. The model containing all variables identified by the previous steps for fish, habitat, and drainage variables showed the most support via Akaike weight $\left(W_{i}, 0.72\right.$, Table 4). The model containing only the important habitat and drainage-level variables received the remaining support from the data with an Akaike weight of 0.28 . The computed evidence ratio between these two supported models was 2.55 . Within the best performing models, the only parameter with model averaged values that did not contain zero in their $95 \%$ confidence interval was drainage area (model averaged estimate $=-0.59)$. However, downstream distance to tributary, age-2 fish abundance, and proportion of pool habitat showed useful patterns along with drainage area (Figure 6). 


\section{Discussion}

Identifying factors which may contribute significantly to population growth rates across space in a given year or across time in a given space is crucial to understand the potential for population resistance and resilience. Here, we are able to demonstrate some of this critical information for Brook Trout populations in headwater streams of Central Appalachians. Across space in a given year, our models have shown that age- 0 abundance is significant to the population growth rate. This finding is not at all surprising, due to the great importance of recruitment and spawning success in stream-dwelling salmonids (Knapp et al. 1998). Across time in a given space however, overall abundance as well as fish size and body condition are the most important drivers of population growth rate. The spatially distinct patterns of these variables suggest density dependence and competition may be more regulating of populations in certain areas, while recruitment may be influential regardless of the location. Furthermore, the consistently positive association with fish length may suggest that larger fish are benefitting from better conditions for growth, and have potential to yield more reproductive effort, thereby increasing population growth rates. The consistently negative association with fish abundance suggests density dependence may be the underlying factor to reduce the population growth rate in these streams.

Identifying factors which contribute to populations following synchronous growth patterns across both time and space is challenging due to the reality that these natural systems experience many unpredictable events like disturbances. However, our efforts here have identified some factors which are supported by the data to show differences between streams behaving in asynchrony to others. Factors such as the abundance of age- 2 and age- 0 trout are important due to these groups representing the bulk of spawning effort and recruitment within these populations, respectively. Factors such as spawning area and pool habitat at the local scale 
are important for defining the reproductive and energetic efficiency or capacity of a stream. And watershed scale factors such as distance to downstream tributaries and drainage area help define population networks and movement potentials. All of these data driven factors are important to consider in the context of management and conservation because populations across space which are mostly synchronized may be either more sensitive to regional processes or less sensitive to local processes. If these populations are synchronized in stability, they may be supplemented by constant immigration to offset mortalities or emigration (Hilderbrand 2003). However, synchrony may be harmful in that it could signify a loss of heterogeneity in populations or habitats, thereby creating potential for higher global extinction rates in these subpopulations (Heino et al. 1997).

Most research on spatial synchrony of populations concludes that the principle of spatial autocorrelation governs much of the patterns of synchrony (Koenig 1999). Thus, populations closer together tend to have higher correlations than populations farther apart. This principle holds true in many scenarios with many species as demonstrated in Ranta et al. (1995) with Finnish populations of species as different as Whitefish (Coregonus lavaretus) and Capercaillie (Tetrao urogallus). In these cases, dispersal ability is a key assumption in the spatial correlation relationships. We found evidence to support this in these Brook Trout populations across the entire study area, in areas where dispersal is both likely and improbable. Therefore, it is reasonable to surmise that our data fit partially with this theory.

On the other hand, there is evidence for synchronization of some populations either separated absolutely or lacking dispersal ability. For example, populations of sheep separated on islands within an archipelago have been shown to have levels of population synchrony (Grenfell et al. 1998). Synchrony of growth and reproduction of trees separated by greater than 2000 
kilometers has also been demonstrated in some northern forests (Koenig and Knops 1998). In these cases, environmental conditions may be more important in defining synchrony than dispersal of organisms. This was the finding of Hanski and Woiwod (1993) with regard to spatial synchrony of moth and aphid populations in Britain. Some evidence for this was also found with synchrony of recruitment in centrarchids of Ohio River tributaries separated by 39 mainstem river kilometers explained best by temperature and discharge (Emme 2008). Our findings in this study also fit with this segment of the paradigm due to evidence of populations in synchrony across larger distances or known dispersal barriers.

Furthermore, spatially similar streams did not always show evidence of synchrony whatsoever. Our two pairs of spatially similar streams with one synchronous and one asynchronous provide evidence to support this notion and should be discussed further. In these pairs of streams, the asynchronous stream was characterized by either relatively excellent conditions (i.e. spawning substrate) or relatively poor fish numbers (i.e. abundance). From this, it appears in these scenarios, local variation may create asynchronous populations via both positive and negative influences. Local habitat conditions and variation have been shown to modify outcomes of more general processes like predation in fish populations (Beukers and Jones 1998). We show this in these two pairs of streams, where local factors override regional processes and change predicted outcomes of correlation/synchrony as directed by the principles of spatial autocorrelation. However, it is also possible for regional processes to override local variation and cause mostly uniform changes in populations across a given area (Danylchuk and Tonn 2002). We show this phenomena with the relationship between fall drought in the previous year and age- 0 Brook Trout abundance as it relates to density dependence across all streams in a given year (Figure 2). Drought has been shown to impact recruitment of Brook Trout as it 
increases fine sediment composition in spawning gravel and negatively affects spawning success (Hartman and Hakala 2006).

On the contrary, populations which are not synchronized may be either more resistant to regional processes or more sensitive to local processes. This asynchrony could lead to a reduction in the global extinction probability across subpopulations as asynchronous populations would not likely be as susceptible to negative impacts from disturbance in a uniform manner. However, in these situations negative characteristics could also persist such as limitation of local habitats with respect to food, spawning grounds, etc. If connectivity is an issue in these scenarios, it may lead to isolation which can greatly increase subpopulation extinction risk (Hilderbrand 2003). The causes of asynchrony are certainly unique for each situation and species, however here we offer some suggestions from our findings that may translate to other lotic fish populations with some generality. Asynchrony could be caused by overall low abundance of fish in a poor habitat acting as a population sink, therefore having a consistent population trend rather than fluctuations to remain in synchrony with others. It may also be related to differences in dispersal potential, leading to populations which have more irregular patterns of immigration/emigration and recruitment than others (Cowen and Sponaugle 2009). We found evidence for both of these asynchronous population types, supported by our classification modeling. Three of our asynchronous streams showed signs of high fluvial connectivity with low distance to downstream tributary and higher drainage areas. This is in contrast to the majority of the synchronous streams which are of relatively lower drainage area and higher isolation. One of our asynchronous streams showed signs of being a sink habitat, with consistently low abundance of all age classes of fish across time (Table 1; Lick Run). 
Regardless of the mechanisms driving synchrony/asynchrony, it is important to discuss the importance and relevance of these findings to the future growth and survival of these populations. Anthropogenic impacts are stretching farther into remote forests and encroaching upon headwaters each day. These impacts have the ability to alter ecological states and modify resilience of ecosystems (Nystrom et al. 2000). Changes to local processes and conditions should be considered as it pertains to the local resilience of these populations. Furthermore, climate change scenarios often predict changes in regional processes such as disturbance that must be accounted for with these populations and their ability to be resilient to regional changes. Previous research has concluded that variation of environmental perturbations rather than simply their occurrence will structure synchrony of separate populations regardless of dispersal (Haydon and Steen 1997). However, the relative importance of both dispersal and disturbance with respect to structuring populations could depend on the species (Ruetz et al. 2005). Synchronized stream populations across large areas, as we have demonstrated here, could potentially have more resilience to local changes such as human development. Asynchronous stream populations may therefore be more threatened by local changes, but more resilient to regional changes (e.g. climate effects).

The methods and endpoints used to measure population synchrony may be dependent on each situation given the species and logistics of sampling. Previous studies have used other endpoints such as redd counts (Isaak 2003), local abundance (Cheal et al. 2007), and even growth (Jensen et al. 2011) to examine patterns of correlation and synchrony. For our study, population growth rate was the best choice given the long-term dataset and the ability to measure population changes over time regardless of a single population size at a given site or sampling date. It is also worthwhile to consider the scale at which synchrony is relevant for these 
populations and others. For our populations, spatial scales in the 0-6 kilometer range are relevant to local Brook Trout movement potential (Petty et al. 2012) and scales in the range of 6+ kilometers are relevant to regional climate and disturbance patterns as defined by our study area. However, for Sockeye Salmon (Oncorhynchus nerka), Rogers and Schindler (2008) found that populations relatively close together (less than 40km) were asynchronous based on different levels of juvenile habitat productivity, so species specific scales should be considered.

Qualifications of this study should be mentioned in order to fully understand our conclusions and interpret their meaning among other studies of fish population synchrony. First, not all explanatory variables were collected for all years, owing to the fact that the long-term study this work is based upon has evolved and grown since its inception in 2003. Therefore, modeling the correlation of population data since 2003 with these variables is not possible. However, all variables reported in this paper did include adequate records for modeling. Second, the distinction between modeling population growth rate, $r$ and modeling synchrony in $r$ should be mentioned and described. Models predicting $\mathrm{r}$ itself may be more influenced by local variability across streams in a given year or synoptic variability across years in a given stream. Models using synchrony assume this year to year variation and attempt to identify those parameters which yield similar or different results based upon local resilience characteristics. In this way, population growth rate models are best interpreted in either a single time step or spatial location while synchrony models are best interpreted in more holistic ensemble combining space and time.

The findings of this research are meant to help inform both managers and conservation groups alike, highlighting the importance of both local and regional variables as they relate to population growth rate and synchrony of these native Brook Trout populations. Our findings of 
asynchrony and those variables which correlate with it should help managers identify areas where either 1) local habitat improvement may change these sink habitats or 2) maintenance of fluvial connectivity and stream networks will allow populations to persist and thrive. Synchronous populations should also be examined as management efforts could help desynchronize some populations across space, with the hopes of reducing regional sensitivity to disturbance via locally distinct habitats and population life-histories (Isaak et al. 2003). Consideration of the spatial links between subpopulations may help further understand some dynamics which fluctuate between local and regional regulation within a riverscape (Fausch et al. 2002). Finally, we wish to highlight the value of long-term data collection which allows analysis of these factors through time and separates the effects of isolated events from long-term patterns.

Acknowledgements

We are grateful to Dr. Ida Holaskova of West Virginia University for statistical consultation on this manuscript. Also to the U.S. Forest Service, West Virginia Department of Natural Resources, and Southwestern Energy Company for previous funding and access to some sites. This work was supported by the USDA National Institute of Food and Agriculture, McIntire Stennis project [WVA00115; accession \#102954], and the West Virginia Agricultural and Forestry Experiment Station. The care and handling of all fish was in accordance with approved protocols of West Virginia University Animal Care and Use Committee. 


\section{Literature Cited}

Angermeier, P. L., and M. R. Winston. 1998. Local vs. regional influences on local diversity in stream fish communities of Virginia. Ecology, 79(3), 911-927.

Archer, K. J., and R. V. Kimes. 2008. Empirical characterization of random forest variable importance measures. Computational Statistics \& Data Analysis, 52(4), 2249-2260.

Beukers, J. S., and G. P. Jones. 1998. Habitat complexity modifies the impact of piscivores on a coral reef fish population. Oecologia. 114(1), 50-59.

Breiman, L. 2001. Random forests. Machine learning, 45(1), 5-32.

Breiman, L. 1996. Out-of-bag estimation. Department of Statistics, University of California, Berkeley, California. Available: https://www.stat.berkeley.edu/ breiman/OOBestimation.pdf (September 2016).

Buisson, L., W. Thuiller, S. Lek, P. U. Y. Lim, and G. Grenouillet. 2008. Climate change hastens the turnover of stream fish assemblages. Global Change Biology, 14(10), 2232 2248.

Cheal, A. J., S. Delean, H. Sweatman, and A. A. Thompson. 2007. Spatial synchrony in coral reef fish populations and the influence of climate. Ecology, 88(1), 158-169.

Cowen, R. K., and S. Sponaugle. 2009. Larval dispersal and marine population connectivity. Marine Science, 1.

Danylchuk, A. J., and W. M. Tonn. 2003. Natural disturbances and fish: local and regional influences on winterkill of fathead minnows in boreal lakes. Transactions of the American Fisheries Society. 132(2), 289-298.

Dunham, J. B., A. E. Rosenberger, C. H. Luce, and B. E. Rieman. 2007. Influences of wildfire and channel reorganization on spatial and temporal variation in stream temperature and the distribution of fish and amphibians. Ecosystems, 10(2), 335-346.

Einum, S., and K. H. Nislow. 2005. Local-scale density-dependent survival of mobile organisms in continuous habitats: an experimental test using Atlantic salmon. Oecologia, 143(2): 203-210.

Emme, K. A. 2008. Synchrony in recruitment of fishes in Ohio River tributaries. Master's thesis. Southern Illinois University at Carbondale, Carbondale, Illinois.Fausch, K. D., C. E. Torgersen, C. V. Baxter, and H. W. Li. 2002. Landscapes to riverscapes: bridging the gap between research and conservation of stream fishes a continuous view of the river is needed to understand how processes interacting among scales set the context for stream fishes and their habitat. BioScience, 52(6), 483-498. 
Ferreira, M. T., L. Sousa, J. M. Santos, L. Reino, J. Oliveira, P. R. Almeida, and R. V. Cortes. 2007. Regional and local environmental correlates of native Iberian fish fauna. Ecology of Freshwater Fish, 16(4), 504-514.

Fulton, T. W. 1904. The rate of growth of fishes. Twenty-second Annual Report, Part III. Fisheries Board of Scotland, Edinburgh, pp. 141-241.

Grenfell, B. T., K. Wilson, B. F. Finkenstädt, T. N. Coulson, S. Murray, S. D. Albon, and M. J. Crawley. 1998. Noise and determinism in synchronized sheep dynamics. Nature, 394(6694), 674-677.

Grenouillet, G., D. Pont, and C. Hérissé. 2004. Within-basin fish assemblage structure: the relative influence of habitat versus stream spatial position on local species richness. Canadian Journal of Fisheries and Aquatic Sciences, 61(1), 93-102.

Hankin, D. G., and G. H. Reeves. 1988. Estimating total fish abundance and total habitat area in small streams based on visual estimation methods. Canadian journal of fisheries and aquatic sciences, 45(5), 834-844.

Hanski, I. and I. P. Woiwod. 1993. Spatial synchrony in the dynamics of moth and aphid populations, Journal of Animal Ecology. 62, 656-668.

Hartman, K. J., and J. P. Hakala. 2006. Relationships between fine sediment and brook trout recruitment in forested headwater streams. Journal of Freshwater Ecology, 21(2), 215230.

Haydon, D. and H. Steen. 1997. The effects of large- and small-scale random events on the synchrony of metapopulation dynamics: a theoretical analysis, Proceedings of the Royal Society of London B. 264, 1375-1381.

Heino, M., V. Kaitala, E. Ranta., and J. Lindström. 1997. Synchronous dynamics and rates of extinction in spatially structured populations. Proceedings of the Royal Society of London B: Biological Sciences,264(1381), 481-486.

Hilderbrand, R. H. 2003. The roles of carrying capacity, immigration, and population synchrony on persistence of stream-resident cutthroat trout. Biological conservation, 110(2), 257266.

Hoeinghaus, D. J., K. O. Winemiller, and J. S. Birnbaum. 2007. Local and regional determinants of stream fish assemblage structure: inferences based on taxonomic vs. functional groups. Journal of Biogeography, 34(2): 324-338.

Hudy, M., T. M. Thieling, N. Gillespie, and E. P. Smith. 2008. Distribution, status, and land use characteristics of subwatersheds within the native range of brook trout in the eastern United States. North American Journal of Fisheries Management, 28(4), 1069-1085. 
Isaak, D. J., R. F. Thurow, B. E. Rieman, and J. B. Dunham. 2003. Temporal variation in synchrony among Chinook Salmon (Oncorhynchus tshawytscha) redd counts from a wilderness area in central Idaho. Canadian Journal of Fisheries and Aquatic Sciences, 60(7), 840-848.

Jensen, A. J., P. Fiske, L. P. Hansen, B. O. Johnsen, K. A. Mork, and T. F. Næsje. 2011. Synchrony in marine growth among Atlantic salmon (Salmo salar) populations. Canadian Journal of Fisheries and Aquatic Sciences, 68(3), 444-457.

Knapp, R. A., V.T. Vredenburg, and K. R. Matthews. 1998. Effects of stream channel morphology on golden trout spawning habitat and recruitment. Ecological Applications, 8(4), 1104-1117.

Koenig, W.D. and J. M. H. Knops. 1998. Scale of mast-seeding and tree-ring growth, Nature 396, 225-226.

Koenig, W. D. 1999. Spatial autocorrelation of ecological phenomena. Trends in Ecology \& Evolution, 14(1), 22-26.

Liebhold, A., W. D. Koenig, and O. N. Bjørnstad. 2004. Spatial synchrony in population dynamics. Annual Review of Ecology, Evolution, and Systematics, 467-490.

Nyström, M., C. Folke, and F. Moberg. 2000. Coral reef disturbance and resilience in a humandominated environment. Trends in Ecology \& Evolution, 15(10), 413-417.

Palmer, W. C. 1965. Meteorological drought (Vol. 30). Washington, DC: US Department of Commerce, Weather Bureau.Petty, J. T., P.J. Lamothe, and P. M. Mazik. 2005. Spatial and seasonal dynamics of brook trout populations inhabiting a central Appalachian watershed. Transactions of the American Fisheries Society, 134(3), 572-587.

Petty, J. T., J. L. Hansbarger, B. M. Huntsman, and P. M. Mazik. 2012. Brook trout movement in response to temperature, flow, and thermal refugia within a complex Appalachian riverscape. Transactions of the American Fisheries Society, 141(4), 1060-1073.

Pont, D., B. Hugueny, and T. Oberdorff. 2005. Modelling habitat requirements of European fishes: do species have similar responses to local and regional environmental constraints?. Canadian Journal of Fisheries and Aquatic Sciences 62(1):163-173.

Ranta, E., V. Kaitala, J. Lindstrom, and H. Linden. 1995. Synchrony in population dynamics. Proceedings of the Royal Society of London B: Biological Sciences, 262(1364), 113-118.

Rogers, L. A., and D. E. Schindler. 2008. Asynchrony in population dynamics of sockeye salmon in southwest Alaska. Oikos, 117(10), 1578-1586. 
Ruetz, C. R., J. C. Trexler, F. Jordan, W. F. Loftus, and S. A. Perry. 2005. Population dynamics of wetland fishes: spatio-temporal patterns synchronized by hydrological disturbance? Journal of Animal Ecology. 74(2), 322-332.

Smith, T. A., and C. E. Kraft. 2005. Stream fish assemblages in relation to landscape position and local habitat variables. Transactions of the American Fisheries Society, 134(2), 430 440.

Wenger, S. J., D. J. Isaak, C. H. Luce, H. M. Neville, K. D. Fausch, J. B. Dunham, and A. F. Hamlet. 2011. Flow regime, temperature, and biotic interactions drive differential declines of trout species under climate change. Proceedings of the National Academy of Sciences, 108(34), 14175-14180.

Witzel, L. D. 1980. Relation of gravel size to spawning site selection and alevin production by Salvelinus fontinalis and Salmo trutta. M. S. Thesis, University of Guelph, Ontario.

Zorn, T. G., and A. J. Nuhfer. 2007. Regional synchrony of brown trout and brook trout population dynamics among Michigan rivers. Transactions of the American Fisheries Society, 136(3), 706-717. 
Tables

Table 1: Summary of stream attributes for 25 streams sampled for habitat and Brook Trout population surveys. Mean wetted widths were calculated by field measurements during summer low flow conditions and averaged across a 10 year period. Mean Brook Trout (BKT) abundance was calculated using fall catch data from all streams across a 10 year period. Mean slope, drainage area, elevation, and percent forested land cover were calculated using ArcGIS.

\begin{tabular}{|c|c|c|c|c|c|c|c|c|c|}
\hline Stream & $\begin{array}{c}\text { X coordinate } \\
\text { (UTM zone 17) }\end{array}$ & $\begin{array}{c}\text { Y coordinate } \\
\text { (UTM zone 17) }\end{array}$ & $\begin{array}{c}\text { Mean } \\
\text { slope } \\
(\%)\end{array}$ & $\begin{array}{c}\text { Drainage } \\
\text { area at } \\
\text { sampling } \\
\text { points }\left(\mathbf{k m}^{2}\right)\end{array}$ & $\begin{array}{c}\text { Mean } \\
\text { BKT } \\
\text { abundance } \\
\text { (per 300m } \\
\text { sample) }\end{array}$ & $\begin{array}{c}\text { Mean } \\
\text { wetted } \\
\text { width }(\mathbf{m})\end{array}$ & $\begin{array}{c}\text { Mean } \\
\text { elevation } \\
\quad(\mathbf{m})\end{array}$ & $\begin{array}{l}\text { Flow accumulation } \\
\text { difference with } \\
\text { nearest downstream } \\
\text { tributary (FAC } \\
\text { units) }\end{array}$ & $\begin{array}{c}\text { Percent forested } \\
\text { land cover in } 100 \\
\text { meter riparian } \\
\text { buffer zone }(\%)\end{array}$ \\
\hline Big Run & 625231 & 4284591 & 7.9 & 3.82 & 48.54 & 2.58 & 1155 & 3585 & 98.6 \\
\hline Birch Fork & 579624 & 4284679 & 3.2 & 5.07 & 90.31 & 2.84 & 865 & 2684 & 99.6 \\
\hline Block Run & 609877 & 4254467 & 8.1 & 7.34 & 91.00 & 3.05 & 1023 & 21580 & 99.5 \\
\hline Clubhouse Run & 608000 & 4276916 & 7.8 & 8.09 & 84.31 & 3.22 & 955 & 31441 & 96.7 \\
\hline Crooked Fork & 577008 & 4243148 & 5.4 & 8.36 & 48.23 & 3.28 & 1020 & 9284 & 92.1 \\
\hline Elklick Run & 616186 & 4325943 & 18.1 & 13.65 & 89.00 & 4.04 & 613 & 1462 & 79.4 \\
\hline Elleber Run & 612237 & 4256237 & 19.7 & 5.57 & 108.92 & 2.65 & 1129 & 4395 & 84.5 \\
\hline Lick Run & 613619 & 4270503 & 9.3 & 2.58 & 14.54 & 2.28 & 972 & 7757 & 84.7 \\
\hline Light Run & 580998 & 4288342 & 9.4 & 6.13 & 44.38 & 3.33 & 757 & 22925 & 92.6 \\
\hline Little Branch & 562760 & 4230419 & 6.7 & 1.99 & 56.62 & 1.75 & 1075 & 24797 & 100.0 \\
\hline Little Low Place & 621335 & 4272024 & 13.2 & 5.51 & 128.23 & 1.90 & 970 & 2762 & 90.8 \\
\hline Long Run (Middle Fork) & 579975 & 4296405 & 7.5 & 7.65 & 58.46 & 3.73 & 695 & 4909 & 81.0 \\
\hline North Fork Panther Run & 587712 & 4296977 & 13.4 & 3.60 & 41.00 & 3.85 & 760 & 7720 & 100.0 \\
\hline North Fork Red Run & 626783 & 4324681 & 13.1 & 13.89 & 77.77 & 5.19 & 942 & 5360 & 85.6 \\
\hline Panther Run & 587712 & 4296977 & 8.2 & 5.51 & 71.69 & 3.21 & 755 & 5584 & 100.0 \\
\hline Poca Run & 614393 & 4271844 & 13.6 & 2.53 & 72.00 & 2.31 & 1055 & 4062 & 79.7 \\
\hline Roaring Creek & 580914 & 4286220 & 10.6 & 6.32 & 73.54 & 2.85 & 765 & 15067 & 92.0 \\
\hline Rocky Run & 638548 & 4305844 & 7.5 & 8.44 & 52.31 & 4.54 & 817 & 12410 & 99.1 \\
\hline Sand/Red Run & 562560 & 4230913 & 4.2 & 4.55 & 49.31 & 3.08 & 1065 & 31595 & 100.0 \\
\hline Schoolcraft Run & 582384 & 4290157 & 17 & 7.94 & 54.54 & 4.11 & 736 & 56976 & 94.5 \\
\hline Seneca Creek & 627012 & 4287619 & 12.4 & 5.28 & 42.31 & 2.76 & 1144 & 1550 & 85.0 \\
\hline Sugar Drain & 579500 & 4285621 & 8.5 & 1.73 & 85.54 & 1.91 & 872 & 6436 & 99.4 \\
\hline Whites Run & 631094 & 4301277 & 10.9 & 12.80 & 116.46 & 3.57 & 728 & 47959 & 85.6 \\
\hline Average & & & 10.1 & 7.22 & 69.83 & 3.05 & 893 & 13626 & 91.0 \\
\hline
\end{tabular}


Table 2: Local and regional variables used as potential covariates in data analysis. Data source defined as either collected/calculated in the field or calculated remotely via GIS or other software.

\begin{tabular}{cl}
\hline Variable & Data Source \\
\hline Proportion of Riffle Habitat & Field Collection \\
Proportion of Run Habitat & Field Collection \\
Proportion of Pool Habitat & Field Collection \\
Proportion of Glide Habitat & Field Collection \\
Avg. Max. Pool Depth & Field Collection \\
Avg. Overall Depth & Field Collection \\
Standardized Spawning Area & Field Collection \\
Large Wood Density & Field Collection \\
Overall Brook Trout Density & Field Collection \\
Brook Trout Age Class Densities & Field Collection \\
Brook Trout Body Condition & Field Collection \\
Brook Trout Length & Field Collection \\
Avg. Wetted Width & Field Collection \\
Avg. Bankfull Width & Field Collection \\
Seasonal Water Temperature Avg. & Field Collection \\
Regional & \\
Geologic Unit & Remote Calculation \\
Elevation & Remote Calculation \\
Drainage Area & Remote Calculation \\
Percent Forested Riparian Area & Remote Calculation \\
Seasonal Drought Index Condition & Remote Calculation \\
Flow Accumulation Difference with Tributary & Remote Calculation \\
Distance to Downstream Tributary & Remote Calculation \\
Slope & Remote Calculation \\
\hline
\end{tabular}


Table 3: Significant variables from model set $(n=14)$ for population growth rate, $r$ across all streams in a given year.

\begin{tabular}{cc}
\hline Significant Variable & $\begin{array}{c}\text { Number of } \\
\text { Occurrences in Model } \\
\text { Set }\end{array}$ \\
\hline Age 0 Abundance & 4 \\
Age 1 Abundance & 2 \\
Age 2 Length & 2 \\
Avg. Length & 2 \\
Age 0 Length & 2 \\
Avg. Spawning Area per 100m² & 2 \\
Age 1 Condition & 1 \\
Age 0 Condition & 1 \\
Avg. Condition & 1 \\
Access & 1 \\
Avg. Wet Width & 1 \\
Brook Trout Abundance & 1 \\
Avg. Overall Depth & 1 \\
Avg. Max Pool Depth & 1 \\
\hline
\end{tabular}


Table 4: Significant variables from model set $(n=25)$ for population growth rate, $r$, across all years in a given stream.

\begin{tabular}{cc}
\hline Significant Variable & $\begin{array}{c}\text { Number of } \\
\text { Occurrences in Model } \\
\text { Set }\end{array}$ \\
\hline Brook Trout Abundance & 6 \\
Avg. Length & 5 \\
Age 1 Condition & 3 \\
Age 1 Abundance & 3 \\
Drought Index - Fall & 2 \\
Age 2 Length & 2 \\
Age 0 Length & 2 \\
Age 0 Condition & 2 \\
Drought Index - Fall t-1 & 1 \\
Age 2 Condition & 1 \\
Age 2 Abundance & 1 \\
Age 1 Length & 1 \\
Drought Index - Summer & 1 \\
Drought Index - Summer t-1 & 1 \\
Age 0 Abundance & 1 \\
\hline
\end{tabular}


Table 5: Significant variables from both year and stream model sets $(n=39)$ and either positive or negative association with population growth rate, $r$, in significant model occurrences.

\begin{tabular}{ccc}
\hline Significant Variable & $\begin{array}{c}\text { Number of } \\
\text { Occurrences in } \\
\text { Model Set }\end{array}$ & $\begin{array}{c}\text { Positive or Negative } \\
\text { Association with r }\end{array}$ \\
\hline Avg. Length & 7 & Positive \\
Brook Trout Abundance & 7 & Negative \\
Age 0 Abundance & 5 & Negative \\
Age 1 Abundance & 5 & Negative \\
Age 0 Length & 3 & Positive \\
Age 1 Condition & 3 & Positive \\
Age 0 Condition & 2 & Negative \\
Age 1 Length & 2 & Positive \\
Age 2 Length & 2 & Positive \\
Drought Index - Fall t-1 & 2 & Positive \\
Drought Index - Fall & 2 & Positive \\
Avg. Spawning Area per 100m $\mathrm{m}^{2}$ & 2 & Positive \\
\hline
\end{tabular}


Table 6: AIC results table showing model comparisons for generalized linear models with binomial response of synchronous or asynchronous and logit link function.

\begin{tabular}{|c|c|c|c|c|c|}
\hline Model & $\mathbf{K}$ & $\mathrm{AIC}_{\mathbf{c}}$ & $\begin{array}{c}\text { Delta } \mathrm{AIC}_{c} \\
(\Delta i)\end{array}$ & $\begin{array}{c}\text { Akaike } \\
\text { Weight } \\
\text { (Wi) }\end{array}$ & $\begin{array}{c}\text { Residual } \\
\text { Devianc } \\
\text { e }\end{array}$ \\
\hline Habitat + Fish + Drainage Variables & 9 & 42.18 & 0.00 & 0.72 & 21.23 \\
\hline Habitat + Drainage Variables & 6 & 44.05 & 1.87 & 0.28 & 30.79 \\
\hline Habitat + Fish Variables & 6 & 57.66 & 15.48 & 0.00 & 44.35 \\
\hline Habitat Variables & 3 & 66.80 & 24.61 & 0.00 & 60.45 \\
\hline Fish + Drainage Variables & 7 & 134.42 & 92.24 & 0.00 & 119.94 \\
\hline Drainage Variables & 4 & 143.24 & 101.06 & 0.00 & 135.08 \\
\hline Fish Variables & 4 & 197.84 & 155.66 & 0.00 & 189.67 \\
\hline Intercept Only (Null) & 1 & 221.85 & 179.67 & 0.00 & 219.83 \\
\hline
\end{tabular}


Figure Captions

Figure 1: Population growth rate, r, plotted across time in all 25 sampled streams. Note the predominant trend over time and the individual streams (lines) which differ from this trend, indicating synchrony and asynchrony respectively.

Figure 2: Panel A-) Relationship between age-0 Brook Trout abundance in a given year and the Palmer $\mathrm{Z}$ regional drought index of the previous fall (overall correlation $=0.32$ ). Panel $\mathrm{B}$ ) Relationship between the average Brook Trout Abundance across all streams in a given year and the population growth rate, $r$, of the following year. A significant negative relationship $\left(\mathrm{R}^{2}=0.63, \mathrm{p}<0.01\right)$ is plotted but excludes the dark highlighted point which represents the year class of 2008-2009 which shows the effect of drought on this density-dependence relationship.

Figure 3: Panel A) Example classification tree using classification groups of synchronous "sync" and asynchronous "async" as endpoints and fish variables age-2 length, age-2 abundance, and age- 0 abundance to partition the response. At each node a response of yes moves to the left and response of no moves to the right with the classification rate of each respective group shown as a ratio. Panel B) Results from random forest models of 500 classification trees with variable importance defined by highest mean reduction in the Gini impurity criterion across all trees.

Figure 4: Panel A) Example classification tree using classification groups of synchronous "sync" and asynchronous "async" as endpoints and local habitat variables spawning area and proportion of pool habitat to partition the response. At each node a response of yes moves to the left and response of no moves to the right with the classification rate of each respective group shown as a ratio. Panel B) Results from random forest models of 500 classification trees with variable importance defined by highest mean reduction in the Gini impurity criterion across all trees.

Figure 5: Panel A) Example classification tree using classification groups of synchronous "sync" and asynchronous "async" as endpoints and drainage-scale variables distance to downstream tributary, drainage area, and flow accumulation difference with downstream tributary to partition the response. At each node a response of yes moves to the left and response of no moves to the right with the classification rate of each respective group shown as a ratio. Panel B) Results from random forest models of 500 classification trees with variable importance defined by highest mean reduction in the Gini impurity criterion across all trees.

Figure 6: Logistic plots showing results from GLMs with binomial (logit) link function. Model averaged parameters that showed significant patterns are plotted against the binary response (synchrony) probability as well as their frequency within the dataset. Lines show predicted logistic curves fit to each variable relationship. 
Figures

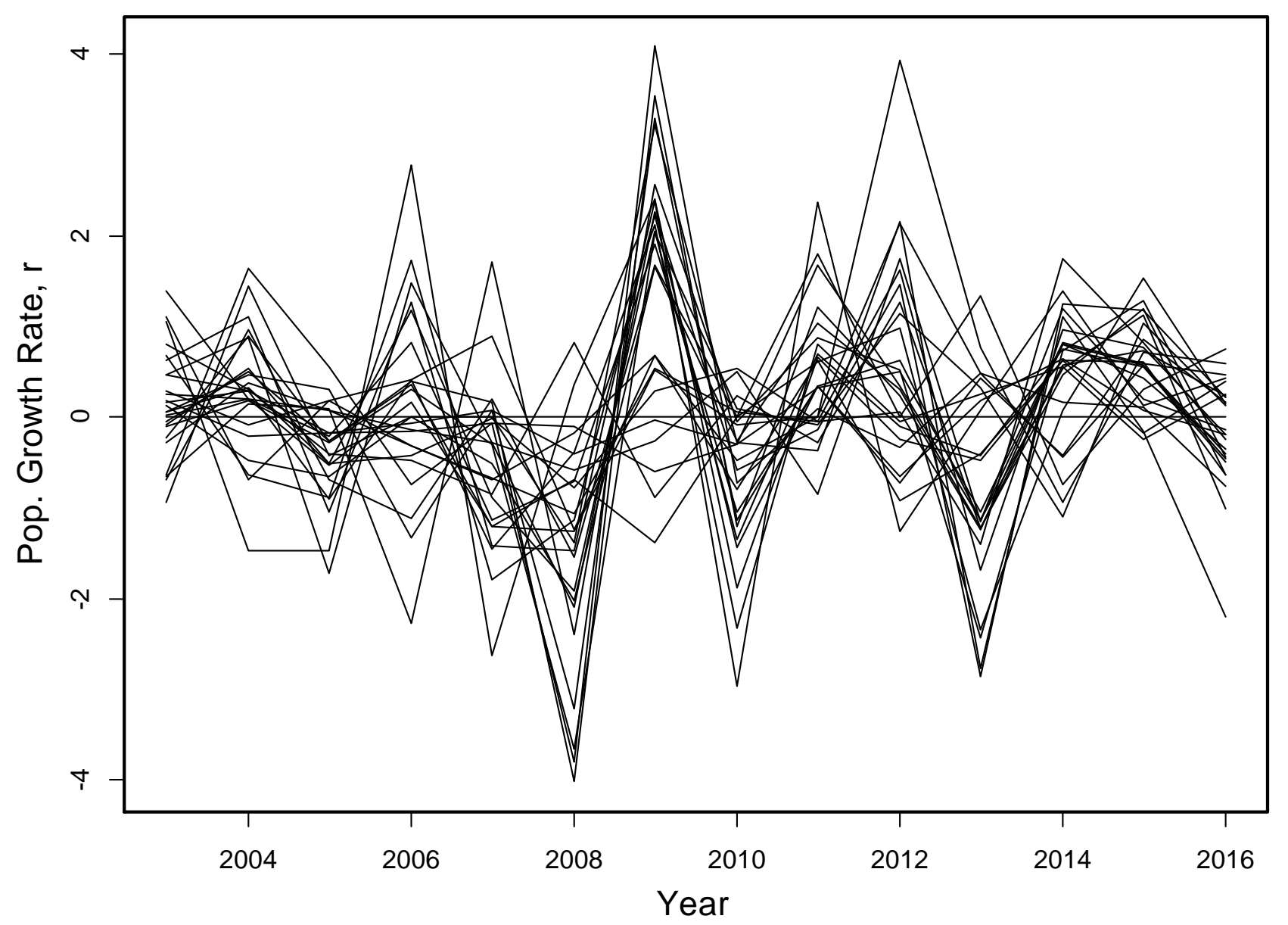

Figure 1 

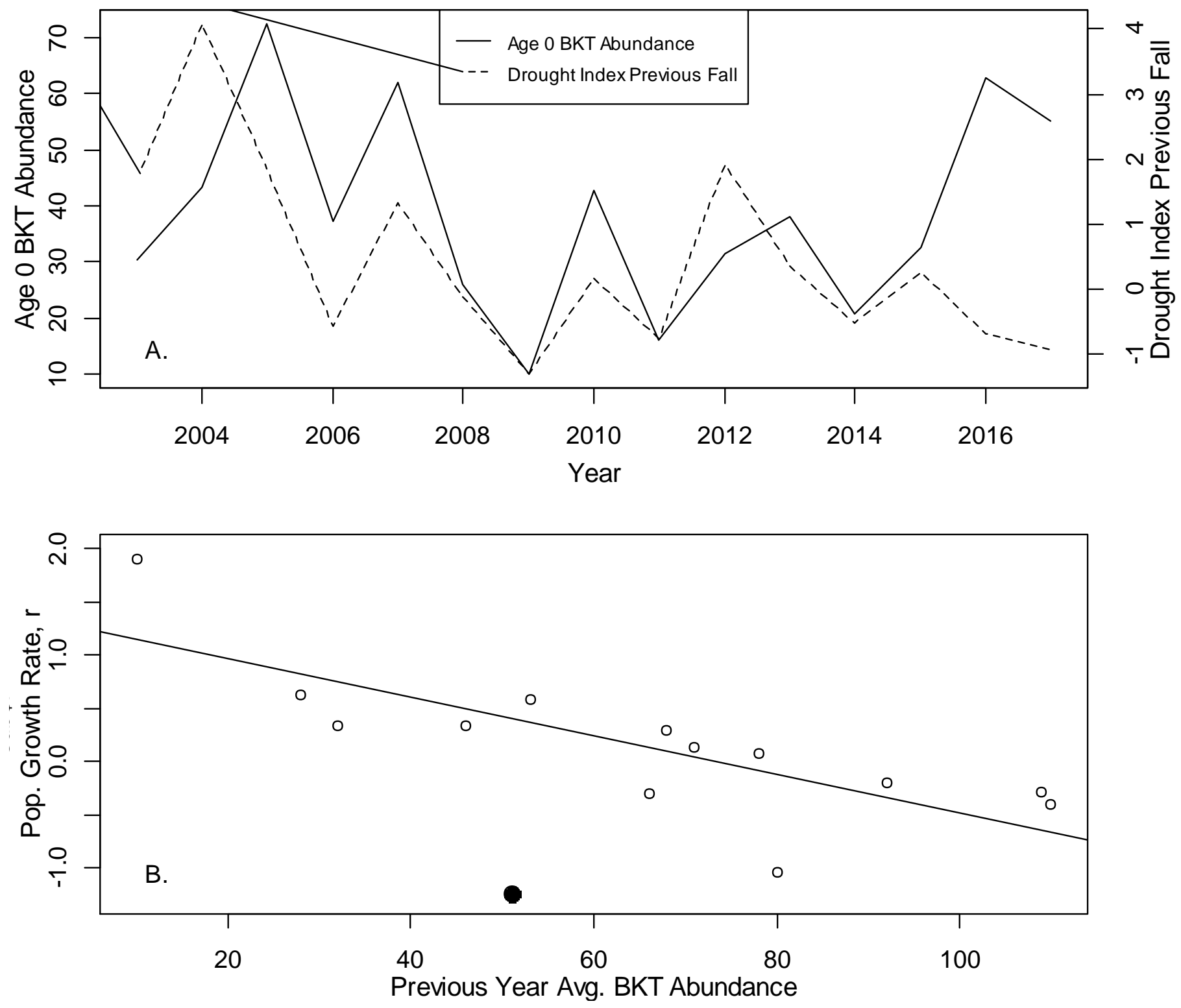

Figure 2 


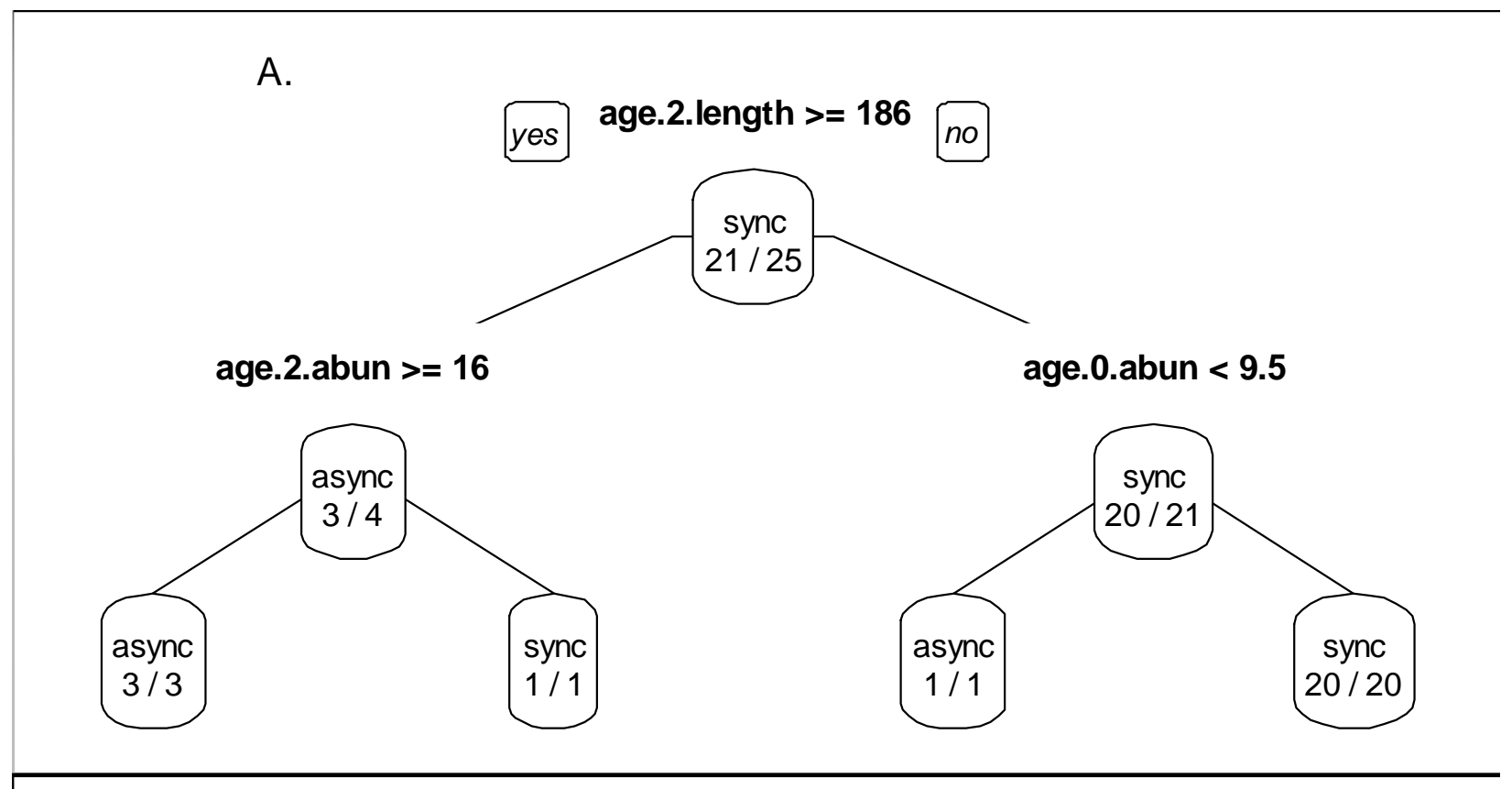

B.

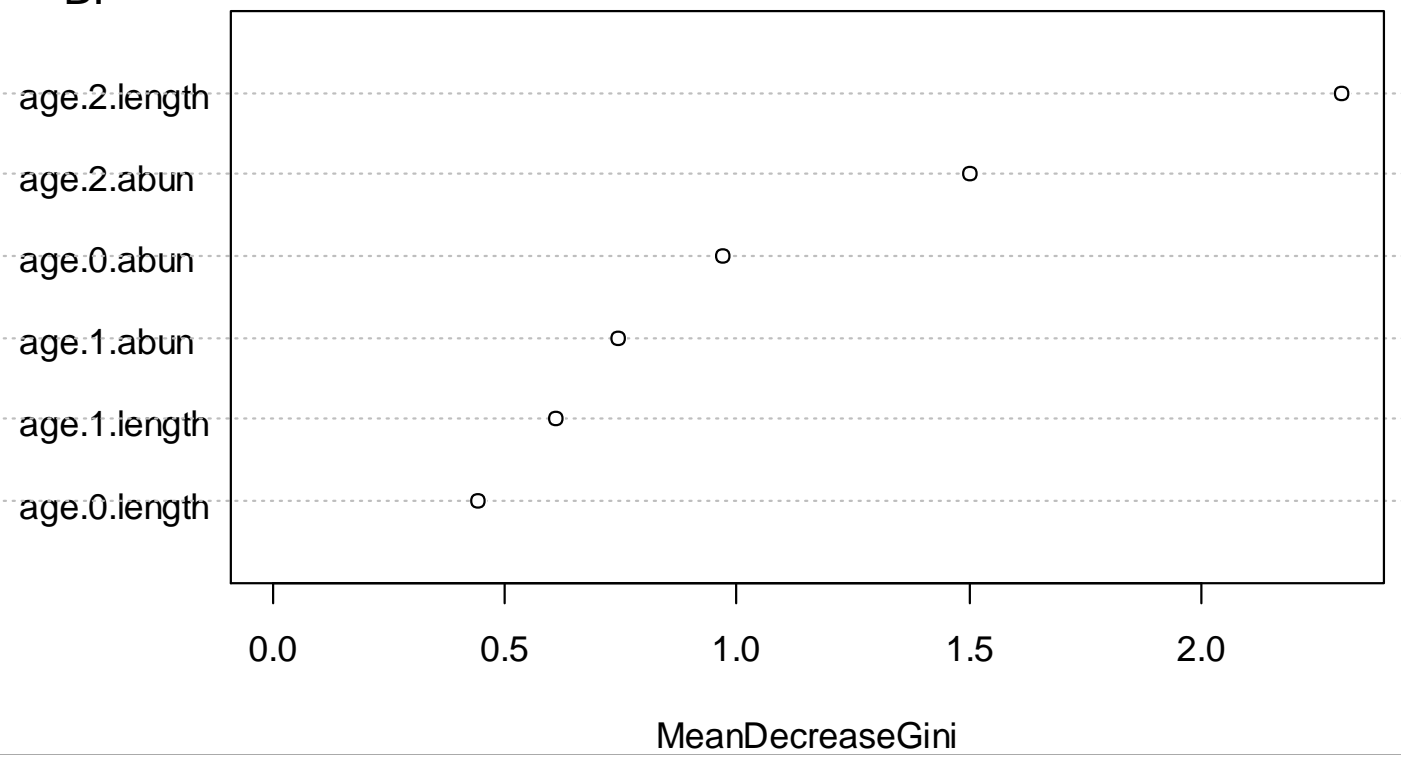

Figure 3 


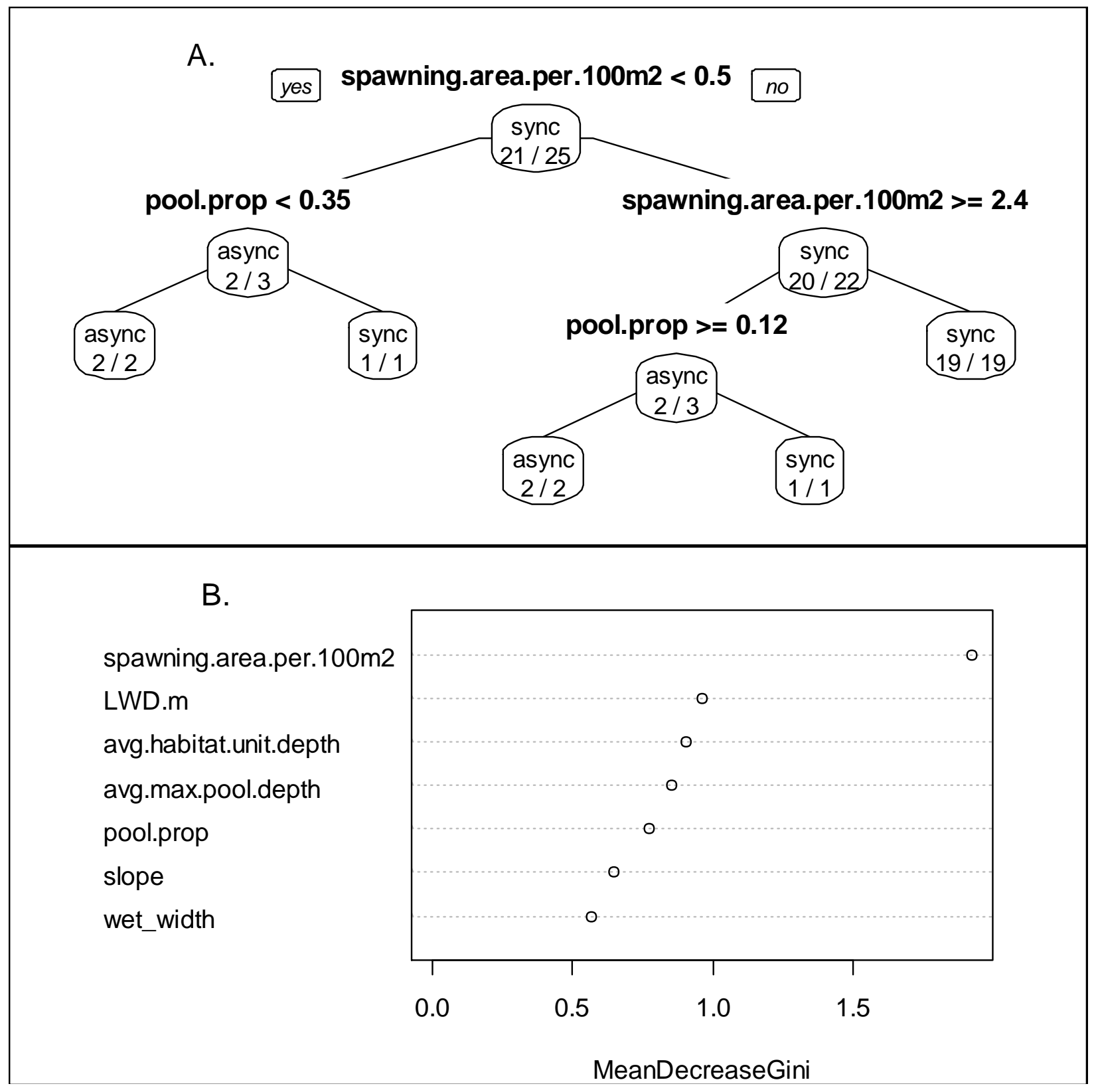

Figure 4 


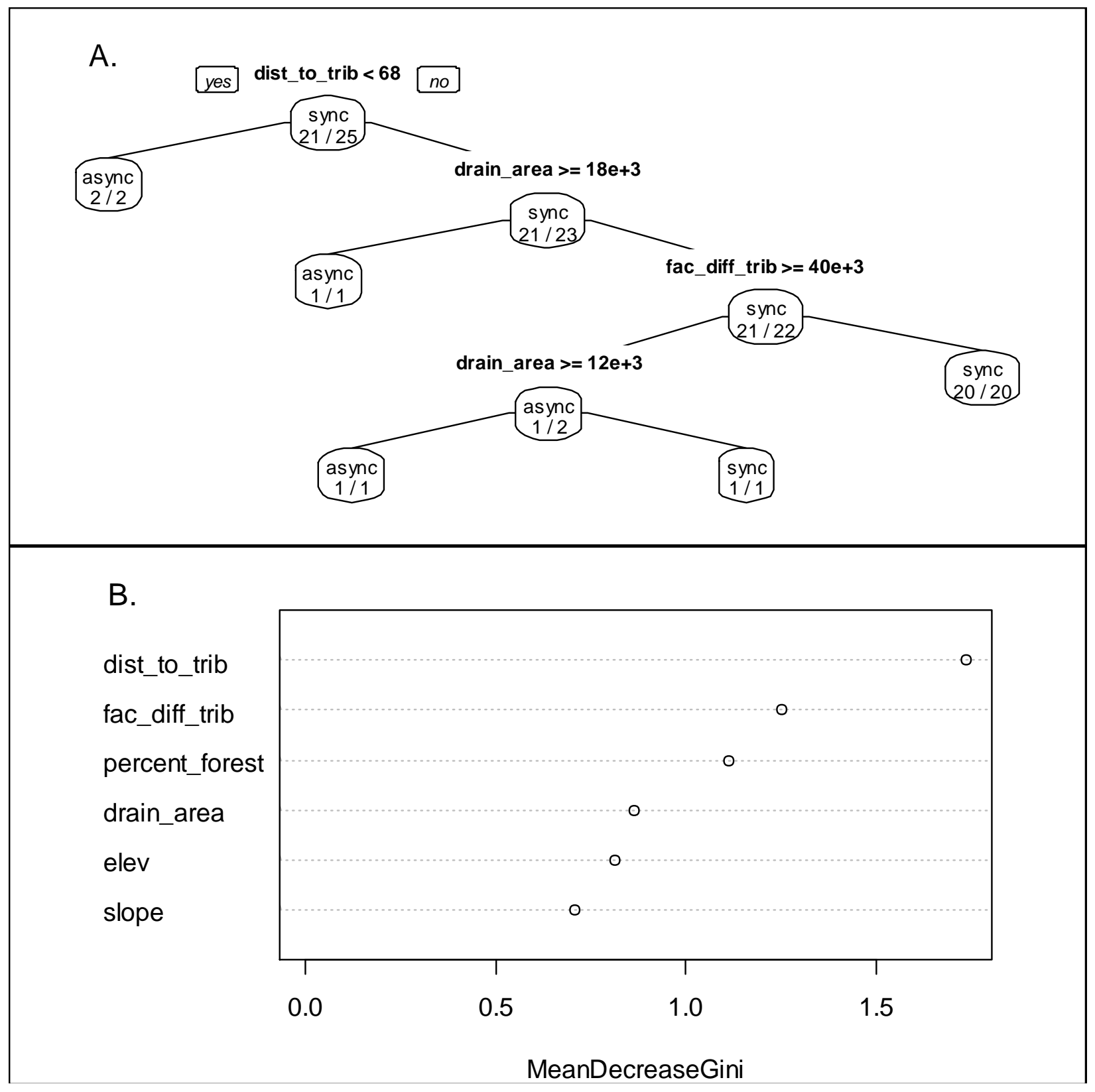

Figure 5 


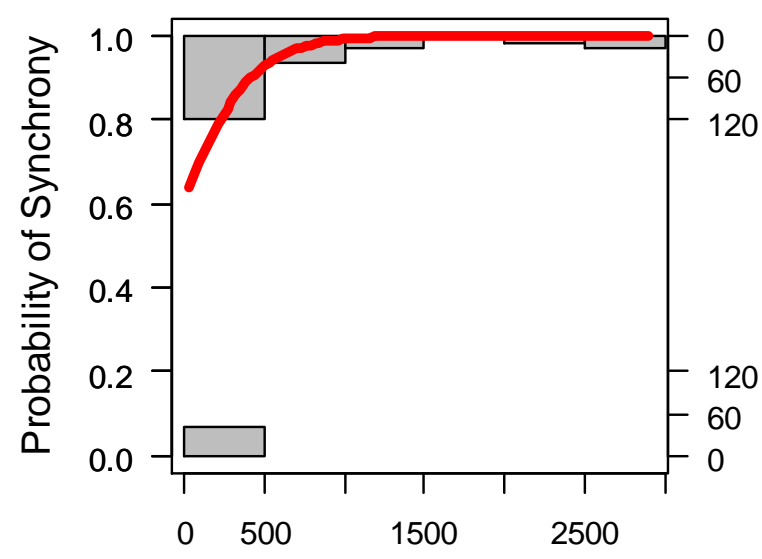

Distance to Downstream Trib (m)

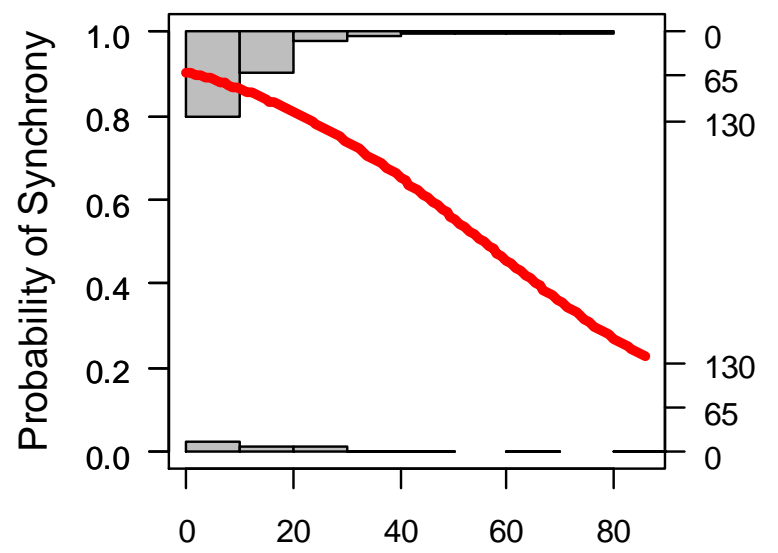

Age Two Fish Abundance

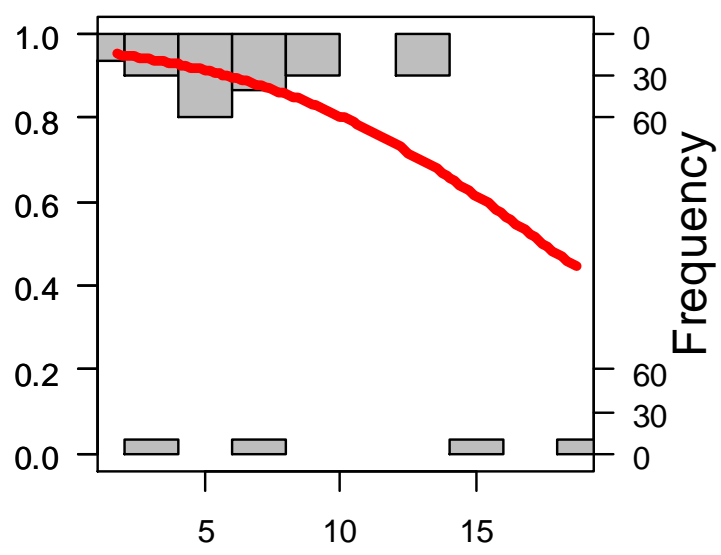

Drainage Area (sq. km)

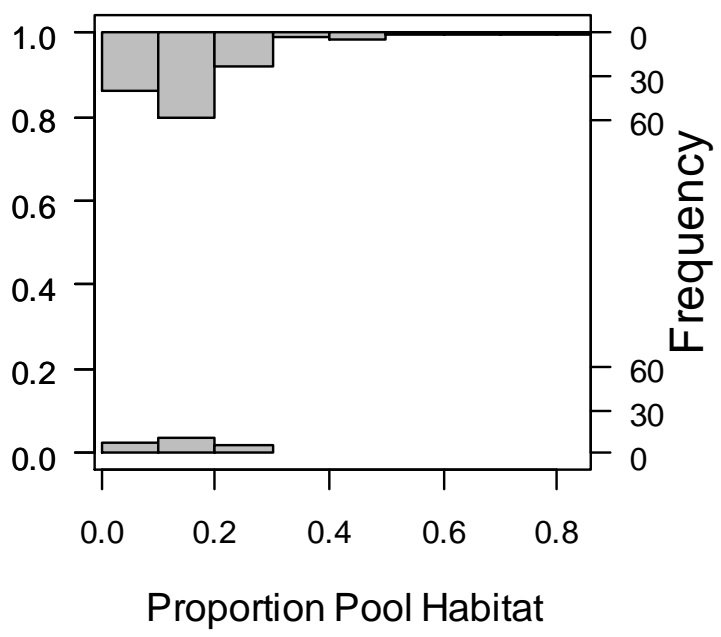

Figure 6 


\title{
Chapter 3: Large Wood Fate, Channel Structure, and Macroinvertebrate Community Characteristics Following Superstorm Sandy in Central Appalachian Headwater Streams
}

\author{
Ross G. Andrew* and Kyle J. Hartman \\ Division of Forestry and Natural Resources, Davis College of Agriculture, Natural Resources, \\ and Design, 322 Percival Hall, West Virginia University, Morgantown, WV 26506-6125, USA \\ *Corresponding author, randrew4@ mix.wvu.edu Ph: (304)-293-0053 Fax: (304) 293-2441
}


Abstract

Impacts from Superstorm Sandy created significant deposition of large wood (LW) in many headwater streams of West Virginia, USA. Following this deposition, fourteen headwater streams were sampled for LW and benthic macroinvertebrates to assess the impact on physical stream habitat and invertebrate communities. Large wood was tagged and tracked for two years following Sandy and benthic macroinvertebrate samples were taken in the same locations across the same time period. Mixed linear models and repeated measures analysis of variance were used to assess the effect of LW density on habitat and invertebrate metrics across sites and years. Non-metric multidimensional scaling ordinations were used to assess the invertebrate communities in each sample year and were compared to a previous sample from 2007 to identify possible community changes following Sandy. Mean large wood movement was significantly ( $p$ $<0.01)$ higher in year one than year two following Sandy (19.7 \& 4.5 meters, respectively) and was only significantly influenced (positively) by drainage area across all samples. Habitat variables such as pool quality and proportion of $16 \mathrm{~mm}$ diameter gravel increased significantly with increasing LW density but a portion of the variance explained came from stream, year, and geologic unit across model sets $(36.2,25.1$, and $9.7 \%$ respectively). Comparisons of habitat variables before and after Sandy showed significant increases in mean pool depth, mean maximum pool depth, and LW density. Macroinvertebrate communities showed no significant change from year one to year two of post-Sandy sampling but did show a significant difference when compared between pre and post-Sandy communities, with the dominant functional feeding groups shifting from grazer pre-Sandy to collector post-Sandy. We conclude that significant additions of LW to central Appalachian headwater streams may help supplement habitat in years immediately following their addition, but may not actually create new habitat units via pool formation. We further recognize the role that LW addition may play in retention of organic matter and production of macroinvertebrates that feed on particulate organic matter within these systems. 
Introduction

Instream habitat forms a basis for understanding potential mechanisms of biotic interactions and behaviors in lotic ecosystems. Stream habitat may be viewed within a framework at multiple spatial scales (Frissell et al. 1986), and with multiple biotic endpoints. Such endpoints include fish density, species richness, diversity (Wang et al. 2001) and macroinvertebrate diversity (Lammert and Allan 1999), among others. Furthermore, the nature of stream habitat changes and stability may alter biotic assemblages (Gorman and Karr, 1978). Understanding the appropriate scale and measures of stream habitat as it relates to the focal endpoint of study remains a challenge in freshwater ecology research (Maddock 1999). Thus, identifying the role of, and response to, large magnitude habitat alteration/supplementation is critical to understanding biotic resilience pathways within stream systems.

A legacy of such habitat alteration exists within many stream systems of the Appalachian region of North America. In the late nineteenth and early twentieth centuries, the timber industry went boom and bust in states like West Virginia and left behind much environmental damage (Lewis 1998). Common impacts included "...fire, flood, erosion, and the silting and polluting of once pure streams.." (Lewis 1998) in many mountain streams of the region during this period. Since the period of unregulated disturbance, regulation for forestry activities using best management practices (BMPs) has increased (WVDOF 1986) following the federal Clean Water Act of 1972. Also, the logging sediment control act (LSCA) in 1992 set up logger licensing, certification, and enforcement programs to ensure cooperation with BMPs (Wang et al. 2004). 
Evaluation of the effectiveness of regulated BMPs has shown the importance of proper road construction to minimize runoff (Kochenderfer et al. 1997) as well as the use of buffer strips to capture and reduce fine sediment runoff into streams (Aubertin and Patrick 1974). Other research has found effects on sediment deposition and aquatic macroinvertebrate communities following forestry practices. Davies and Nelson (1993) found that logged watersheds had significantly more fine sediment $(125-500 \mu \mathrm{m})$ than unlogged watersheds. These researchers also found road crossings to contribute to fine sediment infiltration to hyporheos over long time periods (30-50 years post construction). In streams that are protected from logging activities by wide buffer strips rather than thin buffer strips or no buffer strips at all, more diverse macroinvertebrate communities may be found (Newbold et al. 1980). These management practices, along with natural forest succession have produced differing states of recovery within stream systems across the region.

One major issue with stream habitat recovery is the lack of channel structure previously formed with the help of large wood (LW) pieces. Previous research shows LW is important for creating habitat and cover for fish and creating channel heterogeneity which helps production of macroinvertebrates and other components of aquatic food webs. Complex LW snags hold more macroinvertebrates with higher richness and evenness (O'Connor 1990). Furthermore, Fausch and Northcote (1992) found that higher habitat complexity featuring more LW and more pool depth/area led to more biomass of salmonids in headwater streams. Management efforts often use LW as a way to improve habitat in impacted streams as a way to work towards restoration to the old growth state. These additions of LW have been shown to increase habitat complexity along with richness and abundance of aquatic macroinvertebrates (Gerhard and Reich 2000). 
Furthermore, LW addition has been shown to improve fish biomass and richness in some streams (Shields et al. 2006).

Addition of LW into small streams may have variable effects, depending on the manner in which the LW is deposited and positioned within the channel (Kail et al. 2007). These differences could influence the retention and functionality of the LW within the stream, causing different biotic responses. Often, additions of LW are most successful at creating desirable habitat features when they mimic natural wood additions (Kail et al. 2007). However, understanding how natural LW additions behave and function can be challenging due to the variable timing and magnitude of such events. Large magnitude wood additions that occur naturally can be rare, and identifying the effects following such events may help guide management efforts which seek to emulate such events for habitat improvement. One such natural wood addition occurred following hurricane Sandy in 2012 in the mountains of West Virginia (Andrew and Hartman 2015). This unusual event produced dramatic increases (up to $195 \%$ change from previous years) of LW loading in some headwater streams (Andrew and Hartman 2015). Although this large disturbance produced a significant amount of LW addition to these streams, the retention and function of the LW was unknown.

The retention and function of LW must be considered as it pertains to both channel and biotic features of the system. Channel substrate and stability has been shown to greatly affect the retention of LW and its effectiveness at providing habitat for organisms (Shields et al. 2006). Large wood may modify water flow, creating areas of increased or decreased flow rate that ultimately changes microhabitat structure for biota (Dolloff and Melvin 2003). However, without retention and functional incorporation to the channel structure, newly added LW cannot provide habitat benefits. Furthermore, some climate change scenarios predict an increase in the 
frequency and magnitude of disturbances like hurricane Sandy (Bender et al. 2010), so understanding the initial behavior of LW within the channel may offer a useful foundation to understanding future impacts or benefits to these aquatic communities.

Focusing on 14 headwater streams which were impacted by LW loading from hurricane Sandy in West Virginia, this study seeks to quantify variables related to both LW retention and function. Specifically, LW movement rates, LW channel positions, channel morphology characteristics, and aquatic macroinvertebrate community characteristics are investigated in detail for each stream following the disturbance.

\section{Methods}

\section{Study Sites and Field Sampling}

Fourteen headwater streams in the mountainous region of eastern West Virginia were selected for this study. The selected streams have all been surveyed as part of a long-term monitoring and inventory project since 2003 which provides detailed habitat information with respect to width, depth, substrate, and other basinwide visual survey variables (Table 1). The sample streams were selected based upon variation in their elevation, slope, underlying geologic unit, and LW loading following hurricane Sandy in late 2012 (Table 1). Immediately following the melt of snow and ice from the streams in spring and summer 2013, each stream was sampled for LW density and aquatic macroinvertebrates. Large wood was identified as either newly added (by Sandy) or previously present (before Sandy) based upon the easily identifiable fresh appearance of the newly added wood. Within a randomly selected 500 meter reach of each stream, all pieces of $\mathrm{LW}(\geq 1 \mathrm{~m}$ length and $5 \mathrm{~cm}$ diameter) were double tagged with unique numerical metal tags and secured with galvanized metal nails. The location and position of each piece of tagged wood was also recorded at the time of tagging. Therefore, in subsequent sampling events, changes in movement and position could be recorded. Also during the spring 
and summer of 2013 and 2014, within each 500 meter sampling section, macroinvertebrates were sampled using a $0.25 \mathrm{~m}^{2}$ kicknet with attached 500 micron mesh collection chamber following procedures outlined by the West Virginia Department of Environmental Protection Watershed Assessment Program and United States Environmental Protection Agency Rapid Bioassessment Protocols for wadeable streams (WVDEP 2003; Barbour et al. 1999). At each sample site, four random habitat units were sampled and combined to create one complete $1 \mathrm{~m}^{2}$ sample and preserved in $85 \%$ ethanol for analysis and identification in the lab.

\section{Laboratory Methods and Analysis}

Macroinvertebrate specimens were separated from debris using a dissecting microscope and further preserved in $85 \%$ ethanol to be identified. Each substrate sample was picked randomly with the goal of $200 \pm 20$ individual macroinvertebrates per sample in accordance with the West Virginia Department of Environmental Protection standard sampling protocols for macroinvertebrates mentioned above. Each macroinvertebrate was identified to genus (family when genus identification was not possible) using dichotomous keys (Merritt and Cummins, 1996).

Habitat variables were initially analyzed using the full dataset period (beginning in 2003) with respect to changes in response variables driven by the explanatory variable of LW density per $100 \mathrm{~m}^{2}$ of sampled stream area. The response variables used were proportion of pool habitat, proportion of pools formed by LW, maximum pool depth, spawning area per $100 \mathrm{~m}^{2}$ of sampled pool area, and pool quality (product of pool size and fish cover standardized by area sampled). Linear mixed models were built using the package "Ime4" in statistical program R (R Development Core Team 2008). Models were constructed to hold each stream as a random effect in one set and each year as a random effect in another set. This was done to create 
grouping variables due to the repeated sampling done in these streams across years and years across streams. Repeated measures analysis of variance was also used in order to assess the statistical differences in habitat variables across all years where detailed sample information could be found. Additional error terms for the variance accounted for by individual streams and underlying geology was added to the repeated measures ANOVA. Years prior to 2012 in the habitat surveys were classified as pre-hurricane Sandy and compared to years after using t-tests and nonparametric equivalents as appropriate.

Movement of tagged LW pieces was analyzed using linear regression with mean movement as the response variable and watershed variables of slope, elevation, geologic unit, and drainage area as explanatory variables. Local habitat variables of LW density and average bankfull width within the tagging section were also included as explanatory variables. Habitat type and position of LW pieces was also quantified and described in summary.

Macroinvertebrate metrics such as richness, percentage of Ephemeroptera, Plecoptera, and Trichoptera (EPT), and West Virginia Stream Condition Index (WVSCI) were compared between a set of previous samples in these streams from a spring 2007 study (Stolarski 2007) and the current samples from 2013 and 2014 using analysis of variance. Additionally, metrics such as the number of shredder and clinger genera and the Genus Level Index of Most Probable Stream Status (GLIMPSS) were calculated and compared for the current samples using the same linear mixed model approach outlined above. Finally, the taxa were ordinated using a nonmetric multidimensional scaling (NMDS) procedure using the package "vegan" in the statistical program R. Sites were plotted within two dimensions grouped by habitat or taxa variables. Taxa and habitat vectors were created and plotted with alpha level 0.05 following 999 permutations to create linear factor averages for explanatory variables. Ordinations were created at the family 
and genus level for the current samples and the family level for the samples from the previous 2007 study. Comparison of the family level ordinations from 2007 and 2013-2014 sample was conducted with a Procrustes test within the package "vegan" which assessed significance of multivariate correlation of the dissimilarity matrices across permutation tests. A Hellinger transformation (Legendre and Gallagher 2001) was used to account for abundance differences between 2007 and 2013-2014 samples due to slight differences in sample techniques. The 2007 samples were picked and identified using a census technique rather than the subsample technique we used and therefore abundances had to be standardized with the transformation to get a suitable comparison.

Results

Within the fourteen streams with tagged LW pieces, 484 pieces were tagged in summer 2013 with an average of 34.6 pieces per 500 meter section of each stream (Table 1). In 2014 sampling, 384 pieces were found and identified within the original 500 meter section and additional 300 meter downstream sampling zone. The 2015 sampling found 305 pieces within the same zones. Across all streams and years, LW pieces moved an average of 13 meters with a range of 0-585.6 meters. Pieces moved an average of 24.7 meters when they moved from a pool to a riffle and 46.7 meters when they moved from a riffle to a pool $(\mathrm{p}=0.32)$. In the first year of sampling, LW pieces moved an average of 19.7 meters with a range of 0-585.6 meters and in the second year of sampling, LW pieces moved an average of 4.5 meters with a range of 0-116 meters. Movement was significantly higher in year one than year two for all pieces of LW ( $\mathrm{p}<$ 0.01). In year one, new pieces of LW moved an average of 24.8 meters while old pieces moved an average of 18.2 meters $(\mathrm{p}=0.41)$. In year two, new pieces moved an average of 6.9 meters while old pieces moved an average of 3.8 meters $(p=0.049)$. Drainage area $(4.91$ meters of LW 
movement per additional $\mathrm{km}^{2}$ drainage area \pm 1.46 ; $\left.\mathrm{p}<0.01\right)$ was the only significant watershed variable that influenced LW movement across our sampling (Figure 1). Estimated mean flow at the time of habitat sampling (Z. Zacavish, unpublished data) was compared across sites for years 2012-2014 using analysis of variance and showed no significant difference $(\mathrm{p}=0.07)$. While non-significant, modeled flow estimates for the year 2013 were approximately 2.5 times higher than 2012 and 2014 averages (6.31 versus 2.49 cubic feet per second, respectively) which could have positively influenced movement rates in the first year after tagging.

The mixed model regressions with the random effect of stream as the grouping variable and fixed effect of LW pieces per $100 \mathrm{~m}^{2}$ of stream showed little significance for the fixed effect of LW density across most habitat response variables (Table 2). Negative coefficients for proportion of pools (-0.06) and proportion of pools formed by LW (-0.07) were significant but very close to zero. Significant positive coefficients for pool quality (0.129) and proportion of 16 millimeter gravel (0.01) were also very small. On average, $36.2 \%$ of the variance explained in habitat response variables came from the random effect of stream. The same set of mixed models with random effect changed to year instead of stream produced no significant results for the fixed effect of LW density (Table 3). On average, $25.1 \%$ of the variance explained came from the random effect of year in this set of models. A final set of mixed models using geologic unit as the random effect showed significant negative coefficients for proportion of pools (0.064) and proportion of pools formed by LW (-0.07) but were also very close to zero (Table 4). The only significant positive correlation was with proportion of 32 millimeter gravel (0.027). On average, only $9.7 \%$ of the variance explained in this set of models came from the random effect of geologic unit. 
When testing the habitat variables themselves over time, the effect of year was significant with respect to mean depth (Figure 2), mean maximum pool depth (Figure 3), and proportion of pool habitat (Figure 4; all $p<0.001$ ). The effect of stream was significant with respect to LW density $(\mathrm{p}=0.03)$ and proportion of pool habitat $(\mathrm{p}<0.01)$. The effect of geologic unit was significant with respect to proportion of pool habitat (Figure 6; $\mathrm{p}<0.001$ ), spawning area (Figure 7; $\mathrm{p}<0.001$ ), mean maximum pool depth (Figure 8; $<<0.001$ ), mean depth (Figure 9; $\mathrm{p}<$ 0.001), and proportion of LW formed pools (Figure 10; $\mathrm{p}<0.001$ ). When comparing pre and post-hurricane Sandy groups, mean depth, mean maximum pool depth, and LW density per $100 \mathrm{~m}^{2}$ all increased significantly (Table 5). Substrate samples were also analyzed pre and postSandy and significant increases occurred post-Sandy for the $2 \mathrm{~mm}, 1 \mathrm{~mm}, 0.25 \mathrm{~mm}$, and fines size classes. Significant decreases occurred for the 0.12 and $0.06 \mathrm{~mm}$ size classes (Table 5).

The mixed model regressions with the random effect of stream as the grouping variable and fixed effect of LW pieces per $100 \mathrm{~m}^{2}$ of stream showed little significance for the fixed effect of LW density across all macroinvertebrate response variables (Table 6). On average, $21.8 \%$ of the variance explained in macroinvertebrate response variables came from the random effect of stream. Ordination on the 2013-2014 macroinvertebrate samples was first done within two dimensions of habitat space with a final stress of 0.08 . The significant $(\mathrm{p}<0.05)$ vectors for habitat variables included LW density, slope, elevation, drainage area, mean pool depth, and mean wetted width. Macroinvertebrate genera vectors with significant relationships were plotted over the sites with a surface fit of drainage area to describe the visual trend (Figure 11). A second ordination of the 2013-2014 macroinvertebrate samples was done within two dimensions of taxa space with a final stress of 0.18 . Ellipses which show $95 \%$ confidence intervals of each year were drawn to illustrate the significant overlap between these two sample sets (Figure 12). 
Furthermore, a Procrustes test was used to assess the multivariate correlation through permutations of the two groups (ran as separate ordinations but using the same data for the purposes of the test code requirements) and showed a symmetric Procrustes rotation correlation of $0.56(\mathrm{p}=0.001)$ across 999 permutations.

Direct comparisons using analysis of variance for macroinvertrebrate metrics between the 2007 samples and the 2013/2014 samples yielded no significant differences for percentage of EPT taxa $(p=0.53)$, EPT richness $(p=0.73)$, family richness $(p=0.06)$, modified Hilsenhoff index $(\mathrm{p}=0.59)$, and WVSCI $(\mathrm{p}=0.82)$. A third ordination was done which compared the 2007 and 2013-2014 macroinvertebrate samples at the family level (for equal comparison) within two dimensions of taxa space with a final stress of 0.19 . Ellipses which show $95 \%$ confidence intervals of each year were drawn to illustrate the lack of significant overlap between these two sample sets (Figure 13). An additional Procrustes test was used to assess the multivariate correlation through permutations of the two groups (ran as separate ordinations but using the same data for the purposes of the test code requirements) and showed a symmetric Procrustes rotation correlation of $0.18(\mathrm{p}=0.41)$ across 999 permutations. Linear vectors were fit to the taxa dimension and assessed for significance over 999 permutations. The significant $(\mathrm{p}<0.05)$ vectors for macroinvertebrate variables included several families plotted with length of the vector associated with relationship strength (Figure 14).

\section{Discussion}

Movement of LW in mountain streams may be variable based upon the conditions of individual streams. We found LW movement in all of our study streams, with larger movement rates occurring in streams of higher drainage area. A study of LW movement in upstate New York found 25 percent of LW pieces to move greater than five meters over a four year period 
(Warren and Kraft 2008). This study was done on a stream with a drainage area of $7.4 \mathrm{~km}^{2}$, which closely approximates our average drainage area. Across the two years of our study, we found 56 and 21 percent of LW pieces to move greater than 5 meters, respectively. The contribution of higher movement rates in streams of larger drainage areas may account for the initial difference, and has been observed in western North American streams as well (Martin and Benda 2001). The higher movement rates we observed in the first year suggest there could be a settling period for newly added LW pieces in these streams. Warren et al. (2007) found less debris dams containing LW in forests of intermediate age in New Hampshire. Given the history of logging and forest disturbance in these watersheds of West Virginia, it is reasonable to suggest the streams are experiencing an intermediate condition with less debris jams and therefore less initial LW retention. Furthermore, new LW pieces moved more than old pieces in both sample years. While non-significant, this pattern adds evidence to the settling period that newly added LW pieces may undergo within the first year in a stream channel.

Documented additions and subsequent retention of LW in these streams did not dramatically influence measured habitat variables consistently. Sweka and Hartman (2006) found experimental additions of LW to similar streams having only a mild effect with increasing number of pools but not area of pools. These authors suggest that three years of post-addition surveying may not be adequate to capture the time required to enact change in measured stream habitat. Furthermore, a later study of the same systems noted no significant changes even after six years following the LW additions and concluded that habitat within high gradient streams may be more influenced by boulders rather than LW presence (Sweka et al. 2010). While some stream habitat variables did show increases or decreases with increasing LW density, most did not change significantly. New LW pieces are potentially only acting to supplement existing 
habitat, as shown by the significant increases of average and maximum pool depth with increasing LW density, but no significant increase in proportion of pool habitats overall. A coastal Oregon stream saw increases in pool depth, area, and number after strategic additions of LW structures (Crispin et al. 1993). The difference in human-added LW structures versus naturally added LW pieces could account for the change in creation of pools while it seems any type of LW addition may show habitat supplementation. Additionally, increased retention of some larger ( $<32$ and $<16 \mathrm{~mm}$ ) gravel sizes with increasing LW density shows potential for pool improvement, rather than creation, within these streams.

Across time, the underlying geology of these streams seemed to be the best indicator of habitat differences. This follows the hierarchical description of stream habitat at the reach scale described by Frissell et al. (1986) while the pool/riffle or microhabitat scales may be more influenced by inputs of wood or annual sediment transport. In high gradient streams much like ours, LW has been shown to have little effect on creating channel changes (Hilderbrand et al. 1997). Individually, unique stream characteristics have been shown to account for over $80 \%$ of the variation in measured habitat variables in mountain streams (Roper et al. 2003). Bisson et al. (2003) echoed this sentiment as the effects of LW addition were found to be difficult to separate from local biophysical conditions in western North American rivers. While our mixed models showed less than $80 \%$ variation explained by stream, year, and geology as they relate to habitat variables, it is worth noting that this variation exists and can play an important role in structuring habitat conditions within streams.

Addition of LW has been documented as a form of restoration of stream habitat in many areas of the world (Gerhard and Reich 2000; Kail et al. 2007). Often, these structures are put into streams with specific placement objectives and anchoring in order to achieve a certain result. 
This engineering-based approach has been shown to have success (Gowan and Fausch 1996) and failure (Frissell and Nawa 1992), depending on the project. A "soft engineering" approach using more natural placement of LW within channels has been shown to retain greater than $80 \%$ of LW structures across a wide array of natural flow regimes (Roper et al. 1998). Our study focused on naturally placed LW following the disturbance of hurricane Sandy, causing many pieces to enter the channel via wind throw and slope instability due to heavy snow. Because of this natural addition, many pieces did not directly enter the water but rather laid across the bankfull channel near the surface of the water. In this way, they may still provide some benefit in terms of capturing other mobile debris but be less susceptible to removal via high discharge themselves. Furthermore, the idea of one large disturbance event and (subsequent LW deposition) being enough to alter habitat in streams which have been deprived of LW loading since heavy timber harvest in the early twentieth century is optimistic. This addition of LW should therefore be considered a supplement to the existing habitat and a step towards the old-growth state that existed hundreds of years ago.

The use of macroinvertebrate taxa to examine the effects of LW addition and associated habitat alteration in small streams has shown promising results previously. In small streams of Minnesota and Michigan, macroinvertebrate richness increased at sites which contained LW pieces (Johnson et al. 2003). In southwestern Virginia headwater streams, additions of LW significantly changed the net abundance of macroinvertebrate taxa in specific habitats (Hilderbrand et al. 1997). We were unable to detect any differences between the 2007 and 2013 and 2014 macroinvertebrate samples using summary metrics. Also, we investigated the community gradients associated with both habitat features and macroinvertebrate taxa and found no significant change between samples in 2013 and 2014 following the LW additions. However, 
the comparison of the same streams using samples from 2007 showed a significant difference in the community ordination. The length of the linear association vector for each ordination indicates the strength of the relationship and which taxa were generally driving the separation of groups between 2007 and 2013-2014. These indicate a shift from the 2007 samples being more associated with scraper taxa and the 2013-2014 samples more associated with collector-gatherers and collector-filterers. While scraper taxa feed primarily on attached periphyton or algae on substrate, collector gatherers and filterers feed on fine particulate organic matter (FPOM; particle size <1mm) (Wallace and Webster 1996). Fine particulate organic matter is the result of processed coarse particular organic matter $(\mathrm{CPOM} ;>1 \mathrm{~mm})$ which occurs via the feeding of shredders on decomposing plant material and woody biomass (Wallace and Webster 1996). Therefore, a community transition from heavy association with scrapers to heavy association with collectors may indicate these systems have a higher capacity for retention of organic matter at the coarse level (leaf litter) which produces more FPOM.

This study included several limitations and assumptions based upon the sampling and analyses. First, all habitat was sampled at low flow conditions during summer which provides a conservative estimate of variables like pool size, available spawning substrate, and others which may increase with increasing water volume. Also, some pieces of LW were either buried by deposition of substrate or removed from the channel by humans (personal observations in the field). These pieces were removed from analyses but other pieces that were not directly observed may have similar fates that were unaccounted for by our sampling. Benthic macroinvertebrates were only sampled in mineral substrates of riffles; leaf packs and deeper water areas of pools were not sampled. While some streams of lower gradient and elevation have shown macroinvertebrate production more associated with LW pieces (Benke et al. 1984), 
most of the LW in this study was not deeply submerged in the water during low flow sampling periods. While our sampling may have excluded some part of the macroinvertebrate community, the sampling we conducted was focused on capturing the production of important taxa that would show the effects of LW addition through their elevated role and dominance in the community.

Physical factors such a slope, geologic unit, and discharge are commonly understood to define habitat structure and distribution within flowing river systems (Frissell et al. 1986; Aadland 1993). However, the addition of large wood may offer enough of a supplementary effect to improve existing habitat structures in small streams. Here we provide evidence for such an effect in first and second order streams of the Central Appalachian Mountains. Significant additions of large wood resulted in downstream transport of some pieces, but incorporation into channel structure of others. Those pieces that were retained within sample sections presumably aided in retention of some biologically useful sediment and helped create deeper water across habitats. Additionally, we describe some shifts in benthic macroinvertebrate community dynamics following the LW addition that lend support to the idea of increasingly effective retention of organic matter with the LW supplementation. This disturbance was natural and compares well with actions often emulated by natural resource managers that seek improvement in habitat structure and function. We recommend the continued study of habitat supplementation by both natural and artificial sources in order to better understand the dynamics of both abiotic and biotic endpoints that benefit from such supplements. Better understanding of these endpoints as they respond to habitat changes may improve readiness for challenging management scenarios into the future with respect to sensitive habitats and communities. 
Literature Cited

Aadland, L. 1993. Stream Habitat Types: Their Fish Assemblages and Relationship to Flow.

North American Journal of Fisheries Management 13(4):790-806.Aubertin, G. M., and J. H. Patric. 1974. Water quality after clearcutting a small watershed in West Virginia. Journal of Environmental Quality, 3(3): 243-249.

Barbour, M. T., J. Gerritsen, B. D. Snyder, AND J. B. Stribling. 1999. Rapid bioassessment protocols for use in streams and wadeable rivers: periphyton, benthic macroinvertebrates, and fish. 2nd edition. EPA 841-B-99-022. Office of Water, US Environmental Protection Agency, Washington, DC.

Bender, M. A., T. R. Knutson, R. E. Tuleya, J. J. Sirutis, G. A. Vecchi, S. T. Garner, and I. M. Held. 2010. Modeled Impact of Anthropogenic Warming on the Frequency of Intense Atlantic Hurricanes. Science 327:454-459.

Bisson, P. and S. M. V. 2003. Trends in Using Wood to Restore Aquatic Habitats. Pages: 391406 in American Fisheries Society Symposium 37.

Crispin, V. A. L., R. House, D. Roberts, L. Management, and S. District. 1993. Changes in Instream Habitat, Large Woody Debris, and Salmon Habitat after the Restructuring of a Coastal Oregon Stream. North American Journal of Fisheries Management 13:96-102.

Davies, P. E., M. Nelson, I. Fisheries, and C. Dave. 1993. The effect of steep slope logging on fine sediment infiltration into the beds of ephemeral and perennial streams of the Dazzler Range , Tasmania , Australia. Journal of Hydrology 150:481-504.

Dolloff, C. A., and M. L. W. 2003. Fish Relationships with Large Wood in Small Streams. Pages: 179-193 in American Fisheries Society Symposium 37.

Fausch, Kurt D, and M. R. 1992. Large Woody Debris and Salmonid Habitat in a Small Coastal British Columbia Stream. Canadian Journal of Fisheries and Aquatic Sciences 49(4):682693.

Frissell, C. A., W. J. Liss, C. E. Warren, and M. D. Hurley. 1986. A Hierarchical Framework for Stream Habitat Classification : Viewing Streams in a Watershed Context. Environmental Management 10(2):199-214.

Frissell, C. A., and R. K. Nawa. 1992. Incidence and Causes of Physical Failure of Artificial Habitat Structures in Streams of Western Oregon and Washington. North American Journal of Fisheries Management 12:182-197.

Gerhard, M., Reich, M. 2000. Restoration of Streams with Large Wood : Effects of Accumulated and Built-in Wood on Channel Morphology, Habitat Diversity and Aquatic Fauna. International Review of Hydrobiology 85(1): 123-137. 
Gowan, C., and K. D. Fausch. 1996. Long-Term Demographic Responses of Trout Populations to Habitat Manipulation in six Colorado Streams. Ecological Applications 6(3):931-946.

Hedman, Craig W., Van Lear, David H., Swank, W. T. 1996. In-stream large woody debris loading and riparian forest seral stage associations in the southern Appalachian Mountains. Canadian Journal of Forest Research 26:1218-1227.

Hilderbrand, R. H., A. D. Lemly, C. A. Dolloff, and K. L. Harpster. 1997. Effects of large woody debris placement on stream channels and benthic macroinvertebrates 939:931-939.

Johnson, L. B., H. Breneman, and C. Richards. 2003. Macroinvertebrate Community Structure and Function Associated with Large Wood in Low Gradient Streams. River Research and Applications 19:199-218.

Kail, J., D. Hering, S. Muhar, M. Gerhard, and S. Preis. 2007. The use of large wood in stream restoration : experiences from 50 projects in Germany and Austria:1145-1155.

Kratzer, J. F., and D. R. Warren. 2013. Factors Limiting Brook Trout Biomass in Northeastern Vermont Streams. North American Journal of Fisheries Management.

Lammert, M., and J. D. Allan. 1999. Assessing Biotic Integrity of Streams : Effects of Scale in Measuring the Influence of Land Use / Cover and Habitat Structure on Fish and Macroinvertebrates 23(2):257-270.

Legendre, P., and E. D. Gallagher. 2001. Ecologically meaningful transformations for ordination of species data. Oecologia 129(2):271-280.Lewis, R. L. 1998. Transforming the Appalachian countryside: Railroads, deforestation, and social change in West Virginia, 1880-1920. University of North Carolina Press.

Martin, Douglas J. \& Benda, L. E. 2001. Patterns of Instream Wood Recruitment and Transport at the Watershed Scale. 940-958.

Newbold, J. D., Erman, D. C., \& Roby, K. B. 1980. Effects of logging on macroinvertebrates in streams with and without buffer strips. Canadian journal of fisheries and aquatic sciences 37(7): 1076-1085.

O'Connor, N. A. 1991. The Effects of Habitat Complexity on the Macroinvertebrates Colonising Wood Substrates in a Lowland Stream. Oecologia 85:504-512.

Parrish, F. K. 1984. Invertebrate Productivity in a Subtropical Blackwater River: The Importance of Habitat and Life History. 54::25-63.

Roper, B. B., J. L. Kershner, E. Archer, R. Henderson, and N. Bouwes. 2003. An Evaluation of Physical Stream Habitat Attributes Used to Monitor Streams 1 38(6):1637-1646. 
Shields Jr., F. D., S. S.Knight, and J. M. Stofleth. 2006. Large Wood Addition for Aquatic Habitat Rehabilitation in an Incised, Sand-Bed Stream, Little Topashaw Creek, Mississippi. River Research and Applications 22:803-817.

Stolarski, J. T. 2007. Age and Growth of Appalachian Brook Trout in Relation to Life-History and Habitat Features. Order No. 1451936 West Virginia University. ProQuest. Web. 3 July 2018.

Sweka, J. A., and K. J. Hartman. 2006. Effects of large woody debris addition on stream habitat and brook trout populations in Appalachian streams. Hydrobiologia 559(1):363-378.

Sweka, J. A., K. J. Hartman, and J. M. Niles. 2010. Long-Term Effects of Large Woody Debris Addition on Stream Habitat and Brook Trout Populations. Journal of Fish and Wildlife Management 1(2):146-151.

U. S. Forest Service, I. Panhandle, N. Forest, , P. Northwest, R. Office, U. S. F. Service, W. River, and R. District. 1998. Durability of Pacific Northwest Instream Structures Following Floods:686-693.

Wallace, J. B., J. R. Webster, and W. Webster. 1996. The Role of Macroinvertebrates in Stream Ecosystems (131).

Wang, J., J. Mcneel, S. Milauskas, and W. Virginia. 2018. Logging Sediment Control Act and Forestry Best Management Practices in West Virginia : A Review 21(June):93-99.

Wang, L., J. Lyons, P. Kanehl, and R. Bannerman. 2001. Impacts of Urbanization on Stream Habitat and Fish Across Multiple Spatial Scales 28(2):255-266.

Warren, D. R., E. S. Bernhardt, R. O. Hall, and G. E. Likens. 2007. Forest age, wood and nutrient dynamics in headwater streams of the Hubbard Brook Experimental Forest, $\mathrm{NH}$ 1163(July):1154-1163.

Warren, D. R., and C. E. Kraft. 2008. Forest Ecology and Management Dynamics of large wood in an eastern U. S. mountain stream 256:808-814.West Virginia Division of Forestry. 1986. Forestry and water quality in West Virginia. Report VIII-Silviculture 208 Program, Charleston, WV. 10 p.

WVDEP (West Virginia Department of Environmental Protection). 2003. Benthic invertebrate sampling, processing, and analysis standard operating procedures. West Virginia Department of Environmental Protection, Charleston, West Virginia. 
Tables

Table 1: Stream characteristics used in analysis of LW movement and retention. Number of LW tags is the number of individual pieces tagged in a random 500 meter reach in 2013 and mean movement is the movement recorded for recaptured pieces in subsequent years of sampling until 2015.

\begin{tabular}{cccccccc}
\hline Stream & $\begin{array}{c}\text { Elevation } \\
(\mathbf{m})\end{array}$ & $\begin{array}{c}\text { Slope } \\
\mathbf{( \% )}\end{array}$ & Geology $^{1}$ & $\begin{array}{c}\text { Bankfull } \\
\text { Width } \\
(\mathbf{m})\end{array}$ & $\begin{array}{c}\text { Drainage } \\
\text { Area } \\
\left(\mathbf{k m}^{\mathbf{2}}\right)\end{array}$ & $\begin{array}{c}\text { \# LW } \\
\text { Tags }\end{array}$ & $\begin{array}{c}\text { Mean LW } \\
\text { Movement } \\
(\mathbf{m})\end{array}$ \\
\hline Birch Fork & 865 & 3.2 & Pottsville (Limed) & 7.1 & 5.07 & 29 & 9.2 \\
Brushy Run & 697 & 6.4 & Mauch Chunk & 7.4 & 18.65 & 16 & 57.4 \\
Clubhouse Run & 955 & 7.8 & Chemung & 7.2 & 8.09 & 63 & 13.1 \\
Crooked Fork & 1020 & 5.4 & Mauch Chunk & 6.6 & 8.36 & 40 & 6.5 \\
Elklick Run & 613 & 18.1 & Hampshire & 10.8 & 13.65 & 46 & 61.9 \\
Elleber Run & 1129 & 19.7 & Chemung & 6.4 & 5.57 & 24 & 1.1 \\
Lick Run & 972 & 9.3 & Chemung & 4.8 & 2.58 & 29 & 7.1 \\
Light Run & 757 & 9.4 & Pottsville (Unlimed) & 6.5 & 6.13 & 44 & 8.9 \\
Little Branch & 1075 & 6.7 & Pottsville (Unlimed) & 4.8 & 1.99 & 66 & 8.9 \\
N. Fork Red Run & 942 & 13.1 & Mauch Chunk & 10 & 13.89 & 19 & 33.7 \\
Poca Run & 1055 & 13.6 & Chemung & 4.1 & 2.53 & 14 & 14.2 \\
Seneca Creek & 1144 & 12.4 & Hampshire & 5.3 & 5.28 & 16 & 8.2 \\
Sugar Drain & 872 & 8.5 & Pottsville (Unlimed) & 4 & 1.73 & 45 & 0.8 \\
Whites Run & 728 & 10.9 & Hampshire & 7.2 & 12.8 & 33 & 142.5 \\
Average & $\mathbf{9 1 6}$ & $\mathbf{1 0 . 3}$ & N/A & $\mathbf{6 . 6}$ & $\mathbf{7 . 6}$ & $\mathbf{3 4 . 6}$ & $\mathbf{2 6 . 7}$ \\
\hline
\end{tabular}

\footnotetext{
${ }^{1}$ The addition of limestone sand to streams with Pottsville geology is conducted by the West Virginia Division of Natural Resources and Department of Environmental Protection to increase buffering capacity in this group that is naturally poor at buffering against acidic water conditions. This allowed the creation of two distinct groups within the Pottsville geologic unit as limed and unlimed.
} 
Table 2: Results from linear mixed models with explanatory variable of LW pieces per $100 \mathrm{~m}^{2} \mathrm{~s}$ ampled. Stream was treated as a random effect (grouping variable) and fit with its own intercept. Significance codes: ${ }^{*} \mathrm{p}<0.05 ; * * \mathrm{p}<0.01 ; * * * \mathrm{p}<0.001$.

\begin{tabular}{ccccc}
\hline Dependent Variable & $\begin{array}{c}\text { Coefficient wit } \\
\text { h LW per 100 } \\
\mathbf{m}^{2}\end{array}$ & $\begin{array}{c}\text { Intercept } \\
\text { (Stream) }\end{array}$ & $\begin{array}{c}\text { Variance Explained } \\
\text { by Random Effect } \\
\text { \%) }\end{array}$ & $\begin{array}{c}\text { Log } \\
\text { Likelihoo } \\
\text { d }\end{array}$ \\
\hline Proportion of Pools & $-0.064^{*}$ & $-2.14^{* * *}$ & 57.44 & -225.7 \\
Proportion of LW formed Pools & $-0.070^{* * *}$ & $0.35^{* * *}$ & 35.05 & -41.5 \\
Mean Max. Pool Depth & 0.730 & $55.83^{* * *}$ & 49.24 & -1011.9 \\
Mean Spawning Area & 0.015 & $1.00^{* * *}$ & 38.19 & -95.7 \\
Pool Quality & $0.129 *$ & $8.29^{* * *}$ & 71.34 & -232.7 \\
Prop. Spawn Gravel (32mm) & 0.026 & $0.32^{* * *}$ & 9.62 & -94.8 \\
Prop. Spawn Gravel (16mm) & $0.013 *$ & $0.34^{* * *}$ & 22.44 & 273.9 \\
Prop. Spawn Gravel (8mm) & 0.0004 & $0.44^{* * *}$ & 33.70 & 447.4 \\
Prop. Spawn Gravel (4mm) & -0.005 & $0.42^{* * *}$ & 28.35 & 435.5 \\
Prop. Spawn Gravel (0.13mm) & -0.005 & $0.17^{* * *}$ & 34.88 & 401.9 \\
Prop. Spawn Gravel (0.06mm) & -0.002 & $0.11^{* * *}$ & 32.79 & 573.9 \\
Prop. Spawn Gravel (fines) & -0.003 & $0.18^{* * *}$ & 21.36 & 666.3 \\
\hline
\end{tabular}


Table 3: Results from linear mixed models with explanatory variable of LW pieces per $100 \mathrm{~m}^{2} \mathrm{~s}$ ampled. Year was treated as a random effect (grouping variable) and fit with its own intercept. Significance codes: $* \mathrm{p}<0.05 ; * * \mathrm{p}<0.01 ; * * * \mathrm{p}<0.001$.

\begin{tabular}{ccccc}
\hline Dependent Variable & $\begin{array}{c}\text { Coefficient with } \\
\text { LW per 100m }\end{array}$ & $\begin{array}{c}\text { Intercept } \\
\text { (Year) }\end{array}$ & $\begin{array}{c}\text { Variance Explained b } \\
\text { y Random Effect (\%) }\end{array}$ & $\begin{array}{c}\text { Log } \\
\text { Likelihood }\end{array}$ \\
\hline Proportion of Pools & -0.096 & $-2.15^{* * *}$ & 10.82 & -299.1 \\
Proportion of LW formed Pools & -0.022 & $0.392^{* * *}$ & 24.09 & -59.0 \\
Mean Max. Pool Depth & -1.17 & $54.62^{* * *}$ & 23.33 & -1055.1 \\
Mean Spawning Area & 0.034 & $0.992^{* * *}$ & 72.38 & -116.7 \\
Pool Quality & 0.026 & $8.328^{* * *}$ & 0.0001 & -298.9 \\
Prop. Spawn Gravel (32mm) & 0.018 & $0.322^{* * *}$ & 7.17 & -94.9 \\
Prop. Spawn Gravel (16mm) & 0.013 & $0.347 * * *$ & 4.98 & 248.0 \\
Prop. Spawn Gravel (8mm) & -0.003 & $0.449^{* * *}$ & 2.01 & 398.0 \\
Prop. Spawn Gravel (4mm) & -0.008 & $0.426^{* * *}$ & 0.24 & 396.1 \\
Prop. Spawn Gravel (0.13mm) & -0.003 & $0.214^{* * *}$ & 71.31 & 605.1 \\
Prop. Spawn Gravel (0.06mm) & 0.00001 & $0.118^{* * *}$ & 48.6 & 699.1 \\
Prop. Spawn Gravel (fines) & 0.002 & $0.164 * * *$ & 35.96 & 700.9 \\
\hline
\end{tabular}


Table 4: Results from linear mixed models with explanatory variable of LW pieces per $100 \mathrm{~m}^{2} \mathrm{~s}$ ampled. Geology was treated as a random effect (grouping variable) and fit with its own interce pt. Significance codes: ${ }^{*} \mathrm{p}<0.05 ; * * \mathrm{p}<0.01 ; * * * \mathrm{p}<0.001$.

\begin{tabular}{ccccc}
\hline Dependent Variable & $\begin{array}{c}\text { Coefficient wit } \\
\text { h LW per 100 } \\
\mathbf{m}^{\mathbf{2}}\end{array}$ & $\begin{array}{c}\text { Intercept } \\
\text { (Stream) }\end{array}$ & $\begin{array}{c}\text { Variance Explained } \\
\text { by Random Effect ( } \\
\text { \%) }\end{array}$ & $\begin{array}{c}\text { Log } \\
\text { Likelihoo } \\
\text { d }\end{array}$ \\
\hline Proportion of Pools & $-0.083^{*}$ & $-2.19^{* * *}$ & 27.67 & -274.5 \\
Proportion of LW formed Pools & $-0.061^{* * *}$ & $0.353^{* * *}$ & 13.58 & -55.9 \\
Mean Max. Pool Depth & 0.034 & $55.54^{* * *}$ & 2.02 & -1070.4 \\
Mean Spawning Area & 0.02 & $0.986^{* * *}$ & 24.28 & -103.1 \\
Pool Quality & 0.061 & $8.29^{* * *}$ & 21.72 & -288.7 \\
Prop. Spawn Gravel (32mm) & $0.027^{*}$ & $0.33^{* * *}$ & 3.80 & -99.3 \\
Prop. Spawn Gravel (16mm) & $0.014 *$ & $0.35^{* * *}$ & 0.66 & 240.3 \\
Prop. Spawn Gravel (8mm) & 0.001 & $0.45^{* * *}$ & 5.70 & 401.2 \\
Prop. Spawn Gravel (4mm) & -0.007 & $0.43^{* * *}$ & 2.92 & 398.4 \\
Prop. Spawn Gravel (0.13mm) & -0.006 & $0.18^{* * *}$ & 2.32 & 360.9 \\
Prop. Spawn Gravel (0.06mm) & 0.0001 & $0.12^{* * *}$ & 10.58 & 533.7 \\
Prop. Spawn Gravel (fines) & -0.002 & $0.18^{* * *}$ & 0.83 & 629.0 \\
\hline
\end{tabular}


Table 5: Results from comparison of habitat variables before hurricane Sandy (2003-2012) and after hurricane Sandy (2013-2017) using unpaired t-tests on transformed variables or MannWhitney U tests. Both tests were performed due to the nonparametric nature of all variables with mean maximum pool depth as the only exception.

\begin{tabular}{cccc}
\hline Variable & $\begin{array}{c}\text { Percent } \\
\text { Change Post } \\
\text { Sandy (\%) }\end{array}$ & $\begin{array}{c}\text { Transformed } \\
\text { Parametric p- } \\
\text { value }\end{array}$ & $\begin{array}{c}\text { Non- } \\
\text { Parametric p- } \\
\text { value }\end{array}$ \\
\hline Proportion of Spawn Gravel (32mm) & -13.45 & 0.78 & 0.86 \\
Proportion of Spawn Gravel $(16 \mathrm{~mm})$ & -1.66 & 0.12 & 0.62 \\
Proportion of Spawn Gravel $(8 \mathrm{~mm})$ & 3.66 & 0.17 & 0.1 \\
Proportion of Spawn Gravel $(4 \mathrm{~mm})$ & -2.18 & 0.74 & 0.95 \\
Proportion of Spawn Gravel $(2 \mathrm{~mm})$ & 6.13 & 0.07 & 0.036 \\
Proportion of Spawn Gravel $(1 \mathrm{~mm})$ & 10.40 & 0.068 & 0.05 \\
Proportion of Spawn Gravel $(0.5 \mathrm{~mm})$ & 5.29 & 0.23 & 0.13 \\
Proportion of Spawn Gravel $(0.25 \mathrm{~mm})$ & 17.28 & $<0.01$ & $<0.01$ \\
Proportion of Spawn Gravel $(0.13 \mathrm{~mm})$ & -42.73 & $<0.001$ & $<0.001$ \\
Proportion of Spawn Gravel $(0.06 \mathrm{~mm})$ & -24.75 & $<0.001$ & $<0.001$ \\
Proportion of Spawn Gravel (fines) & 79.58 & $<0.001$ & $<0.001$ \\
Proportion of Bedrock Substrate & -41.30 & 0.21 & 0.21 \\
LW per 100m & 67.10 & 0.21 & 0.71 \\
Spawning Substrate per 100m² Pool & -15.26 & 0.2 & 0.55 \\
Mean Maximum Pool Depth & 12.52 & $<0.001$ & $</ A$ \\
Mean Depth & 16.29 & $<0.001$ & $<0.001$ \\
Proportion of Pools & -14.09 & 0.01 & $<0.001$ \\
Proportion of LW formed Pools & -39.43 & $<0.001$ & $<0.001$ \\
\hline
\end{tabular}


Table 6: Results from linear mixed models with explanatory variable of LW pieces per $100 \mathrm{~m}^{2} \mathrm{~s}$ ampled. Stream was treated as a random effect (grouping variable) and fit with its own intercept. Significance codes: $* \mathrm{p}<0.05 ; * * \mathrm{p}<0.01 ; * * * \mathrm{p}<0.001$.

\begin{tabular}{ccccc}
\hline Dependent Variable & $\begin{array}{c}\text { Coefficient with } \\
\text { LW per 100m }\end{array}$ & $\begin{array}{c}\text { Intercept } \\
\text { (Stream) }\end{array}$ & $\begin{array}{c}\text { Variance Explained } \\
\text { by Random Effect } \mathbf{~ ( ~} \\
\text { \%) }\end{array}$ & $\begin{array}{c}\text { Log } \\
\text { Likelihoo } \\
\text { d }\end{array}$ \\
\hline Percent EPT Taxa & -310.5 & $5193.1 * * *$ & 44.76 & -532.5 \\
EPT Taxa Richness & -0.329 & $11.41^{* * *}$ & 25.84 & -135.6 \\
Family Richness & -0.325 & $16.95 * * *$ & 28.84 & -155.1 \\
WVSCI & -16139.9 & $546890.6 * * *$ & 31.48 & -788.2 \\
\# Intolerant Genera & -0.354 & $12.52 * * *$ & 21.1 & -150.3 \\
\# Ephemeroptera Genera & 0.093 & $5.98^{* * *}$ & 4.72 & -101.6 \\
\# Plecoptera Genera & -0.023 & $1.637^{* * *}$ & 24.05 & 2.53 \\
\# Clinger Genera & -7.848 & $82.309 * * *$ & 14.84 & -299.9 \\
\# Shredder Genera & -0.021 & $1.451 * * *$ & 0.00 & -12.3 \\
GLIMPSS & -292.12 & $4468.7 * * *$ & 22.34 & -518.7 \\
\hline
\end{tabular}




\section{Figures}

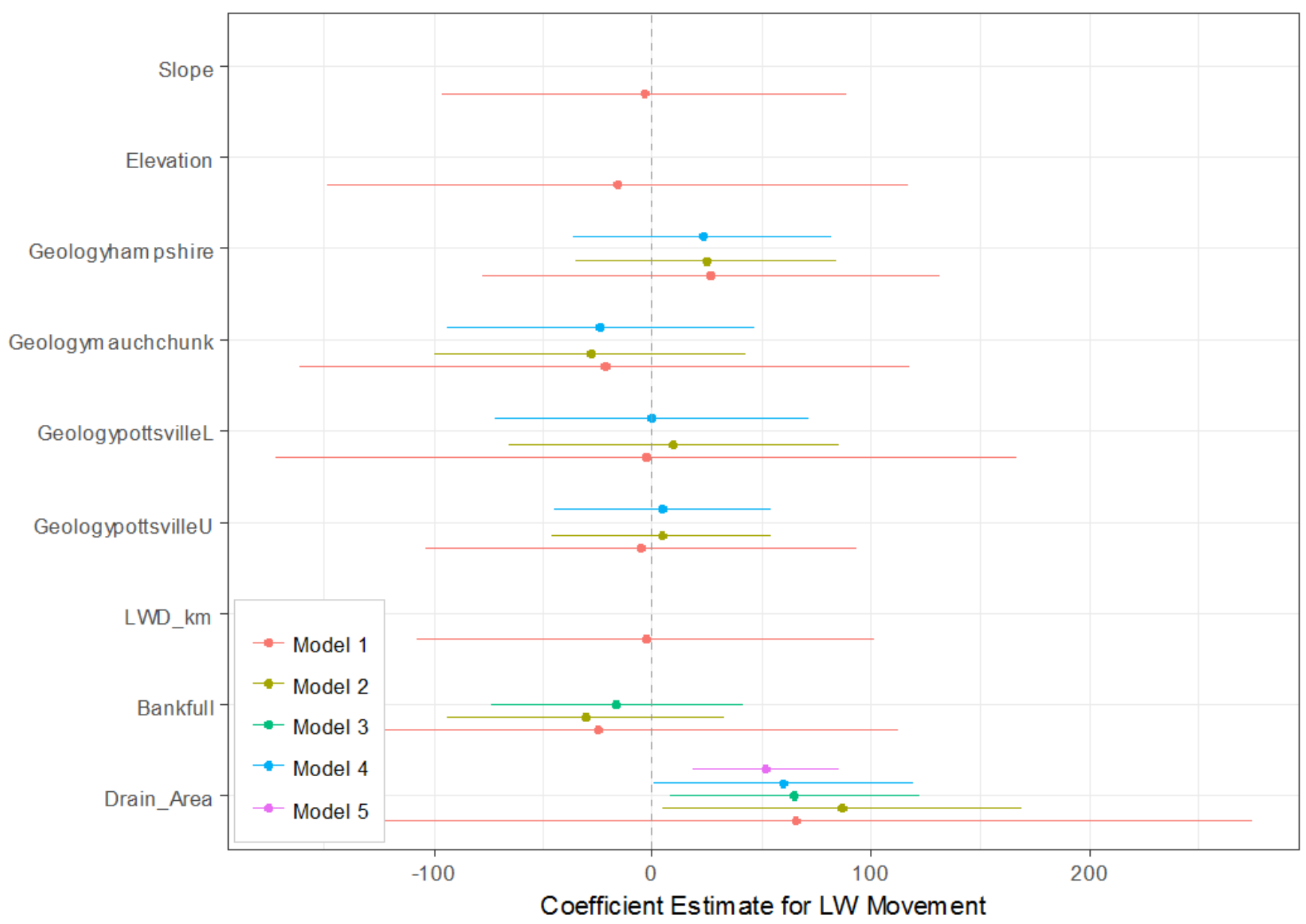

Figure 1: Backward selection stepwise multiple regression results through five models showing drainage area as the only significant predictor of LW movement with a coefficient estimate of $4.911 \pm 1.464(\mathrm{p}<0.01)$. 


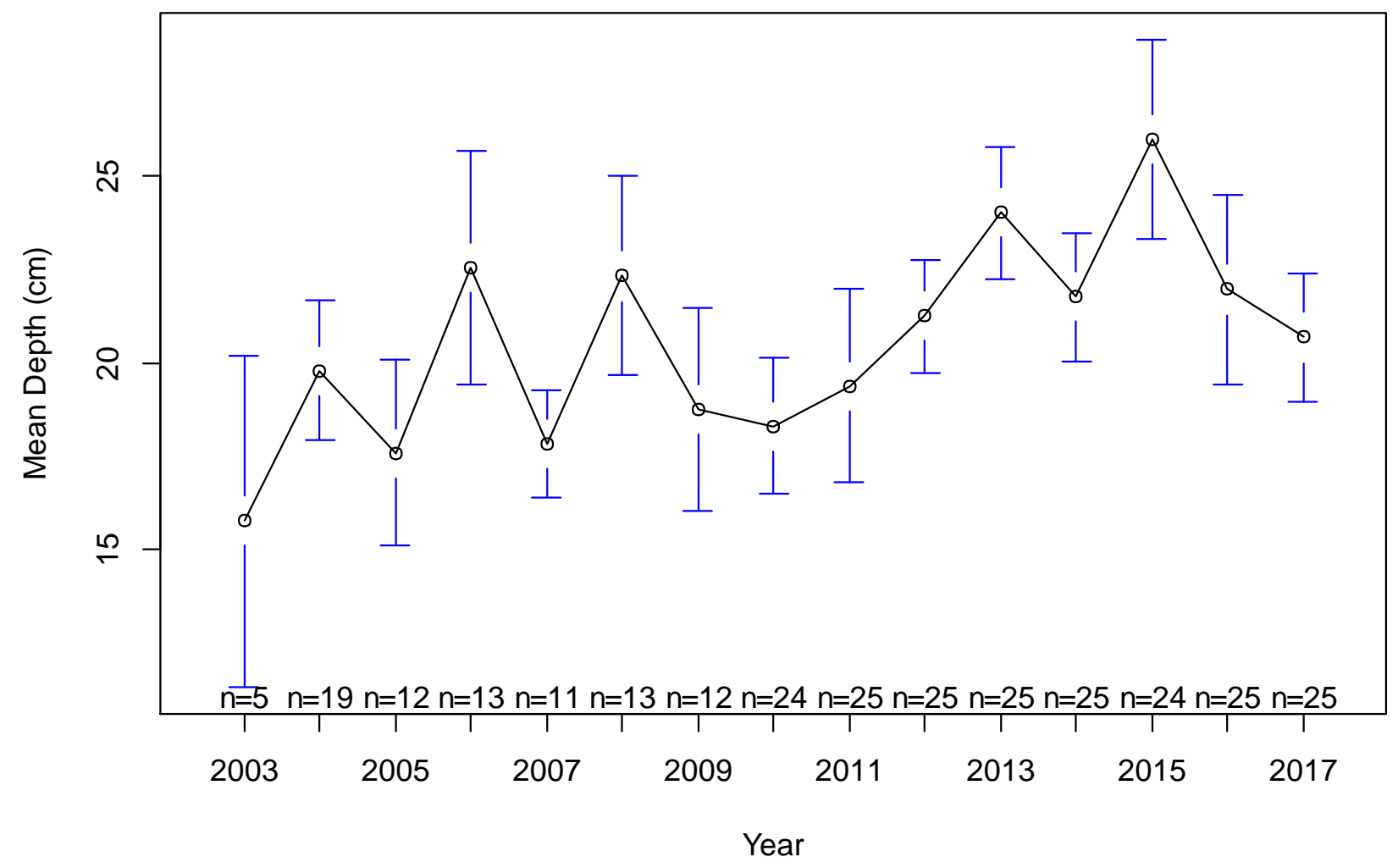

Figure 2: Mean plot of habitat unit depth sampled during summer low flow habitat sampling on long-term survey streams. Repeated measures analysis of variance was significant for effect of year $(\mathrm{p}<0.001)$ and non-significant for effect of stream $(\mathrm{p}=0.33)$ with blue bars representing $95 \%$ confidence intervals. 


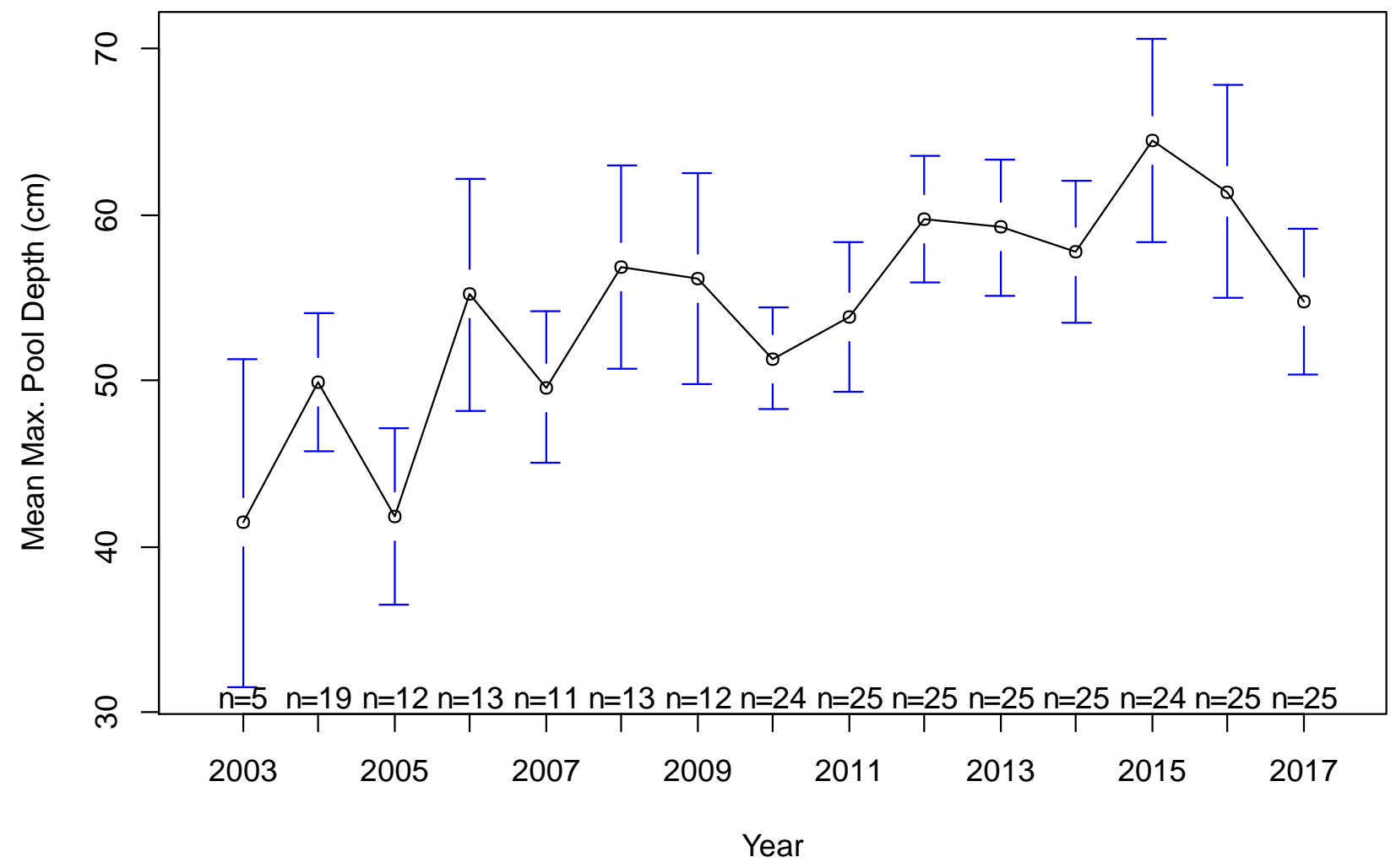

Figure 3: Mean plot of maximum pool depth sampled during summer low flow habitat sampling on long-term survey streams. Repeated measures analysis of variance was significant for effect of year $(\mathrm{p}<0.001)$ and non-significant for effect of stream $(\mathrm{p}=0.35)$ with blue bars representing $95 \%$ confidence intervals. 


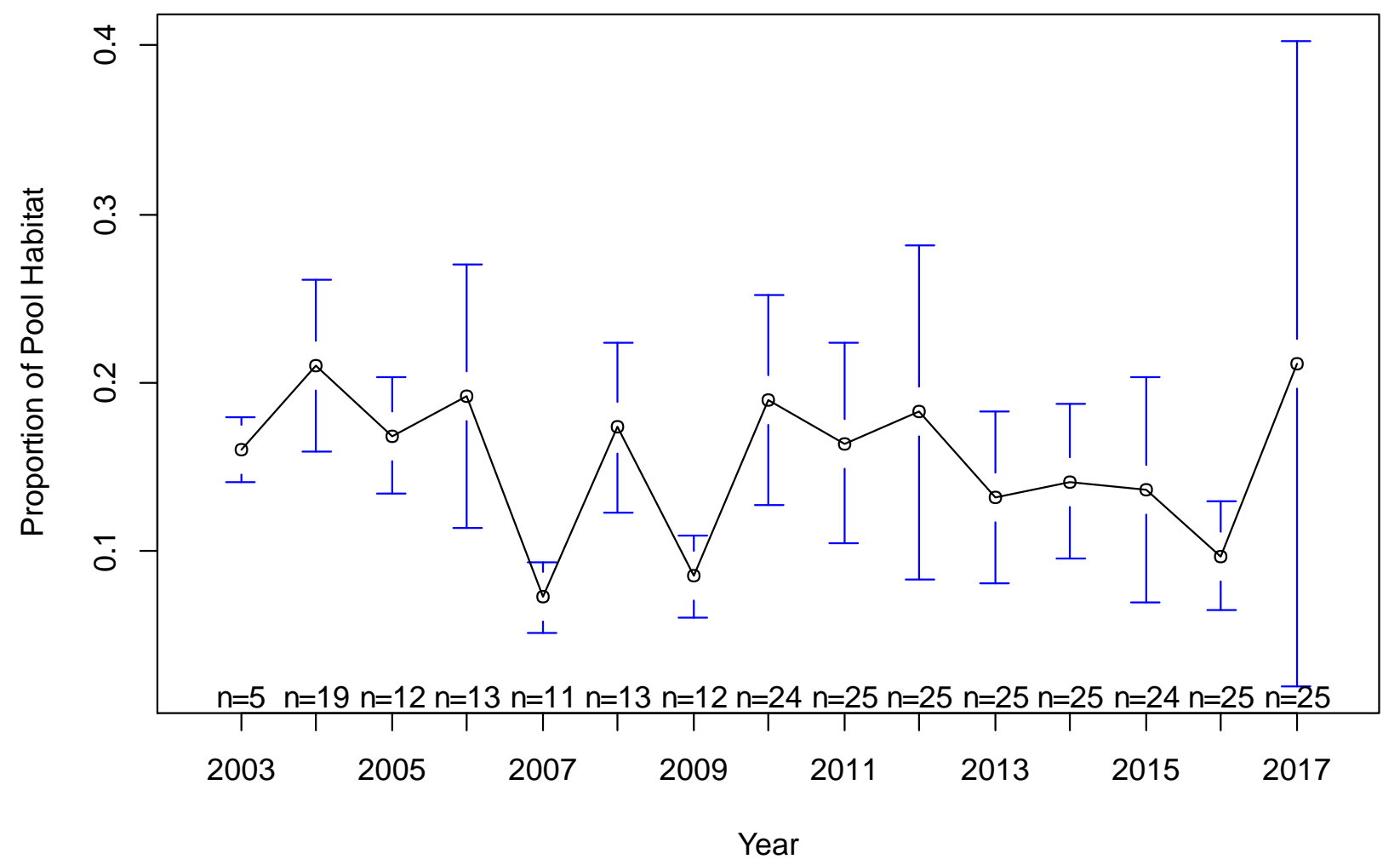

Figure 4: Mean plot of proportion of pool habitat sampled during summer low flow habitat sampling on long-term survey streams. Repeated measures analysis of variance was significant for effect of year $(\mathrm{p}<0.001)$ and significant for effect of stream $(\mathrm{p}<0.01)$ with blue bars representing $95 \%$ confidence intervals. 


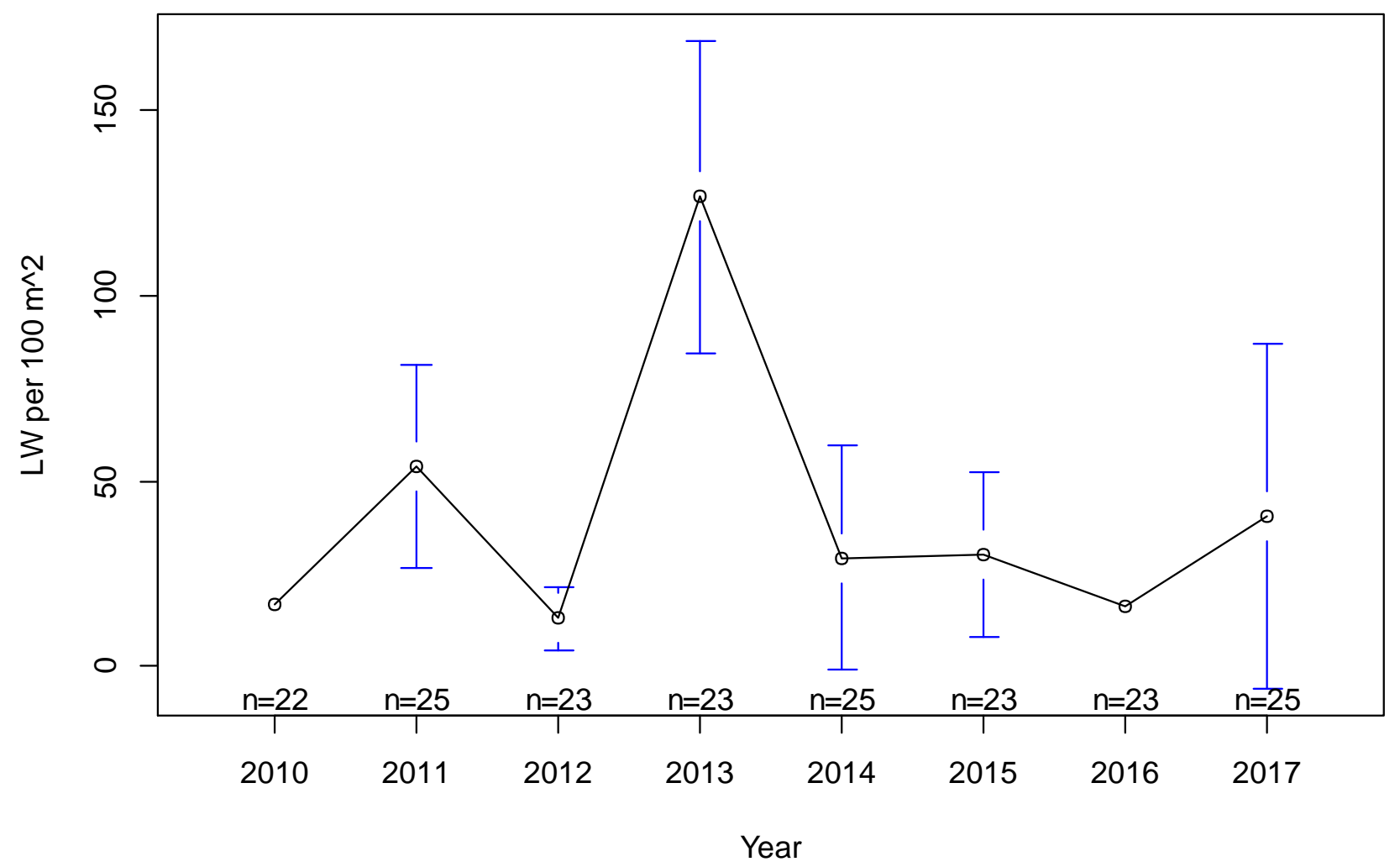

Figure 5: Mean plot of standardized large wood pieces sampled during summer low flow habitat sampling on long-term survey streams. Repeated measures analysis of variance was nonsignificant for effect of year $(\mathrm{p}=0.055)$ and significant for effect of stream $(\mathrm{p}=0.03)$ with blue bars representing $95 \%$ confidence intervals. 


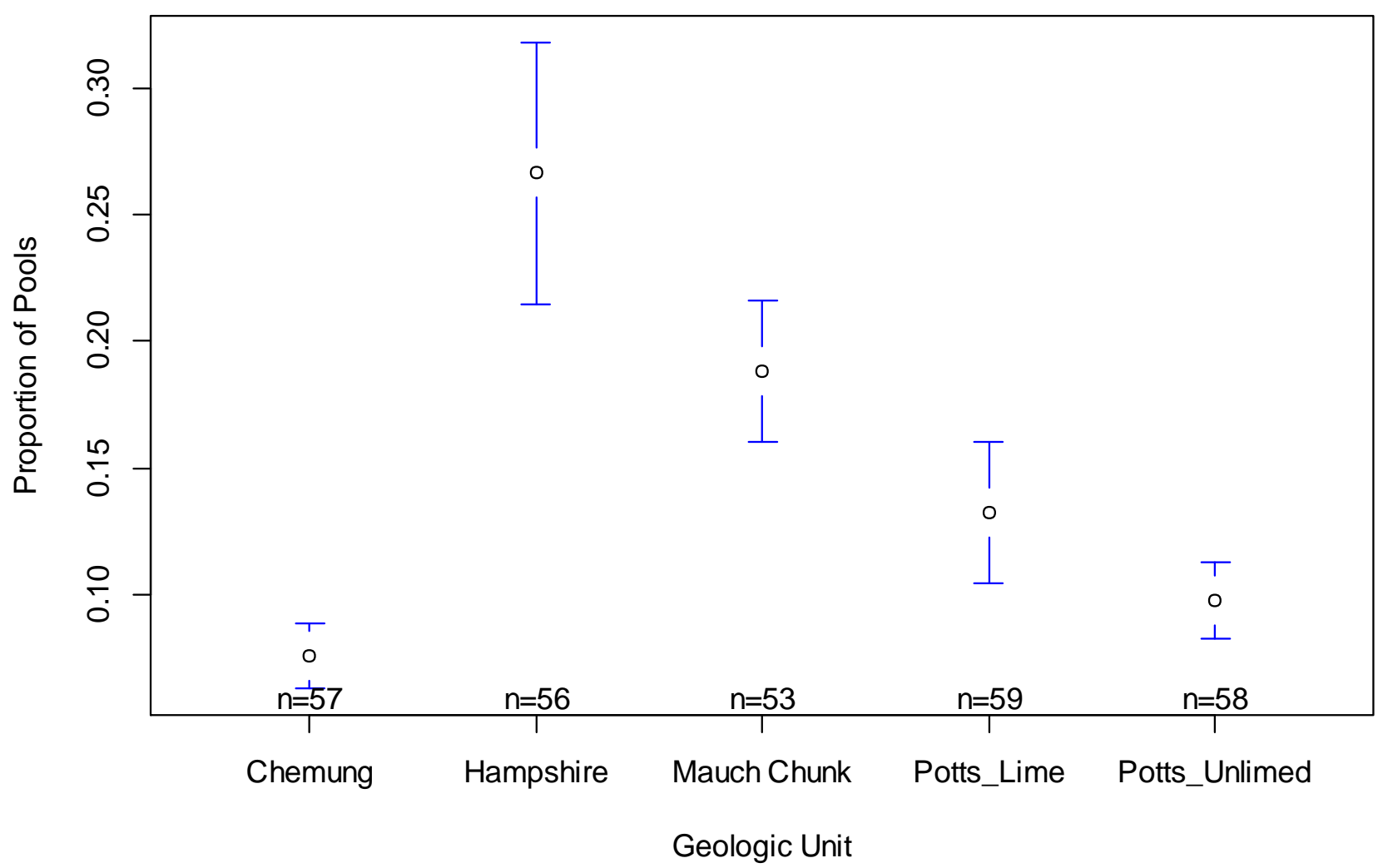

Figure 6: Mean plot of proportion of pool habitats sampled during summer low flow habitat sampling on long-term survey streams. Repeated measures analysis of variance was nonsignificant for effect of year $(\mathrm{p}=0.52)$ and significant for effect of geologic unit $(\mathrm{p}<0.001)$ with blue bars representing $95 \%$ confidence intervals. 


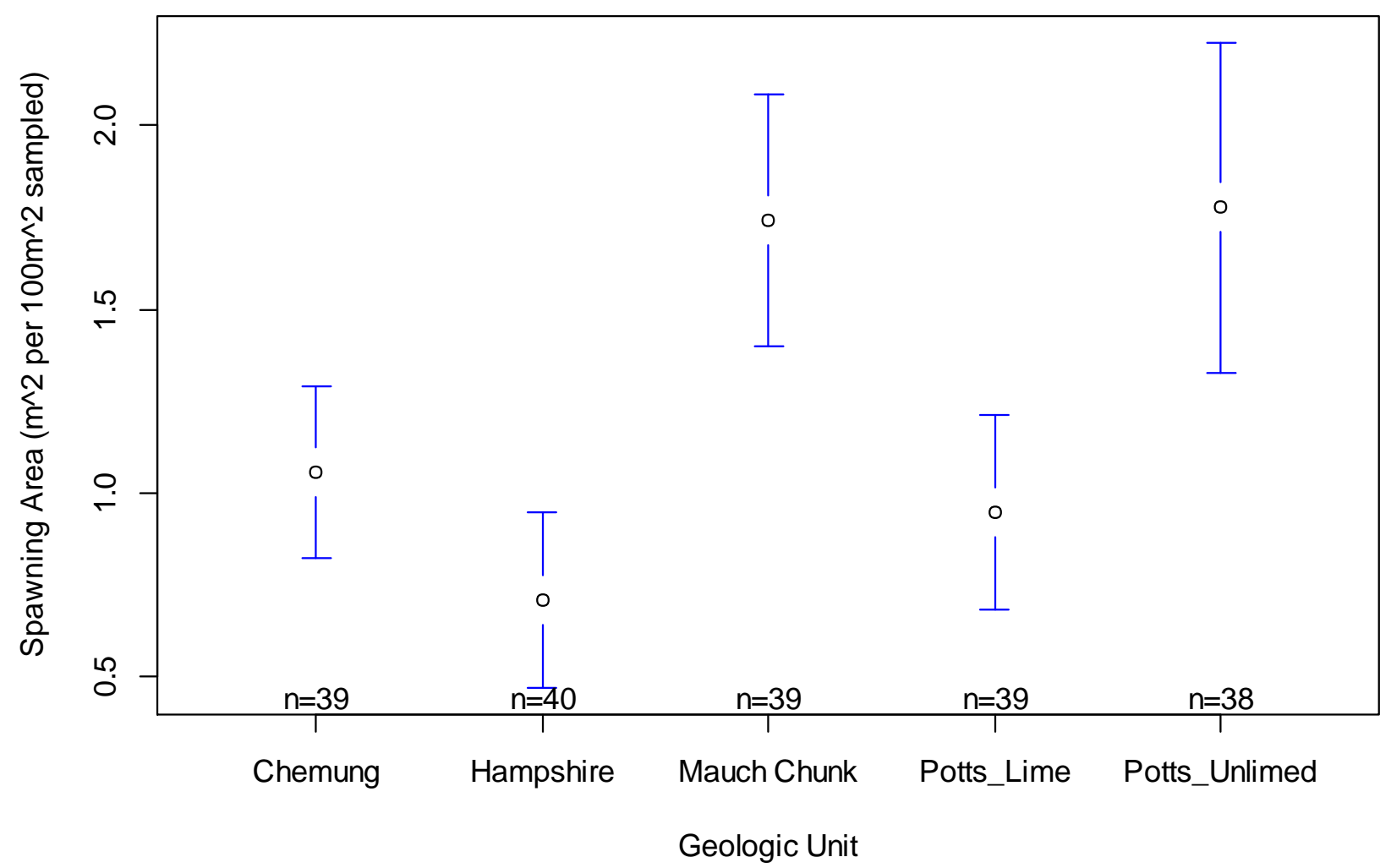

Figure 7: Mean plot of standardized spawning area sampled during summer low flow habitat sampling on long-term survey streams. Repeated measures analysis of variance was nonsignificant for effect of year $(\mathrm{p}=0.98)$ and significant for effect of geologic unit $(\mathrm{p}<0.001)$ with blue bars representing $95 \%$ confidence intervals. 


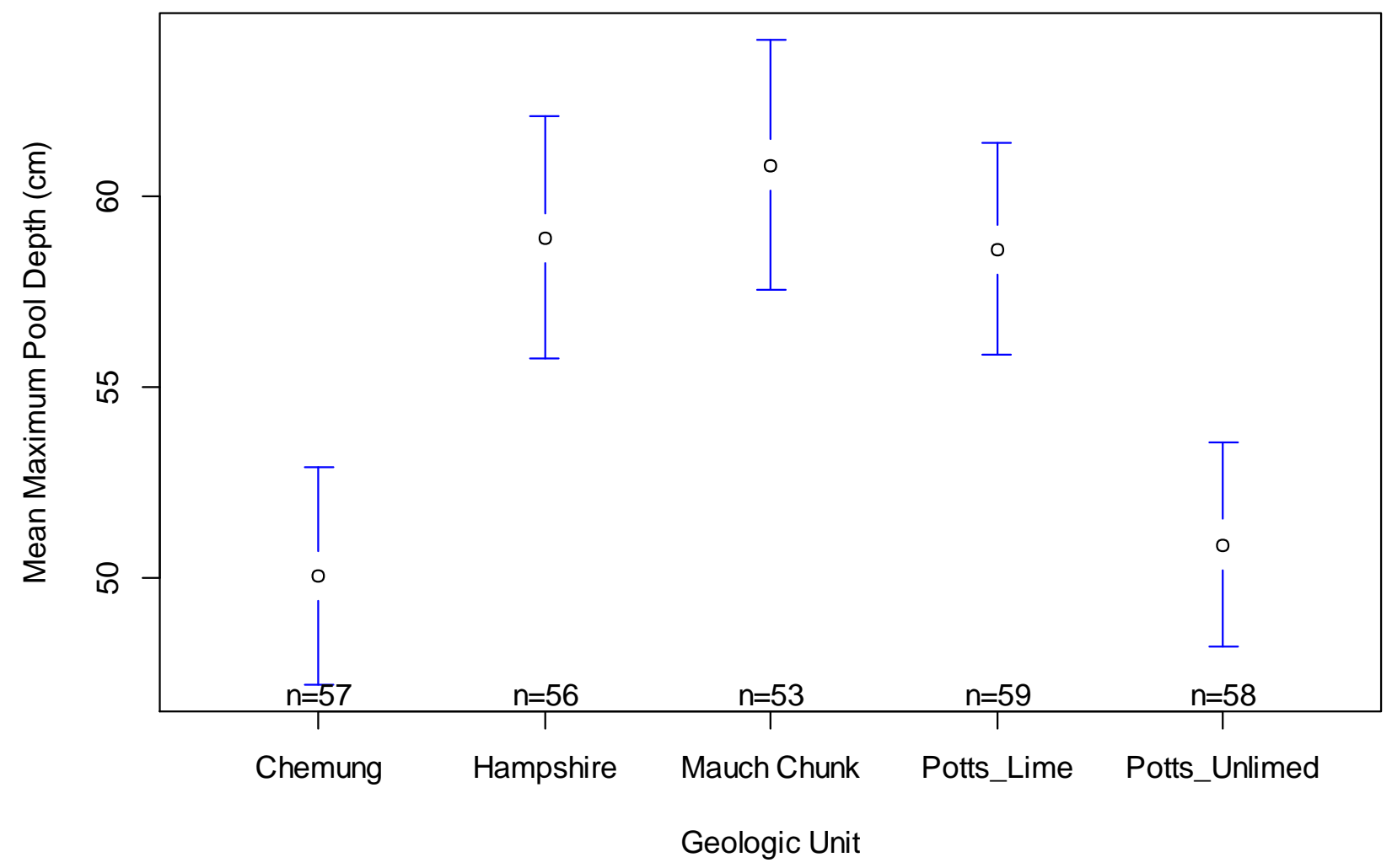

Figure 8: Mean plot of maximum measured pool depth sampled during summer low flow habitat sampling on long-term survey streams. Repeated measures analysis of variance was nonsignificant for effect of year $(\mathrm{p}=0.49)$ and significant for effect of geologic unit $(\mathrm{p}<0.001)$ with blue bars representing $95 \%$ confidence intervals. 


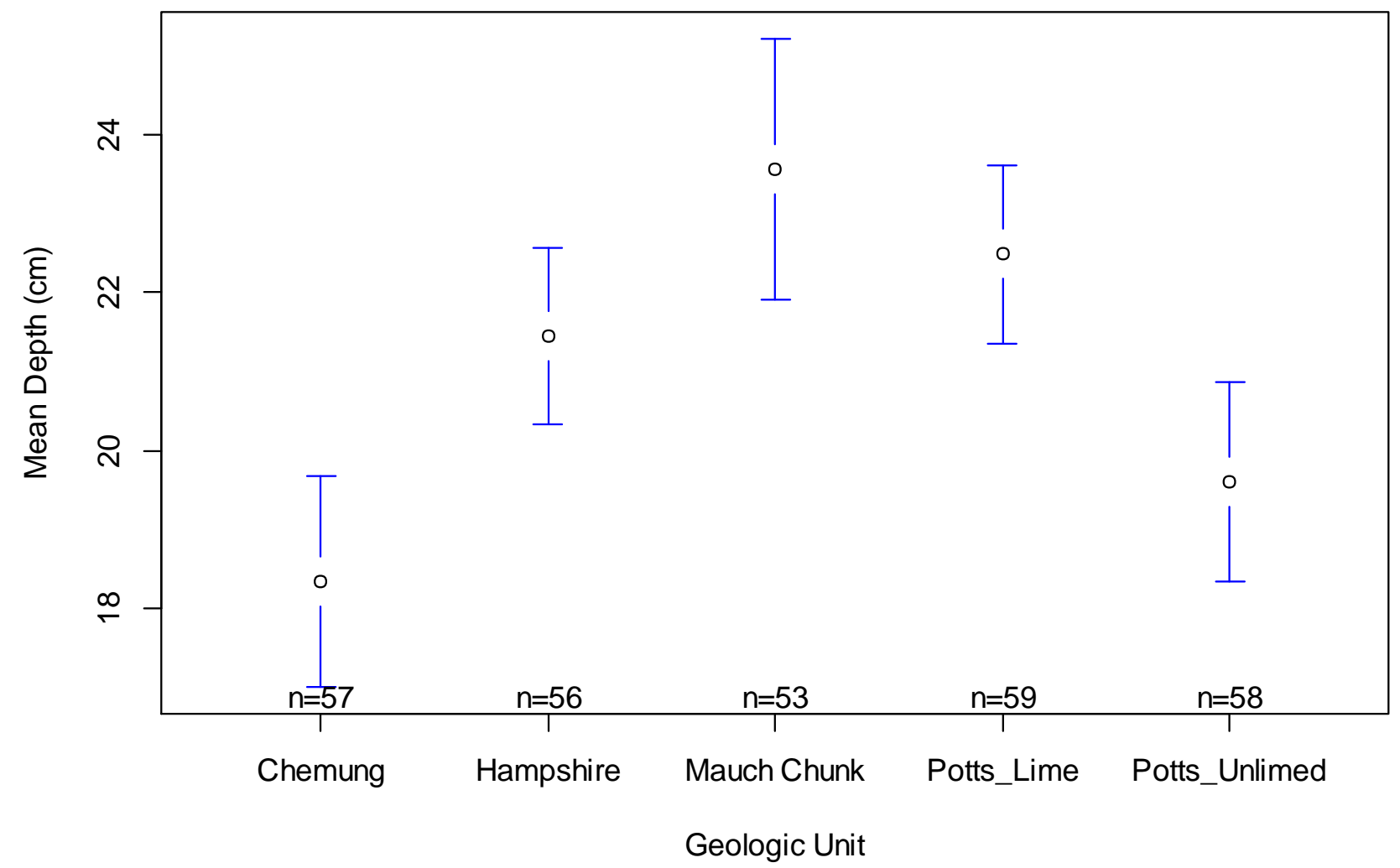

Figure 9: Mean plot of measured water depth sampled during summer low flow habitat sampling on long-term survey streams. Repeated measures analysis of variance was non-significant for effect of year $(p=0.46)$ and significant for effect of geologic unit $(p<0.001)$ with blue bars representing $95 \%$ confidence intervals. 


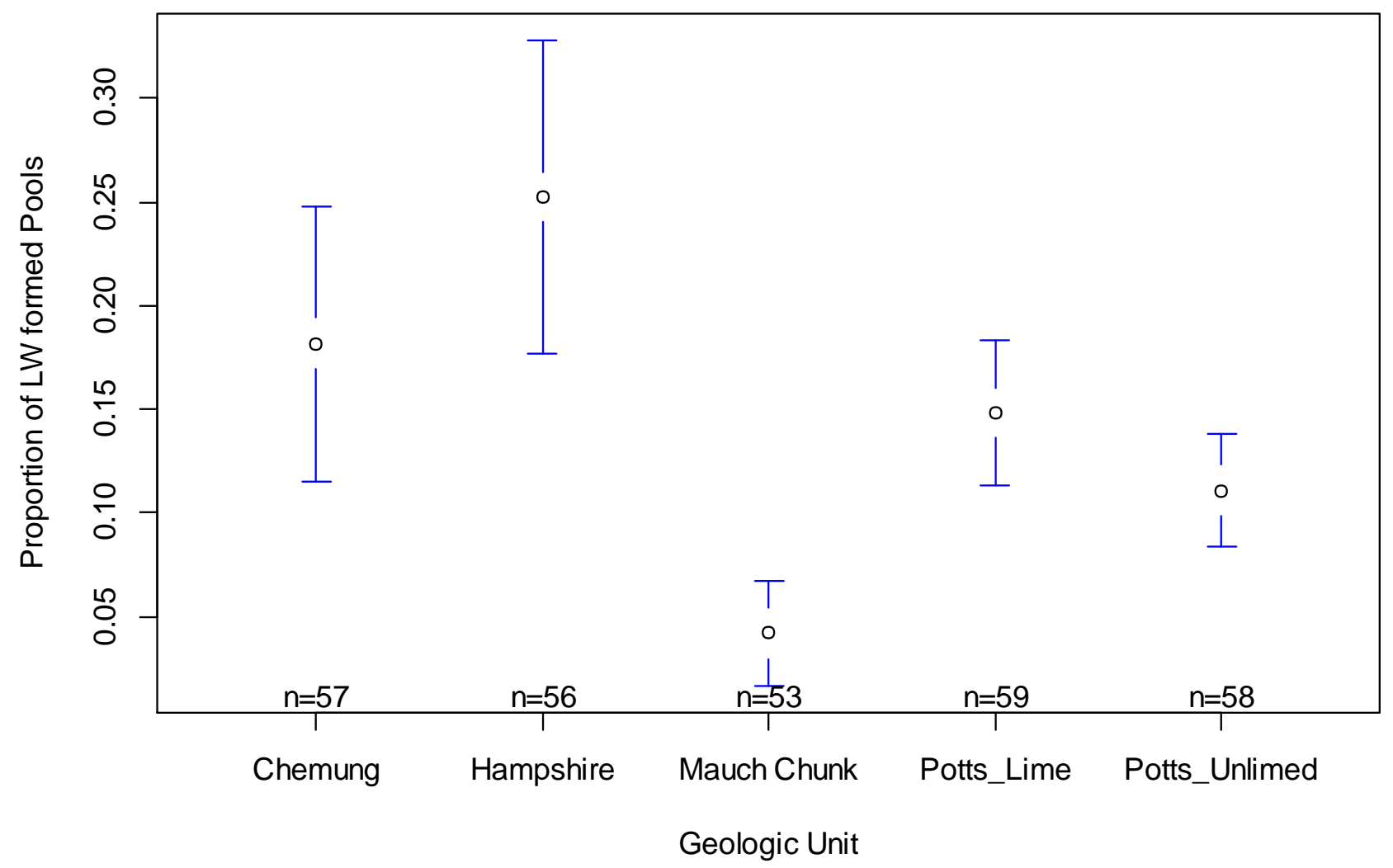

Figure 10: Mean plot of proportion of pools formed by large wood sampled during summer low flow habitat sampling on long-term survey streams. Repeated measures analysis of variance was non-significant for effect of year $(\mathrm{p}=0.12)$ and significant for effect of geologic unit $(\mathrm{p}<0.001)$ with blue bars representing $95 \%$ confidence intervals. 


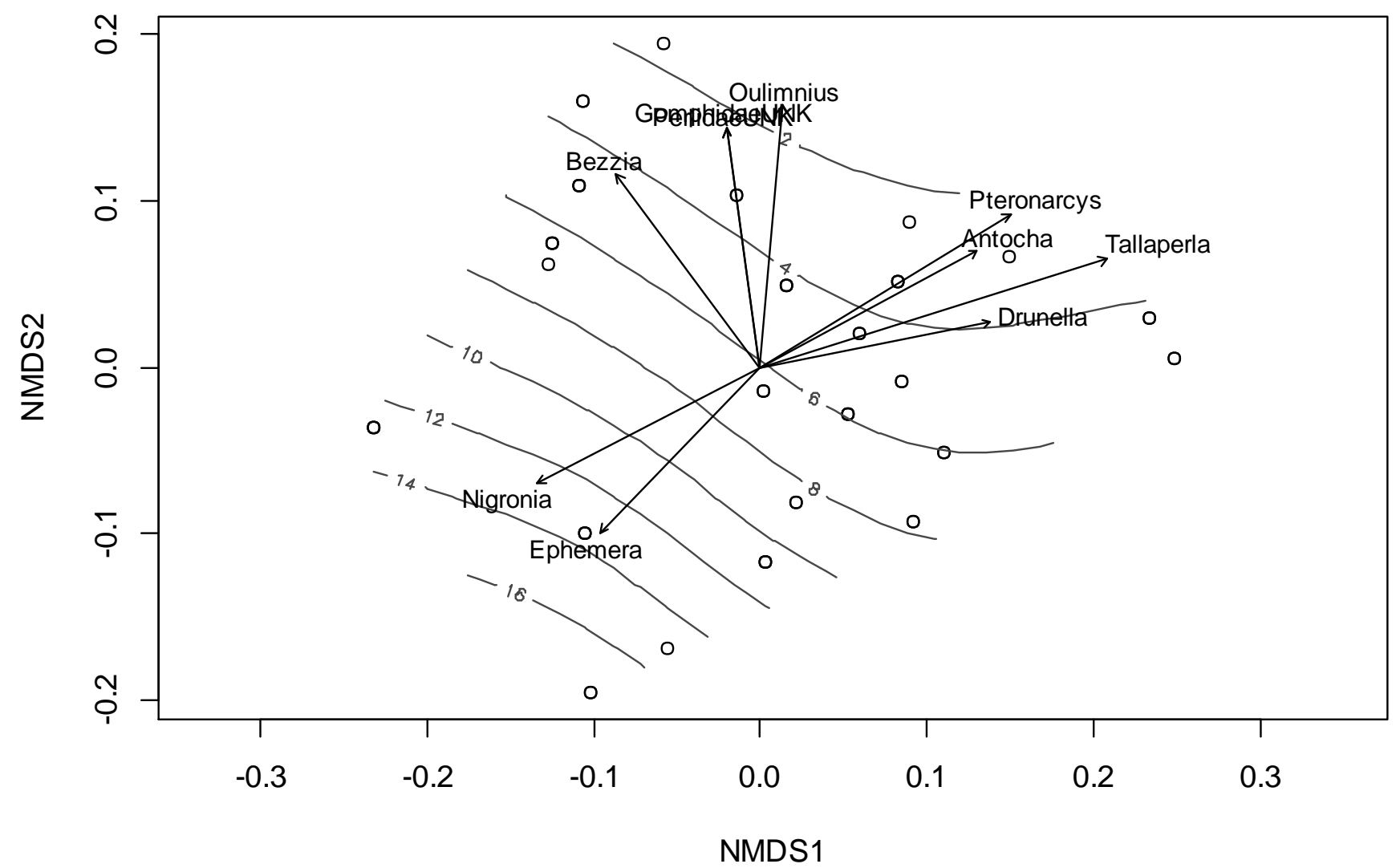

Figure 11: Non-metrical multidimensional scaling ordination plot of sites (2013-2014) within habitat space defined as two ordination axes $(\mathrm{k}=2$; stress $=0.08)$. Vectors shown are macroinvertebrate genera fit as linear relations to ordination dimensions with direction showing gradient and length of arrow approximating strength of relationship. Only those vectors with $\mathrm{p}$ > 0.05 across 999 permutations are displayed. The surface fit displayed as green lines represents drainage area in square kilometers. 


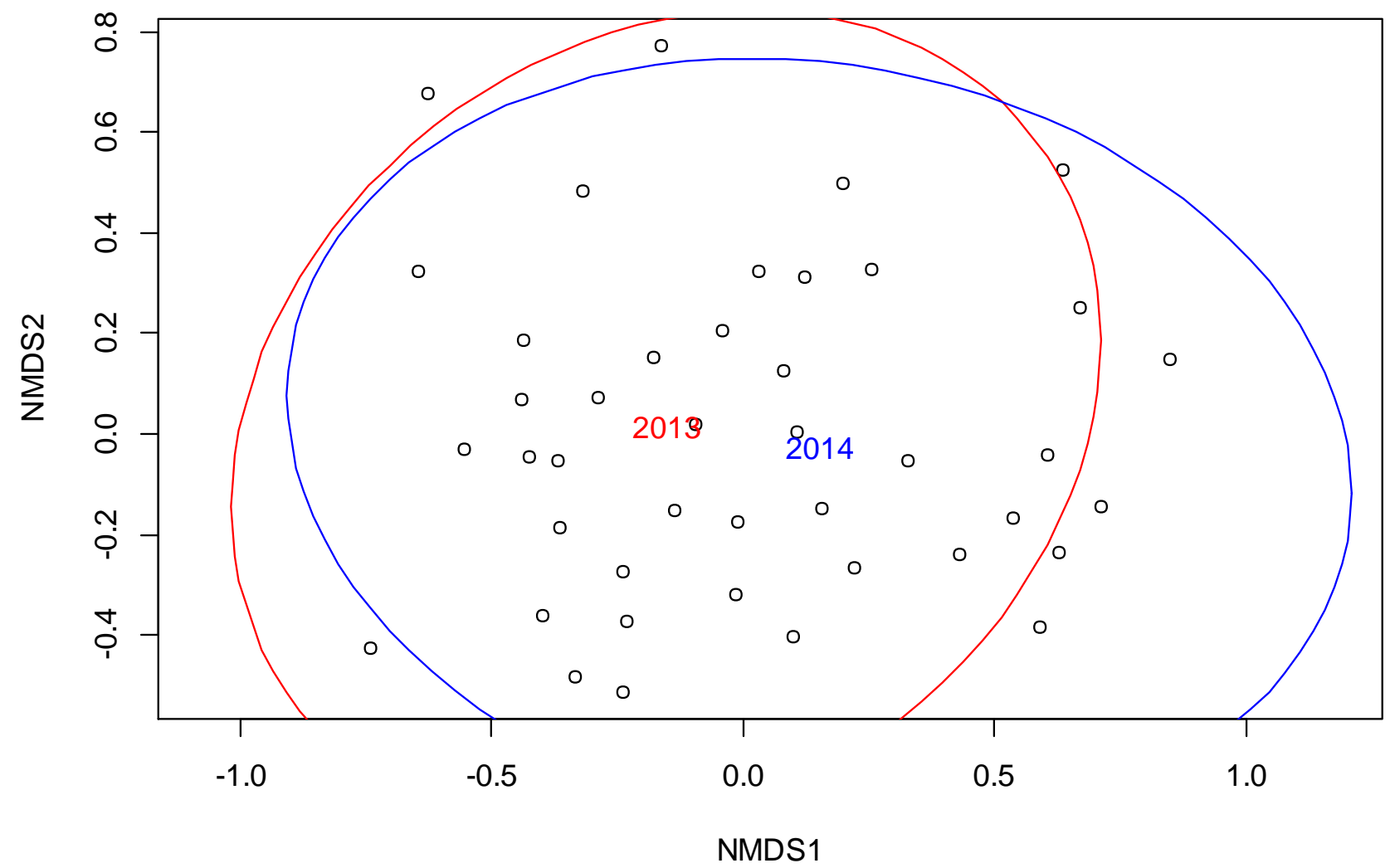

Figure 12: Non-metrical multidimensional scaling ordination plot of sites (2013-2014) within taxa space defined as two ordination axes $(\mathrm{k}=2$; stress $=0.18)$. The taxa used were genus level 2013-2014 with 95\% confidence interval ellipses drawn. This high degree of correlation was also evident by the procrustes test for these two sets which produced a symmetric procrustes rotation correlation of $0.56(\mathrm{p}=0.001)$ across 999 permutations. 


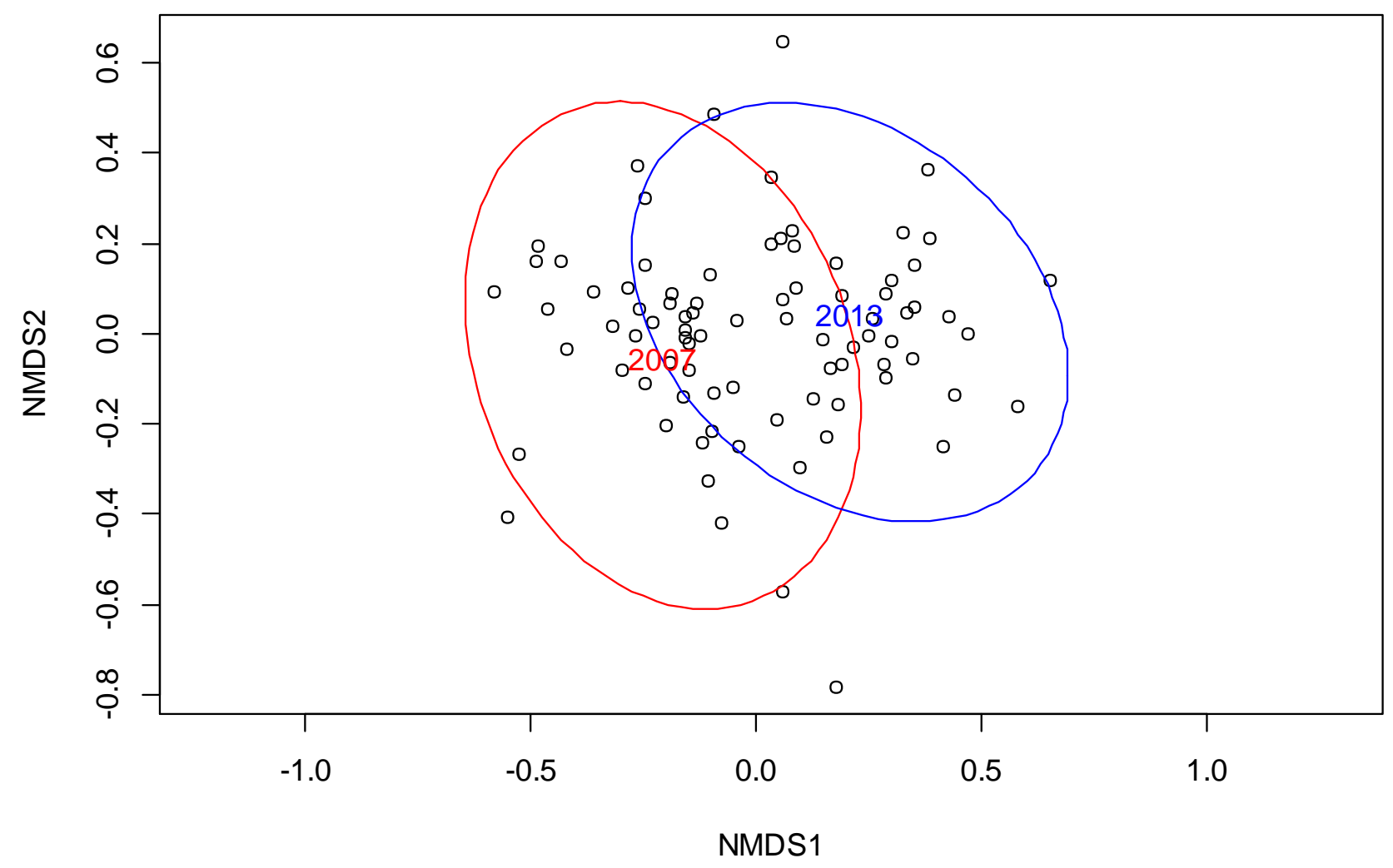

Figure 13: Non-metrical multidimensional scaling ordination plot of sites (2007 vs. 2013-2014 labeled as 2013 for simplicity) within taxa space defined as two ordination axes $(\mathrm{k}=2$; stress $=$ 0.19). The taxa used were family level with $95 \%$ confidence interval ellipses drawn. This low degree of correlation was also evident by the procrustes test for these two sets which produced a symmetric procrustes rotation correlation of $0.18(\mathrm{p}=0.41)$ across 999 permutations. 


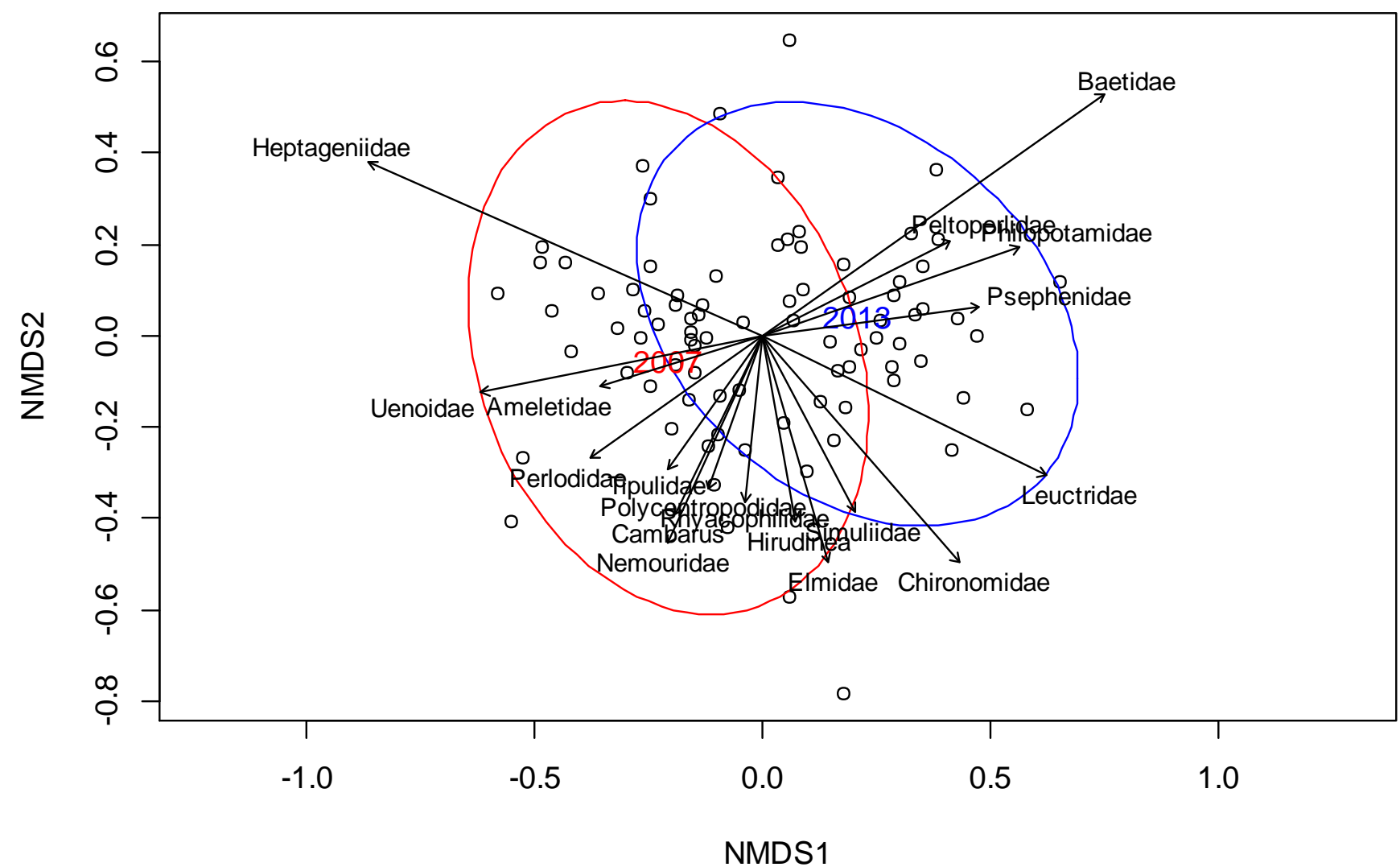

Figure 14: Non-metrical multidimensional scaling ordination plot of sites (2007 vs. 2013-2014 labeled as 2013 for simplicity) within taxa space defined as two ordination axes $(\mathrm{k}=2$; stress $=$ 0.19). The taxa used were family level with $95 \%$ confidence interval ellipses drawn. This low degree of correlation was also evident by the procrustes test for these two sets which produced a symmetric procrustes rotation correlation of $0.18(p=0.41)$ across 999 permutations. Vectors shown are macroinvertebrate families fit as linear relations to ordination dimensions with direction showing gradient and length of arrow approximating strength of relationship. Only those vectors with $\mathrm{p}>0.05$ across 999 permutations are displayed. 
Chapter 4: Using local and catchment-level variables to explain differences in BIA-predicted body composition of Brook Trout in headwater streams of West Virginia, USA

Ross G. Andrew* and Kyle J. Hartman

Division of Forestry and Natural Resources, Davis College of Agriculture, Natural Resources, and Design, 322 Percival Hall, West Virginia University, Morgantown, WV 26506-6125, USA

*Corresponding author, randrew4@ mix.wvu.edu Ph: (304)-293-0053 Fax: (304) 293-2441 
Abstract

Body condition is a driver of both individual and population characteristics such as behavior, survival, and reproduction. We used bioelectrical impedance analysis (BIA) along with markrecapture procedures on populations of Brook Trout to assess factors influencing body composition both spatially and temporally in headwater streams of West Virginia, USA. We hypothesized proximate body composition (measured as percent dry mass) would vary across watershed characteristics such as elevation, geology, and drainage area and local stream characteristics such as proportion of pools, spawning area, and large wood density. Using linear models defined a priori in a model selection framework, we found the greatest weight of evidence in models predicting trout body composition included explanatory variables for benthic macroinvertebrate density, fish length at age, and mean summer water temperature. The influence of drainage area and initial fish size were also examined in the context of the model sets. Trout that were marked and never recaptured were considered migrants and those recaptured over longer periods were considered residents and differences in length and percent dry weight (PDW) were examined between the two groups. Overall, migrants and residents showed no differences in length or PDW, but within two individual streams migrants had significantly longer lengths and higher PDW on average. Our findings suggest that the application of previously developed and validated BIA models to ecological research methods on wild stream fish populations may be informative for understanding habitat conditions and life history patterns that correspond to better or worse body condition across space and time. 
Introduction

Body condition of fishes is a useful measure which relates to both individual and population characteristics such as behavior, survival, and reproduction. Previous research has shown this measure to be related to important life history processes such as survival and transition from one life stage to another (Hoey and McCormick 2004). Spawning movement and effort may also be influenced by body condition (Slotte 1999). Also, basic behavioral attributes which often govern feeding ability, and ultimately survival, like swimming and covering performance may be largely influenced by body condition (Grorud-Colvert and Sponaugle 2006). All of these factors combine into a somewhat comprehensive measure of overall fitness with regard to important life history parameters of most fishes.

Measurements of body condition on fishes typically revolve around the relationships of length and weight in some mathematical function (Bolger \& Connolly 1989; Cone 1989). Several indices for condition have been used by fisheries scientists in the past and their use continues today in many management and research contexts. Simple regressions using length and weight can be effective at determining average weight for a given length and vice versa, but have been shown to contain bias in a negative direction for mean weight at length in some instances (Hayes et al. 1995). Fulton's condition factor (Fulton 1904) is often used and assumes isometric growth and an idealized three-dimensional shape of the fish body. Ricker (1975) created a relative condition factor which assumes allometric growth, but must only be used in comparisons for groups of fishes with similar length/weight relationships with respect to slope. Relative weight (Wege and Anderson 1978) is another index which compares individual fish to a population of "ideal proportions" which assumes the ideal proportion measurements are truly 
ideal and exact. However, all three of the common indices (Fulton's, relative condition, and relative weight) have been described to show bias associated with variation in individual length or other morphometric features in certain instances (Cone 1989).

While traditional methods and indices to assess fish body condition contain unique strengths and weaknesses, they contain assumptions about the body composition of fishes. Body composition refers to the actual components of the body measured as body fat, body muscle, body water, etc. These components represent a more complete picture of body fitness, as energetic supplies for survival and reproduction may be more clearly understood. Fishes are often undergoing significant movements of water and ions entering and exiting their bodies depending on the ionic concentration of both their body and the surrounding environment (Jobling 1995). This may create differences in body weight based upon water absorption or loss that have virtually no impact on fitness. Therefore, a method to assess body composition rather than just body condition could more accurately describe the health and potential fitness of fishes.

One such method for assessment of body composition is called bioelectrical impedance analysis (BIA). Originally developed in the medical field for humans (Lukaski et al. 1985), BIA has been shown to be a fast, accurate, and minimally invasive technique for use on fishes as well (Bosworth and Wolters 2001; Cox and Hartman 2005). The method uses a small current (425 $\mu \mathrm{A}, 50 \mathrm{kHz})$ which passes through the fish and provides a means to measure resistance and reactance of the current in ohms. Resistance, a measure of electrical conductivity (Cox and Hartman 2005), is related to the amount of body fat due to fat's poor conductive properties (Hafs and Hartman 2011). Reactance is more closely related to cellular volume, as it measures the capacitance of a cellular membrane (Lukaski 1987; Hafs and Hartman 2011). Once these values are obtained, calculations of parameters such as body water, fat-free mass, and dry mass (Cox 
and Hartman 2005) are possible along with percentage dry weight (hereafter, PDW) (Hafs and Hartman 2011). These values can then be used to assess populations and compare the average body composition as a proxy for fitness among different groups.

Brook Trout Salvelinus fontinalis is a species which holds great economic and ecological value within its native range. These populations have been impacted by human activities across much of their range, resulting in large declines in many subwatersheds (Hudy et al. 2006). Additionally, many areas of current Brook Trout presence are potentially at risk of extirpation given climate change scenario modeling (Flebbe at al. 2006). Therefore, understanding body composition trends across space and time for a species such as Brook Trout may be beneficial to predicting resilience of populations to future perturbations. This study first sought to identify variables which correlate to differences in PDW as a way to identify factors which may lead to improved condition and fitness of Brook Trout populations within headwater streams. Furthermore, variation in life history patterns for Brook Trout may yield both migratory and nonmigratory components (The'riault and Dodson 2003; Morinville and Rasmussen 2003). Such differences may lead to distinct morphological (Morinville and Rasmussen 2008) and bioenergetic (Morinville and Rasmussen 2003) characteristics. Therefore, we also sought to investigate the differences between these life history patterns with respect to BIA-derived PDW measures in Brook Trout of the same headwater streams of the Central Appalachians.

\section{Methods}

In order to address the questions concerned with BIA-measured PDW across space and time, we first sampled wild Brook Trout across an area $\sim 5500 \mathrm{~km}^{2}$ within their native range in the summer and early fall of 2013. These samples were then used to develop models which related local and watershed scale habitat and fish variables to the PDW of trout within each 
stream. Benthic macroinvertebrate samples were taken in spring and summer of 2013 and 2014 and were used as covariates in models attempting to identify PDW patterns. Stream water temperature was calculated using in-stream logger data from 2011 on these streams as part of another study. Although not a direct match with our sample years, previous work in headwater stream temperature modeling has shown no significant differences in annual mean or maximum temperature across much longer time intervals (Langan et al. 2001). Since canopy cover was very high within our sample sites, we felt confident that stream temperature would change very little (Studinski et al. 2012) and thus used a 7-day moving average to model the effect of water temperature on PDW in our later samples from 2013 and beyond. Additional Brook Trout samples were taken for tagging analysis in summer of 2014, 2015, and 2016 and were added to the overall data set for analysis of habitat association with PDW. The samples taken from 20142016 were focusing on the analysis of resident versus migrant trout using a combination of tagging and BIA. Unless otherwise detailed, habitat and fish variables (e.g. pool depth, fish density, etc.) that were used as covariates in models came from a long-term inventory of habitat and fish surveys on these streams and others conducted by K.J. Hartman at West Virginia University in cooperation with the U.S. Forest Service and WV Department of Natural Resources. Fish age estimates were derived from length-frequency analysis of this dataset which contains over 27,000 individual capture records. Separation of large and small adult Brook Trout was based upon total length of stock size lotic Brook Trout (130 mm TL; Anderson \& Neumann 1996). Additional details of each specific portion of the methodology are given below.

\section{Field Sampling}

Eleven headwater streams within the mountains of West Virginia, USA with persisting Brook Trout populations were selected. Streams with varying attributes such as drainage area, elevation, and geology were used to account for a set of potential conditions inhabited by these 
populations (Table 1). During summer and early fall 2013, Brook Trout were captured within each stream using backpack electrofishing within 200 meter sample reaches randomly selected within larger segments of at least 1000 linear meters. All trout were anesthetized in a solution of tricaine methanesulfonate (MS-222) and stream water before handling to minimize stress. Each individual trout was measured for total length $(\mathrm{mm})$, fork length $(\mathrm{mm})$, and wet weight $(\mathrm{g})$. Individuals with total length $>100 \mathrm{~mm}$ were also measured for resistance and reactance in ohms using a Quantum II bioelectrical body composition analyzer (RJL Systems, Clinton Township, Michigan) following methods described by Hafs and Hartman (2011). Identical subdermal needles were used following the equipment and methodology of Hafs and Hartman (2011). Following measurement, fish were allowed to recover from handling in stream water for several minutes and released back into the stream without noticeable harm. Associated habitat variables such as water temperature, substrate composition, network position, etc. (Table 1) were either measured on site during sampling or calculated remotely via previous habitat survey datasets or using GIS.

Three of the 11 headwater streams were designated for mark-recapture methods in addition to the previously mentioned BIA sampling methods. These streams were selected due to their higher drainage areas at the location of sampling (Table 1) which we believed would allow more efficient detection of migrant versus resident trout. On these three streams, in addition to the BIA measurements, individual Brook Trout received a uniquely identifiable tag in the caudal fin created by injecting visible implant elastomer (VIE; Northwest Marine Technology, Shaw Island, Washington, USA) between the caudal fin rays in unique number and color combinations Four separate sampling events occurred within these sections across a one year recapture period in order to estimate instantaneous recapture rates (within 24 hours of initial 
tagging) and recapture rate after approximately one year. The initial tagging was completed in 2014 and 2015 with recapture events occurring in 2015 and 2016 at respective sites. At the initial sampling event, the entire 200 meter section was continuously electrofished and all captured Brook Trout were held in buckets and live wells while being measured and processed. At subsequent sampling events, a 600 meter section containing the original 200 meter section in the center was electrofished. This was to ensure that recaptured individuals had not simply moved a short distance outside of the original sample reach boundary. Those individuals that were recaptured in subsequent samples following the initial event were then considered resident while those that were not recaptured were considered emigrants or deceased. During the spring and summer of 2013 and 2014, within each sampling section, macroinvertebrates were sampled using a kicknet with attached 500 micron mesh collection chamber following procedures outlined by the West Virginia Department of Environmental Protection Watershed Assessment Program and United States Environmental Protection Agency Rapid Bioassessment Protocols for wadeable streams (WVDEP 2003; Barbour et al. 1999). At each sample site, four random habitat units were sampled to create a total of a one-square meter portion of the stream substrate and preserved in $85 \%$ ethanol for analysis and identification in the lab.

\section{Laboratory Methods and Analysis}

Macroinvertebrate specimens were separated from debris using a dissecting microscope and further preserved in $85 \%$ ethanol to be identified. Each substrate sample was picked randomly with the goal of $200 \pm 20$ individual macroinvertebrates per sample in accordance with the West Virginia Department of Environmental Protection standard sampling protocols for macroinvertebrates. Based upon the amount of standardized sample units used to reach the sample total of $200 \pm 20$ individuals, we were able to calculate mean macroinvertebrate density per sample site. 
Based upon the models created and validated for field measurement of PDW of wild Brook Trout in West Virginia by Hafs (2011), we calculated the estimated PDW of all fish within each sample at each site. Temperature correction was used following guidelines of Hafs and Hartman (2015) to adjust all resistance and reactance measures to standardized temperature of $12.5^{\circ} \mathrm{C}$. We were careful to use the BIA predictive model from Hafs (2011) with the highest $\mathrm{R}^{2}$ value (0.84) which was developed using subdermal needles on age $1+$ fish taken over a monthly mean. This model drove our sampling and analysis scheme and gave us confidence as a previous review of BIA models deemed successful models as those with $\mathrm{R}^{2} \geq 0.8$ (Hartman et al. 2015). Hafs and Hartman (2011) showed considerable variation in PDW in individual Brook Trout and thus only mean values of all fish at a given site were used in the modeling of habitat variables as they related to percent dry mass.

Percent dry weight of fish in each stream was regressed against biotic and abiotic explanatory variables shown in Table 1. Each model was developed a priori with specific hypotheses related to ecological phenomena that were deemed important to defining dry weight of wild fish. Examples include models that were driven by intraspecific competition for resources (fish density and macroinvertebrate density), tradeoffs for growth and metabolism (water temperatures and macroinvertebrate density), and habitat productivity and network position (drainage area and distance to tributary) among others. All candidate models were computed and compiled using R statistical software (R Development Core Team 2008) as linear models. The package "AICcmodavg" was used to calculate Akaike's information criterion corrected for smaller sample sizes (AICc) for each model and compare them using model weights. For the best performing models, parameters were averaged across models and simple linear relationships with estimated dry weight were calculated to more clearly define the 
relationships. In the three streams where mark-recapture methods were used in concert with BIA, individual measures were used to calculated changes in measured wet weight, total length, and PDW across the annual recapture period. Differences in recaptured fish and non-recaptured fish were tested within each site using t-tests adjusting for unequal variances. Individuals recaptured over the annual period were also compared to assess changes in wet weight, PDW, and total length. Also, across all years and streams with sampled Brook Trout, we compiled PDW values and used analysis of variance to identify any significant differences among years.

\section{Results}

In total, 270 adult Brook Trout across 11 streams were used for the candidate model creation and selection analysis. Mean total length was 157.7 millimeters, mean wet weight was 42.5 grams, and mean PDW was $23.36 \%$ (Table 1). We created 23 candidate models including a null model and compared them using AICc value and model weights (Table 2). The top eight models all had AICc scores within four units of the top performing model and were the only models which received any weight in the full ensemble. All of these models included the parameter for macroinvertebrate density (abbreviated label "bug density"). The model averaged parameter estimate for macroinvertebrate density was $2.35 \pm 0.45$ individuals $/ \mathrm{cm}^{2}$. The only other variable with a model averaged parameter estimate not containing zero within the $95 \%$ confidence interval was mean age 2 fish length $(0.06 \pm 0.03$ PDW per mm). The AICc weights and evidence ratios indicate that no model within the top eight was clearly the best model and thus model average parameter estimates were deemed appropriate.

Following the model selection process and parameter estimation, we created four simple linear regression models to further investigate the relationship of single parameters of interest to PDW. The first model was based upon the mean macroinvertebrate density that showed a 
positive relationship with PDW. The regression yielded an estimate of $2.41 \pm 0.42$ PDW per individuals $/ \mathrm{cm}^{2}$ ( $\mathrm{p}<0.001$; adjusted $\mathrm{R}^{2}=0.76$; Figure 1). The single model for only age two trout length yielded a positive estimate of $0.06 \pm 0.03$ PDW per $\mathrm{mm}\left(\mathrm{p}=0.04\right.$; adjusted $\mathrm{R}^{2}=$ 0.32; Figure 2). Single models for mean summer water temperature and maximum summer water temperature were not significant but did show positive coefficient trends $(p=0.09 \& 0.21$; Figures $3 \& 4$, respectively).

Across all years and streams with sampled Brook Trout, there were no significant differences in PDW ( $p=0.32$; Figure 5). While the samples from 2013, 2015, and 2016 were collected primarily in the summer (less than $27 \%$ of individuals collected after September $15^{\text {th }}$ ), the 2014 samples were all collected in the fall (after mid-September). In years where Brook Trout were marked and later recaptured, instantaneous (24 hr.) rates of recapture ranged from 38$72 \%$ with mean 58\%. It was assumed that within 24 hours the Brook Trout did not significantly change their body composition so no comparisons were made on the instantaneous recapture values. However, on the annual recaptured fish, recapture rates ranged from $16-32 \%$ with mean $22 \%$. Across all marked fish, there were no significant differences between recaptured and nonrecaptured individuals with respect to mean PDW and measured total length (Table 3).

However, within one stream, Crooked Fork, non-recaptured fish had significantly higher PDW than recaptured fish (Table 3). North Fork Red Run had significantly higher total length in nonrecaptured fish than recaptured fish (Table 3).

Recaptured trout showed positive growth with respect to total length, wet weight, and PDW across the longer annual recapture period. Increases in total length showed positive significant relationships with change in wet weight $(\mathrm{p}<0.001$; Figure 6$)$ and change in PDW ( $\mathrm{p}$ $=0.03$; Figure 7). However, change in wet weight did not show a significant relationship with 
change in PDW (Figure 8). Fish with relatively smaller initial total length at the time of capture and tagging tended to cluster in groups of higher increases in total length and PDW but not wet weight (Figures 6-8; size of points in plot). Although non-significant, smaller individuals (initial $\mathrm{TL}<150 \mathrm{~mm})$ showed larger increases in total length $(29.4 \mathrm{~mm}$ vs. $21.1 \mathrm{~mm})$ and PDW(3.6\% vs. $2.8 \%)$ than individuals with larger $(>150 \mathrm{~mm})$ initial size. Larger individuals did show a higher increase in wet weight (25.4g vs. $21.8 \mathrm{~g}$ ) than the smaller individuals.

\section{Discussion}

Across our samples, Brook Trout PDW was most related to macroinvertebrate prey density, adult fish length at age, and summer water temperatures. These factors combine to effectively describe constraints on growth for trout living in headwater streams where intraspecific competition is often high. Increased invertebrate prey density in mountain streams has been shown to correspond to increases in Brook Trout consumption of invertebrate prey (Allan 1981). However, previous research has documented the importance of terrestrial prey inputs to the energetics of Brook Trout in these habitats (Utz \& Hartman 2007; Sweka \& Hartman 2008; Petty et al. 2014). We did not sample terrestrial inputs directly but can assume their presence in, and contribution to, the growth of these trout as all sampled habitats had high amounts of canopy cover in the headwater sample areas. Therefore, we may surmise the difference in benthic invertebrate production may account for some level of differentiation in Brook Trout PDW as the more commonly encountered and consumed prey source throughout a given year. Brook Trout have been documented to show feeding preference for aquatic invertebrates over terrestrial invertebrates in some headwater streams of their native range (Wilson et al. 2014), but preference for terrestrial invertebrates in other streams (Courtwright \& May 2013). Therefore, it appears context may be important in defining the invertebrate prey dynamics of a particular system and how it relates to energetic efficiency of Brook Trout. 
Trout that were longer at later ages showed higher PDW. This ability to grow efficiently may be owed to individual fish metabolic characteristics, or more likely the productivity of the local stream habitat. We saw some influence of drainage area to the size of fish at age two (Figure 2), with larger drainage areas generally corresponding to longer lengths at age and higher PDW. Larger drainage area habitats would likely be more productive in terms of food abundance and type, with higher quality food sources such as fish holding significantly more calories per gram than invertebrate prey types (Cummins \& Wuycheck 1971). Petty et al. (2014) showed lower growth efficiencies for larger trout in headwater habitats in fall. In one fluvially connected site (N. Fork Red Run), we saw significantly higher total lengths in fish that were marked then never recaptured (Table 3). These fish likely emigrated from the study reach in order to escape the lower growth efficiencies of the headwaters and move to more productive feeding areas.

Temperature was also a useful determinant in modeling trout PDW across sites. Increasing mean summer water temperature corresponded to increases in PDW across sites. The effects of water temperature on Brook Trout ecology have been documented in previous research (Hartman \& Sweka 2001; Hartman \& Cox 2008; Xu et al. 2010; Petty et al. 2012). Increases of consumption and metabolism for Brook Trout with increasing temperature have been shown with a threshold value near $20-21{ }^{\circ} \mathrm{C}$ where consumption and metabolism plummet due to thermal stress (Hartman \& Cox 2008). Furthermore, the optimal temperature range for Brook Trout growth has been modeled successfully with an upper limit estimate of $19^{\circ} \mathrm{C}$. Our findings of mean summer water temperatures reached a maximum of only $17.5^{\circ} \mathrm{C}$ and thus the positive and nearly significant relationship remained linear with PDW (Figure 3). However, the maximum 
summer temperature estimates showed a clear break in the increasing linear pattern beyond $21^{\circ} \mathrm{C}$ with estimated dry weight (Figure 4). Brook Trout in this region have been shown to select habitats with lower temperatures once ambient water temperatures reach $20^{\circ} \mathrm{C}$ or higher (Petty et al. 2012). This indicates that within that stream of higher summer maximum water temperatures, trout were more likely beyond their optimal thermal limit and began to lose dry mass due to increasing metabolic stress/movement costs outside their Scope for Growth (Brett 1976). Drainage area showed slight relationships to temperature conditions at each sample site (Figures $3 \& 4$ ), but not enough to drive significant relationships. Additionally, the smaller drainage area site with the higher maximum summer water temperature (Figure 4) has logging activity in the riparian zone, which likely elevated the stream temperature significantly based upon loss of canopy cover (Janisch et al. 2012; Studinski et al. 2012).

Across all years with BIA samples taken, there were no significant differences in PDW (Figure 5). However, the majority of samples taken in the 2013, 2015, and 2016 years were taken during the summer months while all of the samples taken in 2014 were taken in the fall (after Sept. 15 ${ }^{\text {th }}$ ). Brook Trout in these systems have been shown to experience large decreases in PDW between the end of summer and middle of fall (Hafs \& Hartman 2017). We suspect this loss of PDW, presumably attributed to energetic effort of spawning, could explain why the 2014 mean PDW was lower than the other years (although non-significant). Fieldwork constraints limited the sample size in 2014, and additional time periods for sampling across seasons would have strengthened the relationships, or lack thereof.

Trout that were recaptured across the annual time interval were somewhat rare. Those that were recaptured showed positive growth with respect to length and both wet weight and PDW. Recaptured trout that increased their total length had greater increases in wet weight 
(Figure 6). Trout that started at a smaller total length generally increased their length and weight more than trout with a larger starting size. A somewhat similar pattern held for increases of total length and PDW (Figure 7). This is not surprising, as consumption and growth rates have been shown to be higher for Brook Trout at smaller sizes (Hartman \& Cox 2008). The lack of a relationship between changes in wet weight and PDW (Figure 8) indicates potential bias associated with larger, spawning trout. While recapture events were not conducted during spawning season, it is reasonable to suggest that large female spawning trout from the previous fall had large energetic losses from egg production (Hafs \& Hartman 2017), which were unable to be fully recovered by our sampling period. Therefore, these fish would carry lower PDW and higher wet weight values as the difference could be due to retention of water weight. Smaller individuals shows a positive relationship with increases of wet weight and PDW (Figure 7).

The majority of trout that were marked initially were never recaptured. Those fish recaptured are considered resident, while non-recaptured fish were considered migrants. Although we cannot separate emigration from death in the migrant fish, we assumed resident fish moved very little compared to migrants based upon previous research in these systems (Hartman \& Logan 2010; Petty et al. 2012). In one stream, migrants were significantly longer than residents while another stream showed migrants with significantly higher PDW (Table 3). The stream with higher PDW for migrants has undergone significant channel reorganization within the study reaches since 2013 due to high flow events. This may contribute to poorer feeding conditions experienced by the resident trout throughout the year and help explain some of the PDW differences. Because these headwater populations often operate under density dependent regulation, the incentive to move could be related to increasing metabolic costs near carrying capacity (Kitchell et al. 1974). Increased respiration level due to increased density-dependent 
hierarchical interactions may cost trout up to $36 \%$ of consumed energy (Kitchell et al. 1974). Therefore, larger fish with higher PDW may be drawn away from the difficult feeding conditions of the headwaters to areas downstream with higher consumption and growth potential (Utz \& Hartman 2006 Petty et al. 2014). In nearby and overlapping streams of West Virginia, headwater resident Brook Trout have been shown to be shorter and in poorer body condition than fluvial adults (Stolarski \& Hartman 2010). This supports our findings of migrants as larger individuals with higher PDW in some streams. Morinville and Rasmussen (2003) found migratory Brook Trout in Canada to be smaller and have lower growth efficiencies than residents. This resulted in higher consumption rates for migrants and the adoption of a mobile life history in order to meet energetic demands that could not be satisfied in resident headwaters. In the Rocky Mountains, trout have shown patterns of higher movement corresponding to larger size and poorer condition (Gowen \& Fausch 1996; Hilderbrand \& Kershner 2004). This both agrees and disagrees somewhat with our findings, but should be viewed with the distinction of the local habitat for each study. Thermal limitation is less for Brook Trout in Canada than West Virginia based upon climate and therefore connectivity to downstream habitats is more likely over longer distances. Further, the origin of a particular strain of Brook Trout has been shown to affect the thermal tolerance and performance across increasing temperature regimes (Stitt et al. 2014). Additionally, the definition of migrant versus resident trout in previous studies was more absolute with traps capturing migrating individuals. Migration may only be advantageous in certain stream networks of West Virginia with less thermal limitation and may be operating to "pull" larger individuals with higher PDW and baseline energetic demands while it appears to "push" smaller individuals who cannot effectively compete/feed to meet their higher energetic demands in less thermally limited systems (e.g. Morinville \& Rasmussen 2003). 
Fishes may be driven to select certain habitats or seek others via movement for many reasons. Tradeoffs that determine energetic efficiency, reproductive ability, and ultimately survival are the axes which fishes must adjust their life history patterns upon. Rosenfeld and Boss (2001) found energetics to help dictate habitat selection for Cutthroat Trout Oncorhynchus clarkii with larger individuals staying in pools to optimize growth while young of the year showed growth in both riffle and pool habitats. Interspecific competition may also influence optimal foraging and habitat selection within stream fishes (Fausch \& White 1981; Essington et al. 1998). In our study sites, Brook Trout are the top fish predator and are seldom sympatric with Brown Trout Salmo trutta but would likely compete with them in many areas downstream of the sampling sites. Therefore, the influence of interspecific competition is likely close to zero within the sampling area, but is unknown and likely higher in downstream areas where migrants may travel. Further use of body composition and energetic modeling will be useful in better understanding the balance of risk and reward these fish take to move and feed in complementary/ supplementary habitats within riverscapes.

The use of bioelectrical impedance analysis in fisheries has grown since the early stages of model development and validation in the early $21^{\text {st }}$ century (Bosworth \& Wolters 2001; Cox \& Hartman 2005). Improvements and refinements of early models have yielded success in additional standardization of methodology for certain species (Hafs \& Hartman 2011). Furthermore, addition of realistic model components such as temperature corrections (Hartman et al. 2011; Hafs \& Hartman 2015) have made these models more applicable to wild fishes and associated ecological questions. This study focuses on the use of a previously validated BIA model for wild Brook Trout (Hafs 2011) to answer ecologically relevant questions defined by habitat and life history conditions. Therefore, it should be evaluated with caution as an early 
attempt to apply a newly developed tool to real world ecological understanding. Cox and Hartman (2005) suggested the use of BIA at the individual, population, and community level for improved understanding of energetic endpoints at differing temporal and spatial scales. Within this work, we show the ability to identify body condition (as PDW) differences across space and relate those differences to local habitat conditions. We also show the ability to track growth on individuals within a given stream to determine successful additions of dry mass along with added length and wet weight. We understand that more research is needed and we suggest higher sample sizes across time and space for more precise detection of body condition trends in future efforts. As the suite of potential disturbance and climatic scenarios diversifies, greater understanding of the elements presented here will surely be needed. The validation and study of the methods themselves are outside the scope of this project, but continued improvements of models, especially those for native fishes, is warranted as it may help inform management and conservation decisions into the future.

\section{Literature Cited}

Allan, J. D. 1981. Determinants of Diet of Brook Trout (Salvenlinus fontinalis) in a Mountain Stream. Canadian Journal of Fisheries and Aquatic Sciences 38(2):184-192.

Amara, R., T. Meziane, C. Gilliers, G. Hermel, and P. Laffargue. 2007. Growth and condition indices in juvenile sole Solea solea measured to assess the quality of essential fish habitat. Marine Ecology Progress Series 351(December 2007):201-208.

Anderson, R. O. \& R. M. Neumann, 1996. Length, weight, and associated structural indices. In Zale, A. V., D. L. Parrish, \& T. M. Sutton. (Eds.). 2012. Fisheries Techniques. $3^{\text {rd }}$ ed. American Fisheries Society, Bethesda, MD: 642-654.

Barbour, M. T., J. Gerritsen, B. D. Snyder, AND J. B. Stribling. 1999. Rapid bioassessment protocols for use in streams and wadeable rivers: periphyton, benthic macroinvertebrates, 
and fish. 2nd edition. EPA 841-B-99-022. Office of Water, US Environmental Protection Agency, Washington, DC.

Bolger, T., \& Connolly, P. L. (1989). The selection of suitable indices for the measurement and analysis of fish condition. Journal of Fish Biology, 34(2), 171-182.

Bosworth, G., R. Wolters, U. States, and C. Genetics. 2001. Evaluation of Bioelectric Impedance to Predict Carcass Yield, Carcass Composition, and Fillet Composition in Farm-Raised Catfish 32(1):72-78.

Brett, J. R. 1976. Scope for Metabolism and Growth of Sockeye Salmon, Oncorhynchus nerka, and Some Related Energetics. Journal of the Fisheries Research Board of Canada 33:307313.

Cone, R. S. 1989. The Need to Reconsider the Use of Condition Indices in Fishery Science. Transactions of the American Fisheries Society (4):510-514.

Courtwright, J., and C. L. May. 2013. Importance of terrestrial subsidies for native brook trout in Appalachian intermittent streams. Freshwater Biology 58(11):2423-2438.Cox, M. K., and K. J. Hartman. 2005. Nonlethal estimation of proximate composition in fish. Canadian Journal of Fisheries and Aquatic Sciences 62(2):269-275.

Cummins, K. W., and J. C. Wuycheck. 1971. Caloric Equivalents for Investigations in Ecological Energetics: with 2 figures and 3 tables in the text. Internationale Vereinigung fur Theoretische und Angewandte Limnologie: Mitteilungen 18(1):1-158.

Essington, T. E., P. W. Sorensen, and D. G. Paron. 1998. High rate of redd superimposition by brook trout ( Salvelinus fontinalis ) and brown trout ( Salmo trutta ) in a Minnesota stream cannot be explained by habitat availability alone 2316:2310-2316.

Fausch, K. D., and R. J. White. 1981. Competition between Brook Trout (Salvelinus fontinalis) and Brown Trout (Salmo trutta) for positions in a Michigan Stream. Canadian Journal of Fisheries and Aquatic Sciences 38(10):1220-1227.

Flebbe, P. A., L. D. Roghair, and J. L. Bruggink. 2006. Spatial Modeling to Project Southern Appalachian Trout Distribution in a Warmer Climate. Transactions of the American Fisheries Society 135:1371-1382.

Fulton, T. W. 1904. The rate of growth of fishes. Twenty-second Annual Report: 141-241.

Gowan, C., and K. D. Fausch. 1996. Mobile brook trout in two high-elevation Colorado streams : re-evaluating the concept of restricted movement 1381:1370-1381.

Grorud-colvert, K., and S. Sponaugle. 2006. Influence of condition on behavior and survival potential of a newly settled coral reef fish, the bluehead wrasse Thalassoma bifasciatum. Marine Ecology Progress Series 327:279-288. 
Hafs, A. W., and K. J. Hartman. 2015. Development of temperature correction equations for bioelectrical impedance analysis models for brook trout Salvelinus fontinalis: 304-316.

Hafs, A. 2011. Bioelectrical Impedance Analysis Methods for Prediction of Brook Trout Salvelinus fontinalis Percent Dry Weight. West Virginia University.

Hafs, A. W., and K. J. Hartman. 2017. Seasonal Changes in Condition of Appalachian Brook Trout. North American Journal of Fisheries Management 37(1):196-206. Taylor \& Francis. Hafs, A. W., and K. J. Hartman. 2011. Influence of Electrode Type and Location upon Bioelectrical Impedance Analysis Measurements of Brook Trout (2008):1290-1297.

Hartman, K. J., and S. B. Brandt. 1992. Estimating Energy Density of Fish. Transactions of the American Fisheries Society 124(3):347-355.

Hartman, K. J., and M. K. Cox. 2008. Refinement and Testing of a Brook Trout Bioenergetics Model. Transactions of the American Fisheries Society 137(1):357-363.

Hartman, K. J., and M. N. Logan. 2010. Movement and Habitat Use by Transplanted Adult Brook Trout in an Appalachian Headwater Stream. Northeastern Naturalist 17(3):357-372.

Hartman, K. J., F. J. Margraf, A. W. Hafs, and M. K. Cox. 2015. Bioelectrical Impedance Analysis : A New Tool for Assessing Fish Condition. Fisheries 40(12):590-600.

Hartman, K. J., W. Virginia, B. A. Phelan, and J. E. Rosendale. 2011. Temperature Effects on Bioelectrical Impedance Analysis (BIA) Used to Estimate Dry Weight as a Condition Proxy in Coastal Bluefish: 307-316.

Hayes, D., J. K. T. Brodziak, and J. B. O. Gorman. 1995. Efficiency and bias of estimators and sampling designs for determining length-weight relationships of fish. Canadian Journal of Fisheries and Aquatic Sciences 92:84-92.

Hilderbrand, R. H., and J. L. Kershner. 2004. Are There Differences in Growth and Condition between Mobile and Resident Cutthroat Trout? Transactions of the American Fisheries Society 133:1042-1046.

Hoey, A. S., and M. I. Mccormick. 2004. Selective predation for low body condition at the larval-juvenile transition of a coral reef fish. Oecologia 139:23-29.

Hudy, M., T. M. Thieling, N. Gillespie, and E. P. Smith. 2005. Distribution, Status and Threats to Brook trout within the eastern United States Mark Hudy and Teresa M. Thieling. Report submitted to the Eastern Brook Trout Joint Venture, International Association of Fish and Wildlife Agencies, Washington, D.C.

Janisch, J. E., S. M. Wondzell, and W. J. Ehinger. 2012. Headwater stream temperature: Interpreting response after logging, with and without riparian buffers, Washington, USA. Forest Ecology and Management 270:302-313. 
Jobling, M. 1995. Environmental Biology of Fishes. Chapman \& Hall, New York.

Kitchell, J. F., J. F. Koonce, R. V. O’Neill, H. H. Shugart, J. J. Magnuson, and R. S. Booth. 1974. Model of Fish Biomass Dynamics. Transactions of the American Fisheries Society 103(4):786-798.

Langan, S. J., L. Johnston, M. J. Donaghy, a F. Youngson, D. W. Hay, and C. Soulsby. 2001. Variation in river water temperatures in an upland stream over a 30-years period. Science of the Total Environment 265:195-207.

Lloret, J., R. Galzin, L. Gil de Sola, A. Souplet, and M. Demestre. 2005. Habitat related differences in lipid reserves of some exploited fish species in the north western Mediterranean continental shelf. Journal of Fish Biology 67(1):51-65.

Lukaski, H. C., P. E. Johnson, W. W. Bolonchuk, and G. I. Lykken. 1985. Assessment impedance of fat-free mass using bioelectrical measurements of the human body. The American Journal of Clinical Nutrition 41:810-817.

Morinville, G. R., and J. B. Rasmussen. 2003. Early juvenile bioenergetic differences between anadromous and resident brook trout (Salvelinus fontinalis). Canadian Journal of Fisheries and Aquatic Sciences 60(4):401-410.

Morinville, G. R., and J. B. Rasmussen. 2008. Distinguishing between juvenile anadromous and resident brook trout (Salvelinus fontinalis) using morphology. Environmental Biology of Fishes 81:171-184.

Oliva-Paterna, F. J., P. A. Miñano, and M. Torralva. 2003. Habitat quality affects the condition of Barbus sclateri in Mediterranean semi-arid streams. Environmental Biology of Fishes 67(1):13-22.

Petty, J. T., J. L. Hansbarger, B. M. Huntsman, and P. M. Mazik. 2012. Brook trout movement in response to temperature, flow, and thermal refugia within a complex Appalachian riverscape. Transactions of the American Fisheries Society 141(4):1060-1073.

Petty, J. T., D. Thorne, B. M. Huntsman, and P. M. Mazik. 2014. The temperature-productivity squeeze: Constraints on brook trout growth along an Appalachian river continuum. Hydrobiologia 727(1):151-166.

Ricker, W. E. 1975. Computation and Interpretation of Biological Statistics of Fish Populations. Bulletin of the Fisheries Research Board of Canada 191:1-382.

Rosenfeld, J. S., and S. M. Boss. 2001. Fitness consequences of habitat use for juvenile cutthroat trout: energetic costs and benefits in pools and riffles. Canadian Journal of Fisheries and Aquatic Sciences 58(1995):585-593. 
Slotte, A. 1999. Effects of fish length and condition on spawning migration in Norwegian spring spawning herring (Clupea harengus). Sarsia 84(2):111-127.

Stolarski, J. T., and K. J. Hartman. 2010. Comparisons of growth and condition of fluvial and resident brook trout within partially migratory populations. Fisheries Management and Ecology 17(1):33-39.

Stitt, B. C., G. Burness, K. A. Burgomaster, S. Currie, L. Mcdermid, C. C. Wilson. 2018. Comparative Biology Intraspecific Variation in Thermal Tolerance and Acclimation Capacity in Brook Trout (Salvelinus fontinalis): Physiological Implications for Climate Change Intraspecific Variation in Thermal Tolerance and Acclimation Capacity in Brook Trout (Salvelinus fontinalis): Physiological Implications for Climate Change*.

Studinski, J. M., K. J. Hartman, J. M. Niles, and P. Keyser. 2012. The effects of riparian forest disturbance on stream temperature, sedimentation, and morphology. Hydrobiologia 686(1):107-117.

Sweka, J. a. 2003. Aquatic-Terrestrial Linkages in Appalachian Streams: Influence of Riparian Inputs on Stream Habitat, Brook Trout Populations, and Trophic Dynamics. West Virginia University.

Sweka, J. A., and K. J. Hartman. 2008. Contribution of Terrestrial Invertebrates to Yearly Brook Trout Prey Consumption and Growth. Transactions of the American Fisheries Society 137(1):224-235.

Theriault, V., and J. J. Dodson. 2003. Body size and the adoption of a migratory tactic in brook charr. Journal of Fi 63:1144-1159.

Utz, R. M., and K. J. Hartman. 2006. Temporal and spatial variation in the energy intake of a brook trout (Salvelinus fontinalis) population in an Appalachian watershed. Canadian Journal of Fisheries and Aquatic Sciences 63(12):2675-2686.

Utz, R. M., and K. J. Hartman. 2007. Identification of critical prey items to Appalachian brook trout (Salvelinus fontinalis) with emphasis on terrestrial organisms. Hydrobiologia 575(1):259-270.

Wege, G. J., and R. O. Anderson. 1978. Relative weight (Wr): a new index of condition for largemouth bass. New approaches to the management of small impoundments. American Fisheries Society Special Publication 5:79-91.

Wilson, M. K., W. H. Lowe, and K. H. Nislow. 2014. What predicts the use by brook trout (Salvelinus fontinalis) of terrestrial invertebrate subsidies in headwater streams? Freshwater Biology 59(1):187-199. 
WVDEP (West Virginia Department of Environmental Protection). 2003. Benthic invertebrate sampling, processing, and analysis standard operating procedures. West Virginia Department of Environmental Protection, Charleston, West Virginia. 
Tables

Table 1: Stream characteristics used in explanatory analysis of Brook Trout percent dry weight. Mean estimated dry weight was calculated on the number of individual fish sampled per stream in spring-fall sampling season of 2013 (mean $\mathrm{N}=25$ fish per stream). Mean macroinvertebrate density was calculated from kicknet samples taken during spring and summer 2013 on the same streams. Mean water temperatures were calculated for each stream using continuous temperature logger data on each stream from the full calendar year of 2011. All other variables were calculated from concurrent habitat and fish surveys on these streams.

\begin{tabular}{|c|c|c|c|c|c|c|c|c|c|c|}
\hline Stream & $\begin{array}{c}\text { Elevation } \\
\text { (m) }\end{array}$ & $\begin{array}{c}\text { Slope } \\
(\%)\end{array}$ & Geologic Unit & $\begin{array}{c}\text { Drainage } \\
\text { Area } \\
\left(\mathbf{k m}^{2}\right)\end{array}$ & $\begin{array}{c}\text { Mean } \\
\text { Brook } \\
\text { Trout Dry } \\
\text { Weight } \\
(\%)\end{array}$ & $\begin{array}{l}\text { Mean Max. } \\
\text { Pool Depth } \\
\quad(\mathrm{cm})\end{array}$ & $\begin{array}{c}\text { Mean Brook } \\
\text { Trout Density } \\
\text { (fish/100 m) }\end{array}$ & $\begin{array}{c}\text { Mean } \\
\text { Macroinverbrate } \\
\text { Density }\left(\# / \mathrm{cm}^{2}\right)\end{array}$ & $\begin{array}{c}\text { Mean } \\
\text { Summer } \\
\text { Water Temp. } \\
\left(\text { 7-day; }{ }^{\circ} \mathbf{C}\right)\end{array}$ & $\begin{array}{c}\text { Mean Max. } \\
\text { Summer } \\
\text { Water Temp } \\
\left(\text { 7-day; }{ }^{\circ} \mathbf{C}\right)\end{array}$ \\
\hline Birch Fork & 865 & 3.2 & Pottsville (Limed) & 5.1 & 23.5 & 60.8 & 30.9 & 1.70 & 16.5 & 20.1 \\
\hline Clubhouse Run & 955 & 7.8 & Chemung & 8.1 & 22.6 & 66.7 & 29.2 & 1.81 & 15.9 & 20.0 \\
\hline Crooked Fork & 1020 & 5.4 & Mauch Chunk & 8.4 & 23.9 & 42.6 & 17.9 & 1.91 & 16.2 & 21.0 \\
\hline Elklick Run & 613 & 18.1 & Hampshire & 13.7 & 24.7 & 71.9 & 31.9 & 2.39 & 17.1 & 20.8 \\
\hline Elleber Run & 1129 & 19.7 & Chemung & 5.6 & 24.6 & 72.2 & 38.3 & 2.39 & 15.3 & 19.0 \\
\hline Lick Run & 972 & 9.3 & Chemung & 2.3 & 22.7 & 46.4 & 4.7 & 1.85 & 16.2 & 24.2 \\
\hline Light Run & 757 & 9.4 & Pottsville (Unlimed) & 6.1 & 24.1 & 55.5 & 16.4 & 2.37 & 17.4 & 21.4 \\
\hline Little Branch & 1075 & 6.7 & Pottsville (Unlimed) & 2.0 & 22.4 & 44.6 & 21.4 & 1.67 & 15.9 & 18.9 \\
\hline N. Fork Red Run & 942 & 13.1 & Mauch Chunk & 13.9 & 22.4 & 80.5 & 26.5 & 1.57 & 15.4 & 20.6 \\
\hline Poca Run & 1055 & 13.6 & Chemung & 2.5 & 23.0 & 45.2 & 23.7 & 1.98 & 15.2 & 18.6 \\
\hline Sugar Drain & 872 & 8.5 & Pottsville (Unlimed) & 1.7 & 22.4 & 46.3 & 28.8 & 1.53 & 15.1 & 18.6 \\
\hline Average & 916 & 10.3 & N/A & 7.6 & 23.3 & $\mathbf{5 7 . 5}$ & 24.5 & 1.92 & 16.0 & 20.3 \\
\hline
\end{tabular}


Table 2: Brook Trout percent dry weight model selection table showing model parameters and AICc scores with associated weights and likelihoods. Evidence ratios are calculated as the ratio between a given model and the best performing model, with higher ratios indicating poorer performance. Starting at the null model, ratios are not calculated due to AICc weight of these models being zero.

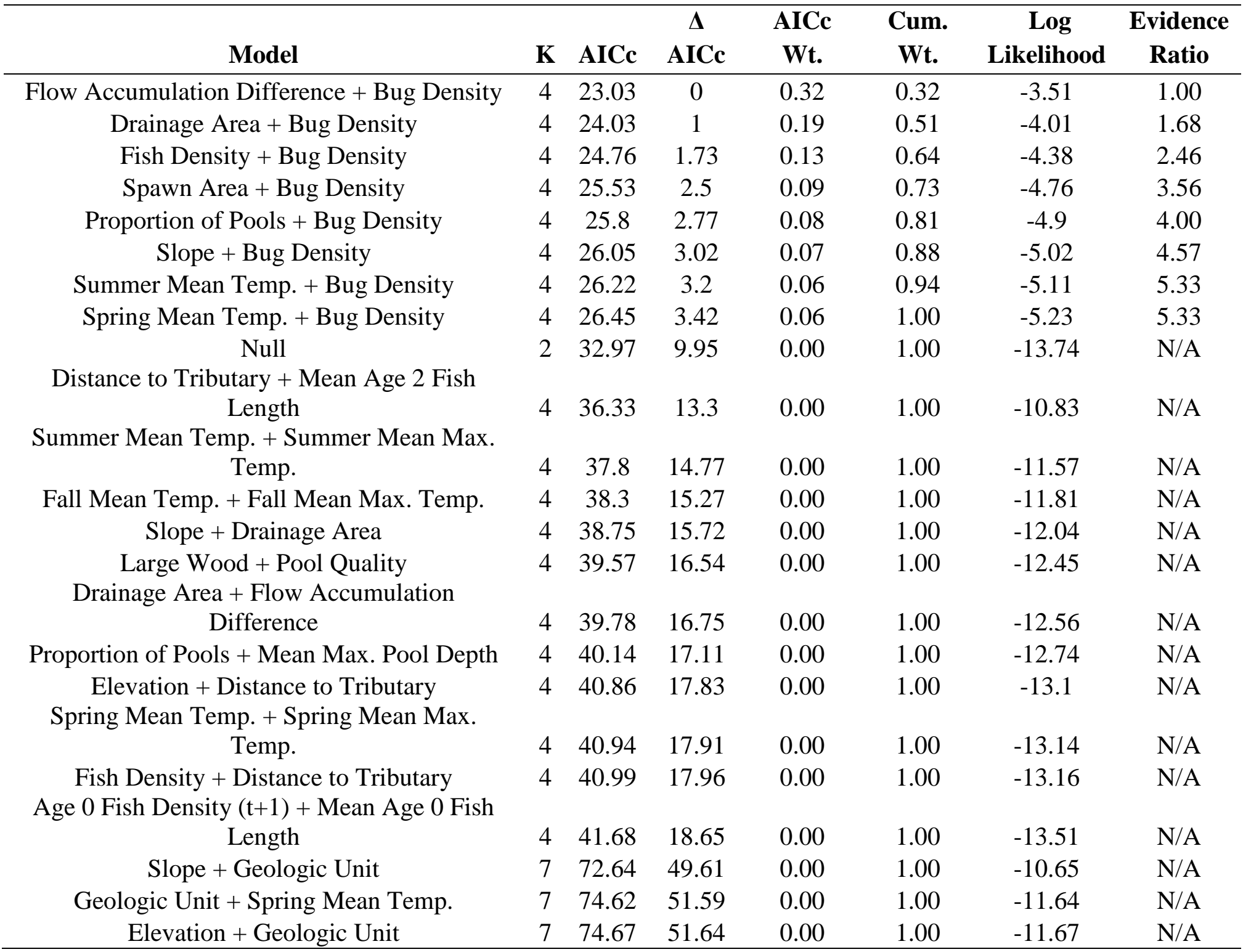


Table 3: Comparison of perceived resident and migrant Brook Trout in three streams with successful recaptures after one year. Reported p-values are resulting from t-tests assuming unequal variances. A cube-root transformation was used on total length to better approximate a normal distribution for the tests.

\begin{tabular}{|c|c|c|c|c|c|c|}
\hline \multirow[t]{2}{*}{ Grouping } & \multicolumn{2}{|c|}{ Mean Dry Weight (\%) } & \multirow[t]{2}{*}{ P-Value } & \multicolumn{2}{|c|}{ Total Length $(\mathbf{m m})$} & \multirow[t]{2}{*}{ P-value } \\
\hline & Resident & Migrant & & Resident & Migrant & \\
\hline All & 23.62 & 24.21 & 0.25 & 158.1 & 158.8 & 0.90 \\
\hline Crooked Fork & 23.51 & 25.05 & 0.01 & 143.7 & 147.8 & 0.70 \\
\hline Elklick Run & 24.75 & 24.26 & 0.68 & 173.8 & 161.2 & 0.21 \\
\hline N. Fork Red Run & 22.74 & 21.88 & 0.14 & 151.6 & 175.4 & 0.03 \\
\hline
\end{tabular}


Figures

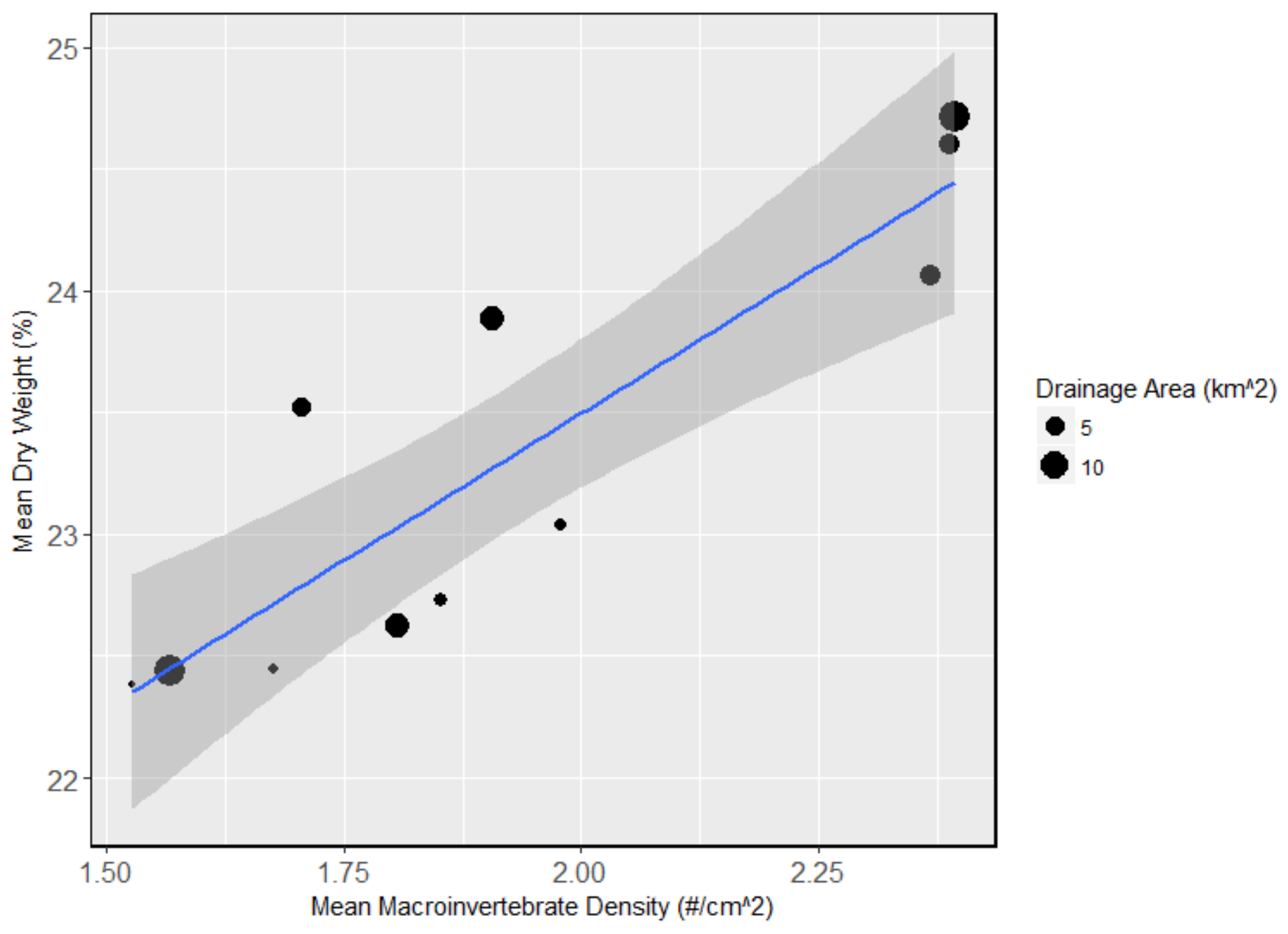

Figure 1: Significant ( $\mathrm{p}<0.001$; adjusted $\mathrm{R}^{2}=0.76$ ) linear relationship between mean macroinverbrate density $\left(\# / \mathrm{cm}^{2}\right)$ from benthic kicknet samples and mean estimated Brook Trout dry weight (\%) across all sampled streams. Each point represents a single stream average and point size corresponds to the subwatershed drainage area $\left(\mathrm{km}^{2}\right)$. 


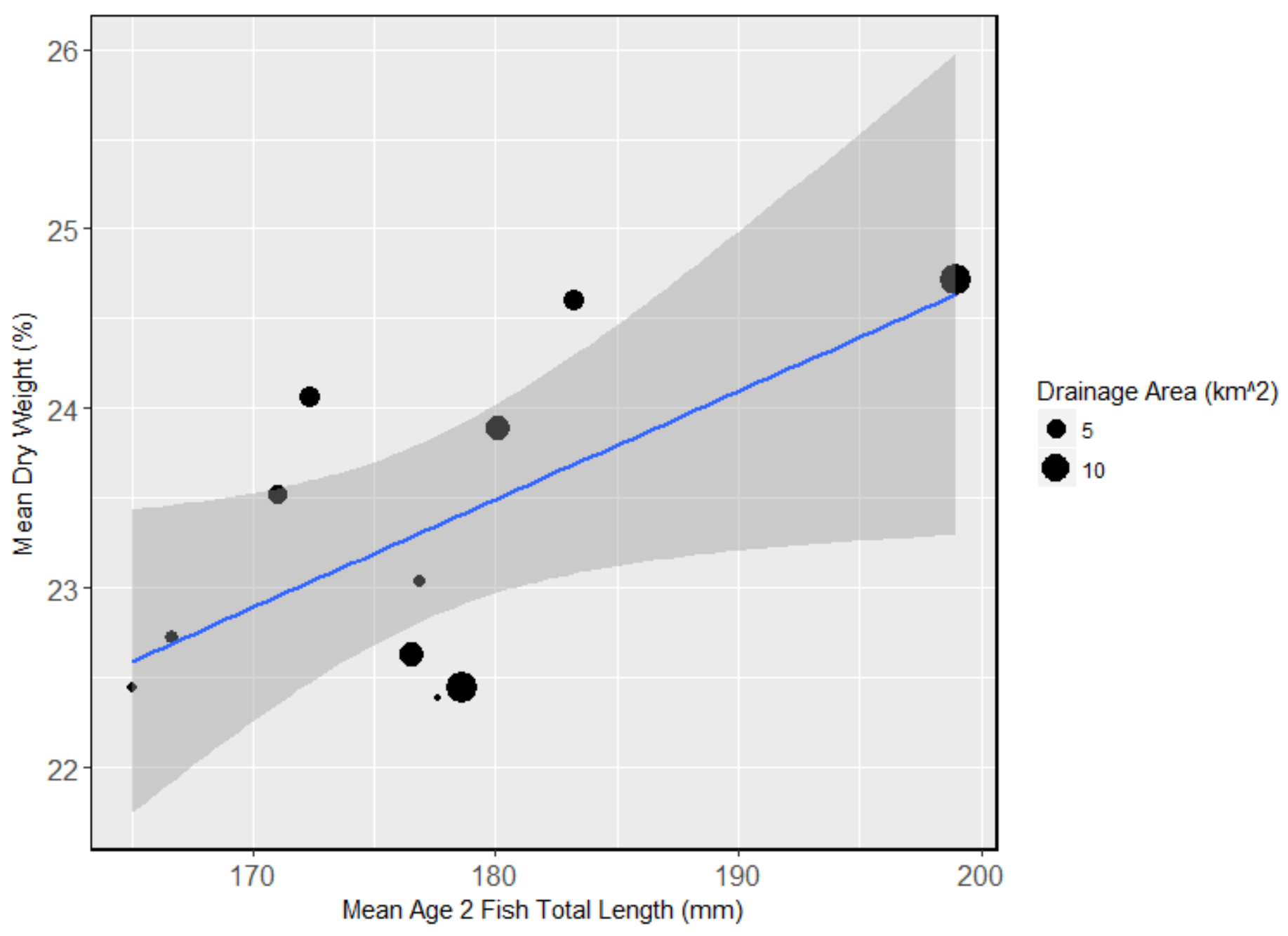

Figure 2: Significant $\left(\mathrm{p}=0.04\right.$; adjusted $\left.\mathrm{R}^{2}=0.32\right)$ linear relationship between mean age two Brook Trout total length $(\mathrm{mm})$ and mean estimated Brook Trout dry weight (\%) across all sampled streams. Each point represents a single stream average and point size corresponds to the subwatershed drainage area $\left(\mathrm{km}^{2}\right)$. 


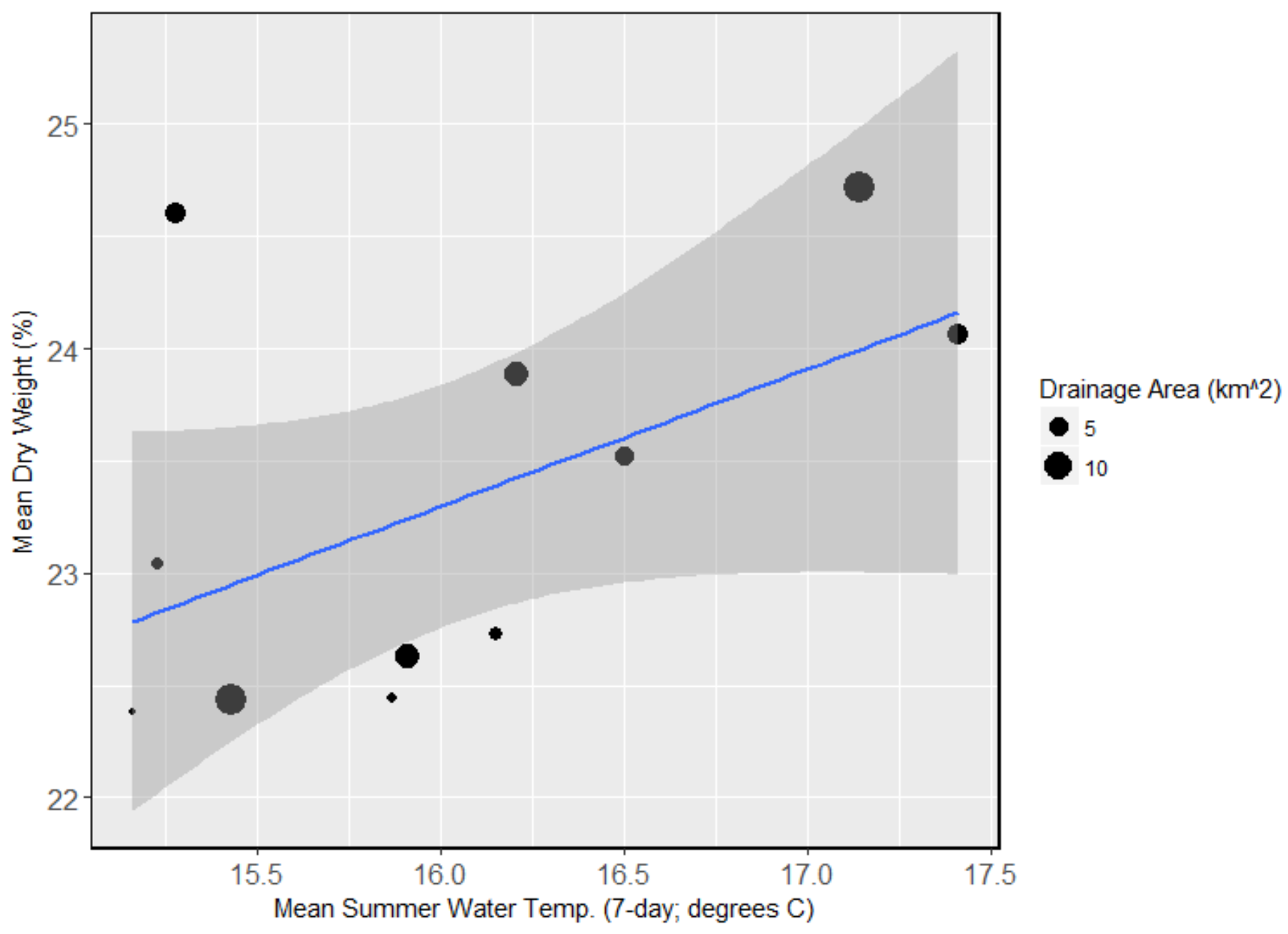

Figure 3: Non-significant ( $\mathrm{p}=0.09$; adjusted $\left.\mathrm{R}^{2}=0.20\right)$ linear relationship between mean summer water temperature $\left({ }^{\circ} \mathrm{C}\right)$ and mean estimated Brook Trout dry weight $(\%)$ across all sampled streams. Each point represents a single stream average and point size corresponds to the subwatershed drainage area $\left(\mathrm{km}^{2}\right)$. 


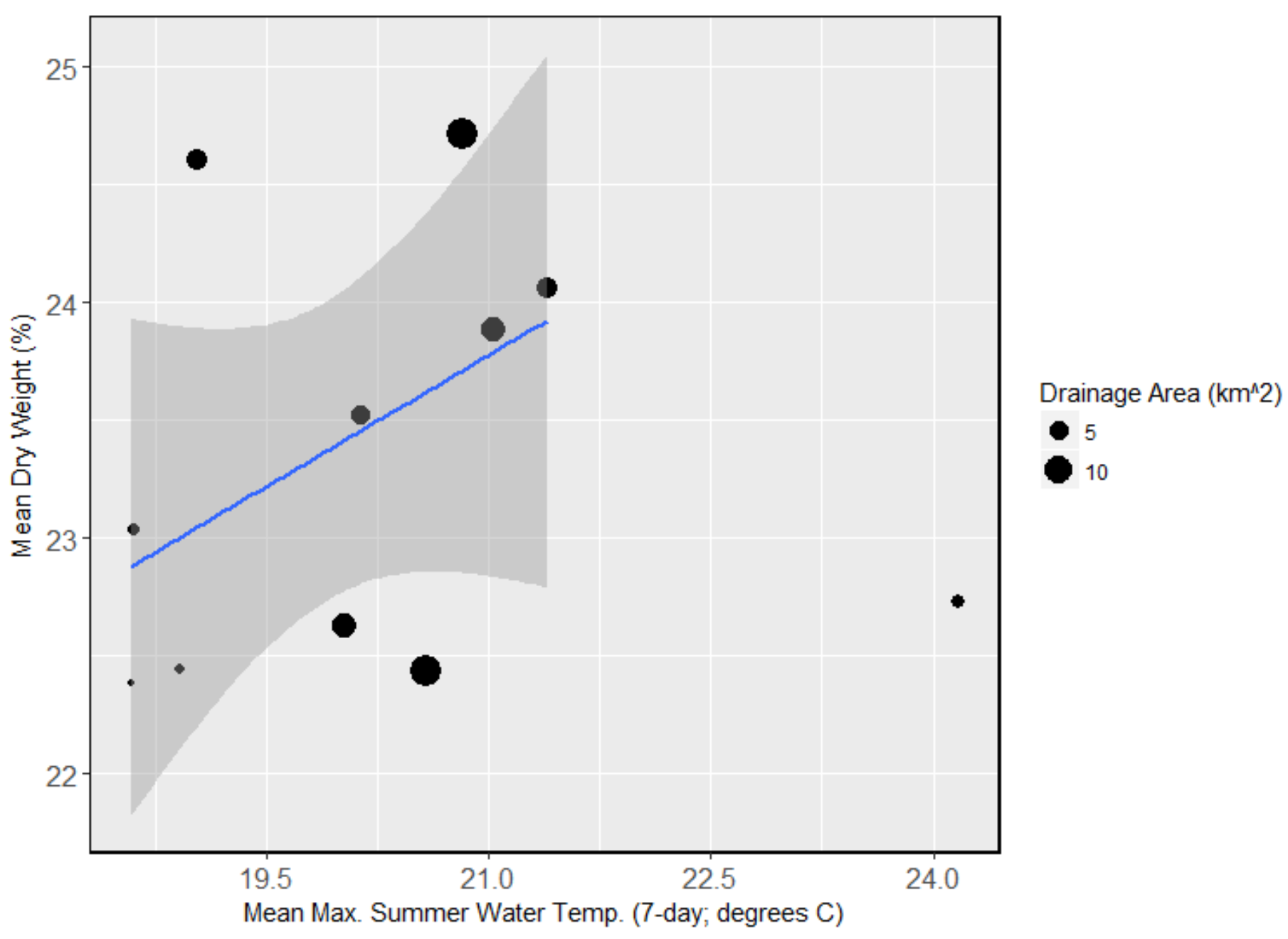

Figure 4: Non-significant $\left(\mathrm{p}=0.21\right.$; adjusted $\left.\mathrm{R}^{2}=0.08\right)$ linear relationship between mean maximum summer water temperature $\left({ }^{\circ} \mathrm{C}\right)$ and mean estimated Brook Trout dry weight $(\%)$ across all sampled streams. Each point represents a single stream average and point size corresponds to the subwatershed drainage area $\left(\mathrm{km}^{2}\right)$. The highest temperature point was excluded from the linear model to illustrate the weak increasing relationship until thermal stress is reached just beyond $21^{\circ} \mathrm{C}$. 


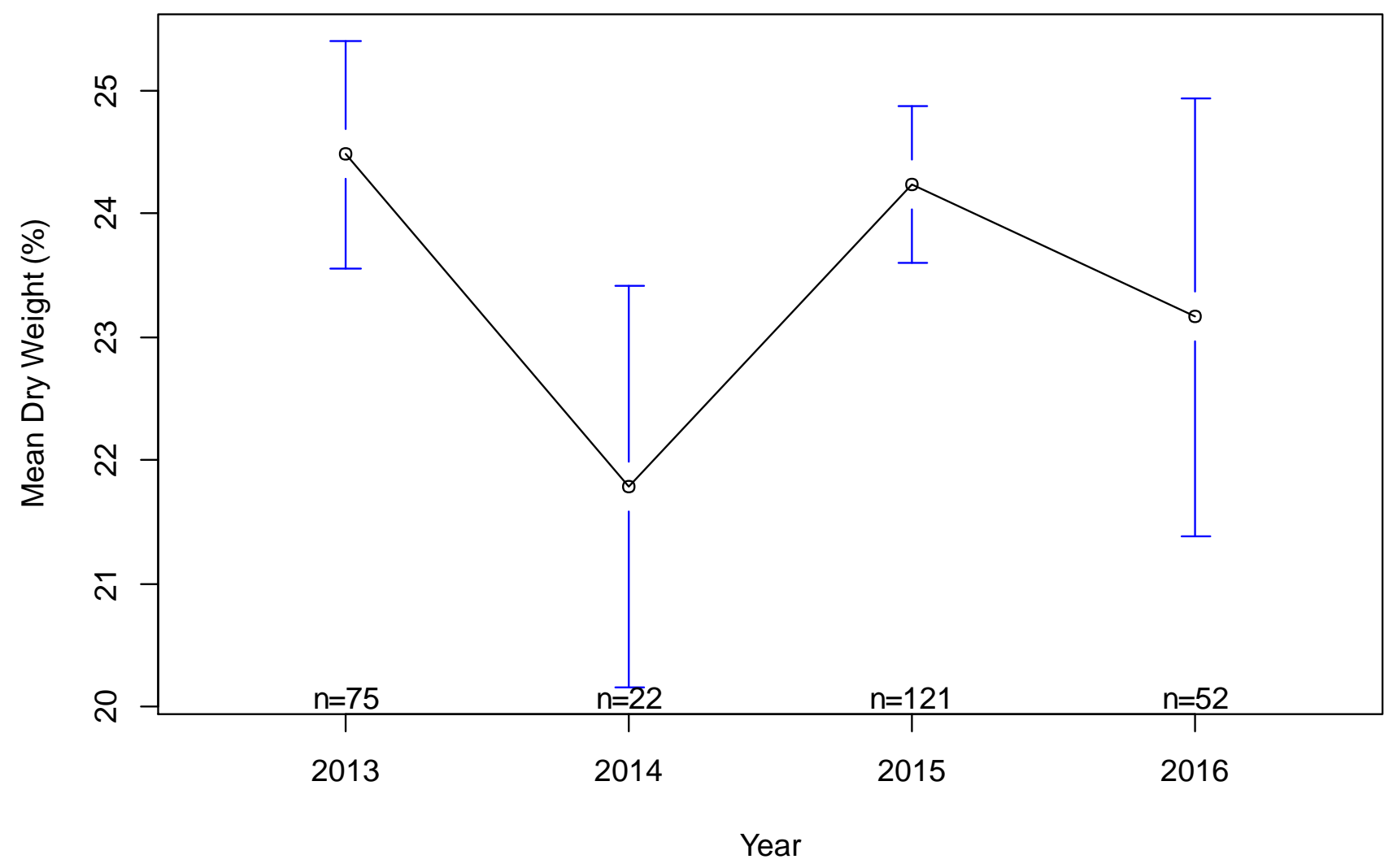

Figure 5: Mean estimated Brook Trout dry weight across all years sampled. Samples were taken primarily in summer for years 2013, 2015, and 2016, but late September in 2014. Analysis of variance showed no significant differences across years $(\mathrm{F}=1.01 ; \mathrm{p}=0.32)$. 


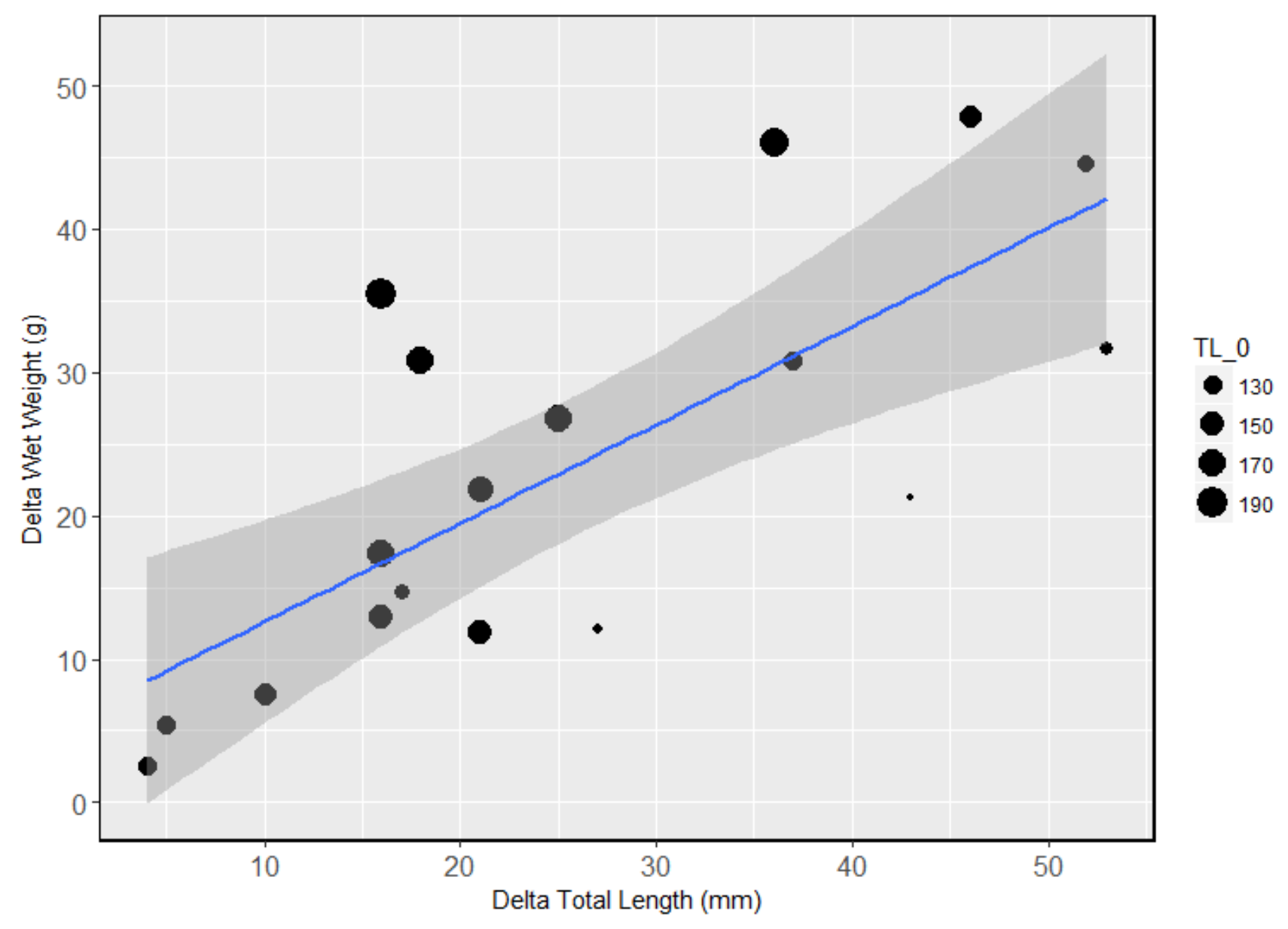

Figure 6: Change in total length $(\mathrm{mm})$ and measured wet weight $(\mathrm{g})$ of Brook Trout recaptured after one year. A significant $\left(\mathrm{p}<0.001\right.$; adj. $\left.\mathrm{R}^{2}=0.53\right)$ linear relationship is shown. Point size indicates the initial total length (TL_0) of a given individual trout. 


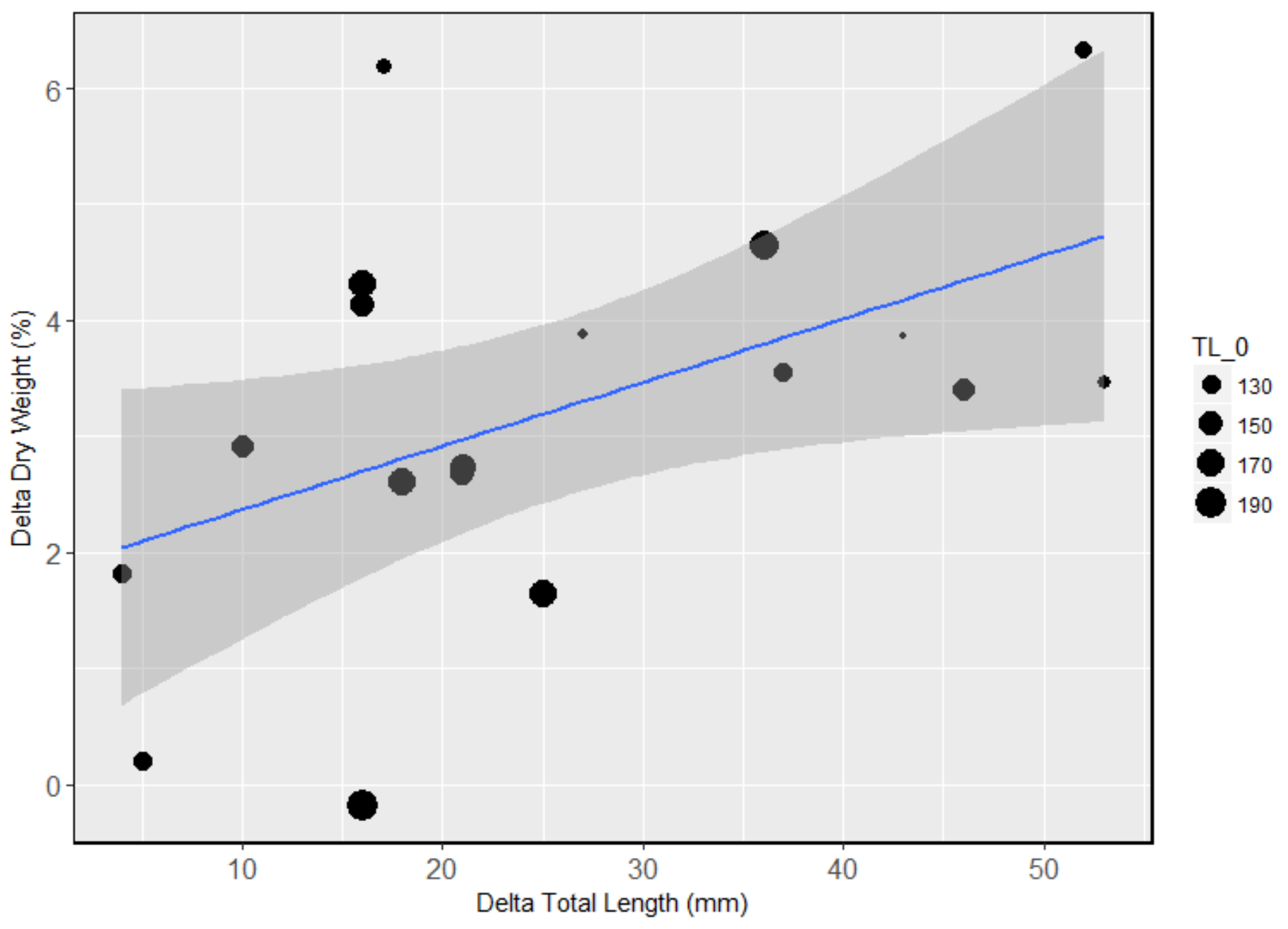

Figure 7: Change in total length $(\mathrm{mm})$ and estimated dry weight $(\%)$ of Brook Trout recaptured after one year. A significant $\left(\mathrm{p}=0.03\right.$; adj. $\left.\mathrm{R}^{2}=0.19\right)$ linear relationship is shown. Point size indicates the initial total length (TL_0) of a given individual trout. 


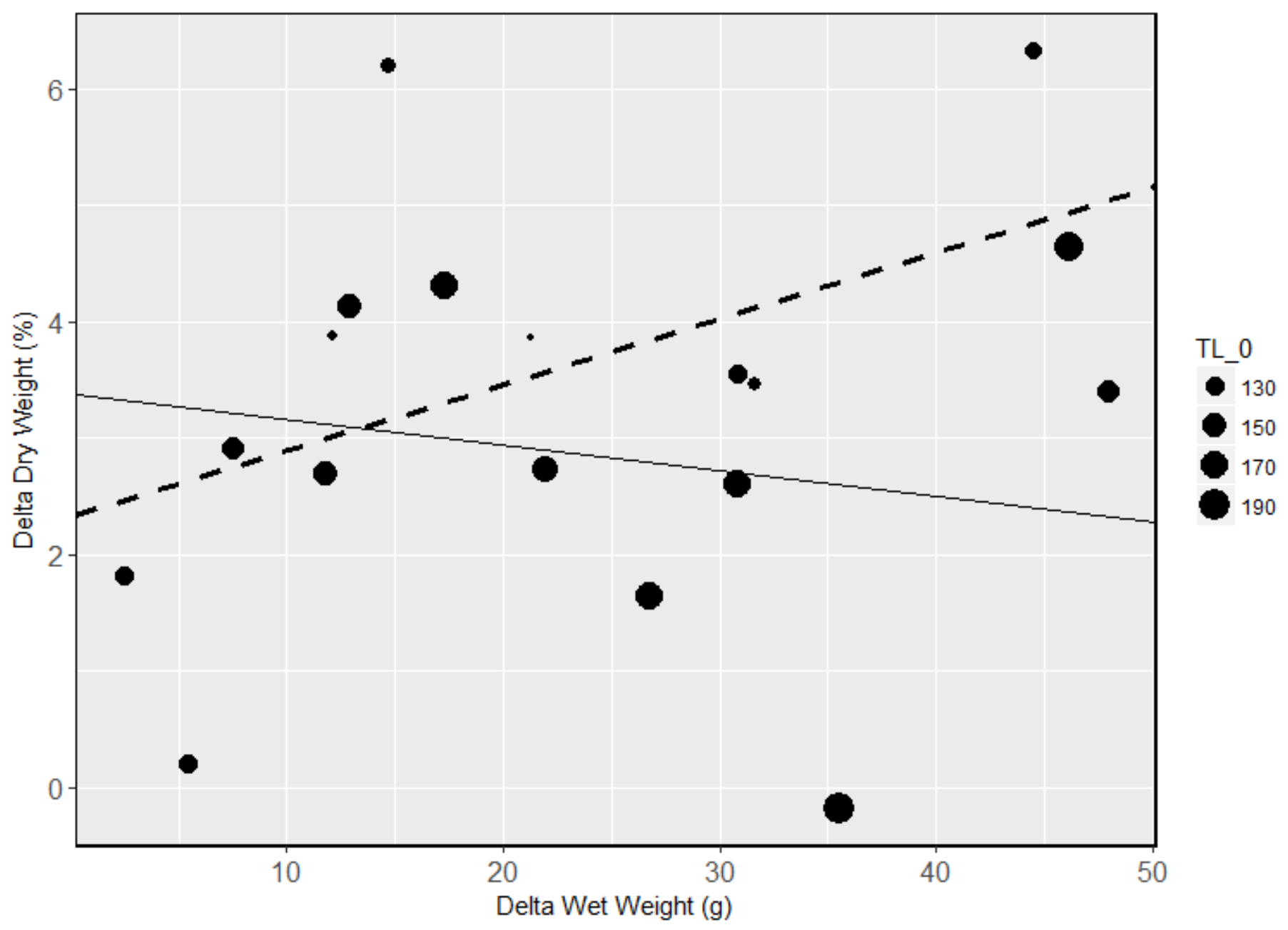

Figure 8: Change in wet weight (g) and estimated dry weight (\%) of Brook Trout recaptured after one year. No significant relationships were found. Point size indicates the initial total length (TL_0) of a given individual trout. The dashed line represents the relationship for smaller $(<130$ $\mathrm{mm} \mathrm{TL}$ ) individuals and the solid line represents the relationship for larger individuals. 